Energy and Carbon Emissions:

\title{
Country Studies
}

Energy Consumption, Efficiency,

Conservation, and Greenhouse Gas

Mitigation in Japan's Building Sector

\author{
Authors: \\ Shuzo Murakami (Keio University) \\ Mark D. Levine (Lawrence Berkeley National Laboratory) \\ Hiroshi Yoshino (Tohoku University) \\ Takashi Inoue (Tokyo University of Science) \\ Toshiharu lkaga (Keio University) \\ Yoshiyuki Shimoda (Osaka University) \\ Shuichi Miura (Tohoku University of Art \& Design) \\ Tomoki Sera (Ministry of Land, Infrastructure and Transport) \\ Masahiro Nishio (Ministry of Economy, Trade and Industry) \\ Yasuhiro Sakamoto (Tokyo Electric Power Company) \\ Wataru Fujisaki (Tokyo Gas)
}

June, 2006

(revised December, 2006)

Lawrence Berkeley National Laboratory in collaboration

with Japanese institutions identified above 


\title{
Energy Consumption, Efficiency, Conservation, and Greenhouse Gas Mitigation in Japan's Building Sector
}

\author{
Shuzo Murakami (Keio University) \\ Mark D. Levine (Lawrence Berkeley National Laboratory) \\ Hiroshi Yoshino (Tohoku University) \\ Takashi Inoue (Tokyo University of Science) \\ Toshiharu Ikaga (Keio University) \\ Yoshiyuki Shimoda (Osaka University) \\ Shuichi Miura (Tohoku University of Art \& Design) \\ Tomoki Sera (Ministry of Land, Infrastructure and Transport) \\ Masahiro Nishio (Ministry of Economy, Trade and Industry) \\ Yasuhiro Sakamoto (Tokyo Electric Power Company) \\ Wataru Fujisaki (Tokyo Gas)
}




\section{DISCLAIMER}

This document was prepared as an account of work sponsored by the United States Government. While this document is believed to contain correct information, neither the United States Government nor any agency thereof, nor The Regents of the University of California, nor any of their employees, makes any warranty, express or implied, or assumes any legal responsibility for the accuracy, completeness, or usefulness of any information, apparatus, product, or process disclosed, or represents that its use would not infringe privately owned rights. Reference herein to any specific commercial, product, process, or service by its trade name, trademark, manufacturer, or otherwise, does not necessarily constitute or imply its endorsement, recommendation, or favoring by the United States Government or agency thereof, or The Regents of the University of California. The views and opinions of authors expressed herein do not necessarily state or reflect those of the United States Government or any agency thereof, or The Regents of the University of California.

This report has been reproduced directly from the best available copy.

Ernest Orlando Lawrence Berkeley National Laboratory is an equal opportunity employer. 
Acronyms

Summary

Preface

1. Introduction

2. Overview of Energy Consumption and Greenhouse Gas (GHG) Emission Trends in Japanese Buildings

2.1 Total Energy Consumption in Japan's Residential and Commercial Sectors

2.2 Review of Energy Consumption by End Use in Japan’s Residential Buildings

2.2.1 Comparison to End-Use Energy Consumption in Other Developed Nations

2.2.2 Trends in Residential Energy Consumption in Japan

Regional Differences in Japan

End-Use Energy Consumption

Hot Water

Influence of Household Size

Efficiency of Home Appliances

2.2.3 Total Global-warming Impact from Daily-life Activities and Home Energy Consumption

$2.3 \mathrm{CO}_{2}$ Emissions from Energy Use in All Sectors in Japan

2.4 Global-warming Impact of Fluorocarbons used in Thermal Insulation of Japanese Homes

2.4.1 Projection of GHG Emissions in 2012 from All Japanese Houses

2.5 Key Drivers of Energy Consumption in Japanese Non-residential Buildings

3. Future Scenarios for $\mathrm{CO}_{2}$ Emissions from the Japanese Building Sector

3.1 Projection of $\mathrm{CO}_{2}$ Emissions from the Japanese Building Sector through 2050

3.2 Future Residential $\mathrm{CO}_{2}$ Emissions in Japan

3.2.1 Background

3.2.2 Nationwide Data on Japanese Households and Reduction of $\mathrm{CO}_{2}$ Emissions through Energy-Conservation Measures

3.2.3 Residential $\mathrm{CO}_{2}$ Emissions Reduction (by Prefecture) from Energy-Conservation Measures

4. Current Technologies and Energy-Conservation/GHG-Mitigation Strategies for Japanese Buildings

4.1 Taking Regional Climate into Account

4.2 Technologies for Residential Buildings in Japan

4.2.1 Walls and Windows

4.2.2 Space Heating

Passive Solar

Kotatsu (Traditional Japanese Heating Units)

Heat-Pumps

Gas Fan Heaters

Biomass Stoves

4.2.3 Cooling 
4.2.4 Hot Water

Water-saving Showerheads

Solar Water Heaters

$\mathrm{CO}_{2}$-refrigerant Heat-Pump Water Heater

Condensing Water Heaters

4.2.5 Residential Power Generation

Photovoltaic (PV) Power

Cogeneration Systems

4.2.6 Lighting

4.2.7 Consumer Appliances

Refrigerators

Washing Machines

Dishwashers

Televisions and Videocassette Recorders (VCRs)

IH Cooking Heater (Induction Heating Stovetop)

Gas Cookstove

4.3 Energy Savings from Lifestyle Changes in Japan

4.4 Technologies for Non-residential Buildings in Japan

4.4.1 Walls and Windows

Glazing

Window Accessories

Window Systems

Exterior Walls \& Roofs

4.4.2 Heating

4.4.3 Cooling

Air Conditioner Load Reduction

Multi-room Air Conditioners

Thermal Storage Systems

Absorption Chiller Heater

Gas-engine Heat Pumps (GHPs)

Vapor-compressed Chillers

Air Conditioner COP Standards

Desiccant Air Conditioning

4.4.4 Hot Water

4.4.5 Power Generation/District Heating and Cooling

Cogeneration Systems

Photovoltaic (PV) Power

District Heating and Cooling

4.4.6 Heating, Ventilation, and Air-Conditioning (HVAC) Systems

4.4.7 Lighting

High-efficiency Fluorescent Lamps 


\author{
Performance Standard \\ Specification Standard (point method) \\ LED Illumination \\ Daylighting
}

4.4.8 Office Equipment

5. Policies to Promote Energy Conservation and Prevention of Global Warming in Japanese Buildings

5.1 Enforcement of Japan's Law Concerning Rational Use of Energy

5.1.1 Energy Conservation Standards for Residential and Non-residential Buildings

5.1.2 Mandatory Reporting of Energy Conservation Measures

5.2 Energy Efficiency Assessment and Labeling Systems

5.2.1 Housing Performance Assessment and Labeling Systems

5.2.2 Comprehensive Assessment System for Building Environmental Efficiency

5.2.3 Top Runner Program

5.3 Financial Incentives

5.3.1 Low-interest Loans for Residential Buildings

5.3.2 Low-interest Loans for Non-residential Buildings

5.3.3 Subsidy for Symbiotic Housing Model Project

5.4 Other programs

5.4.1 NEDO subsidies

5.4.2 Energy Service Company (ESCO) Activities

5.4.3 Japanese Dress Code

6. Public Awareness

6.1 Information Sharing

6.2 Local Initiatives

6.3 Environmental Education

6.4 Municipalities

7. Conclusion

8. References

9. Appendices 


\section{Acronyms}

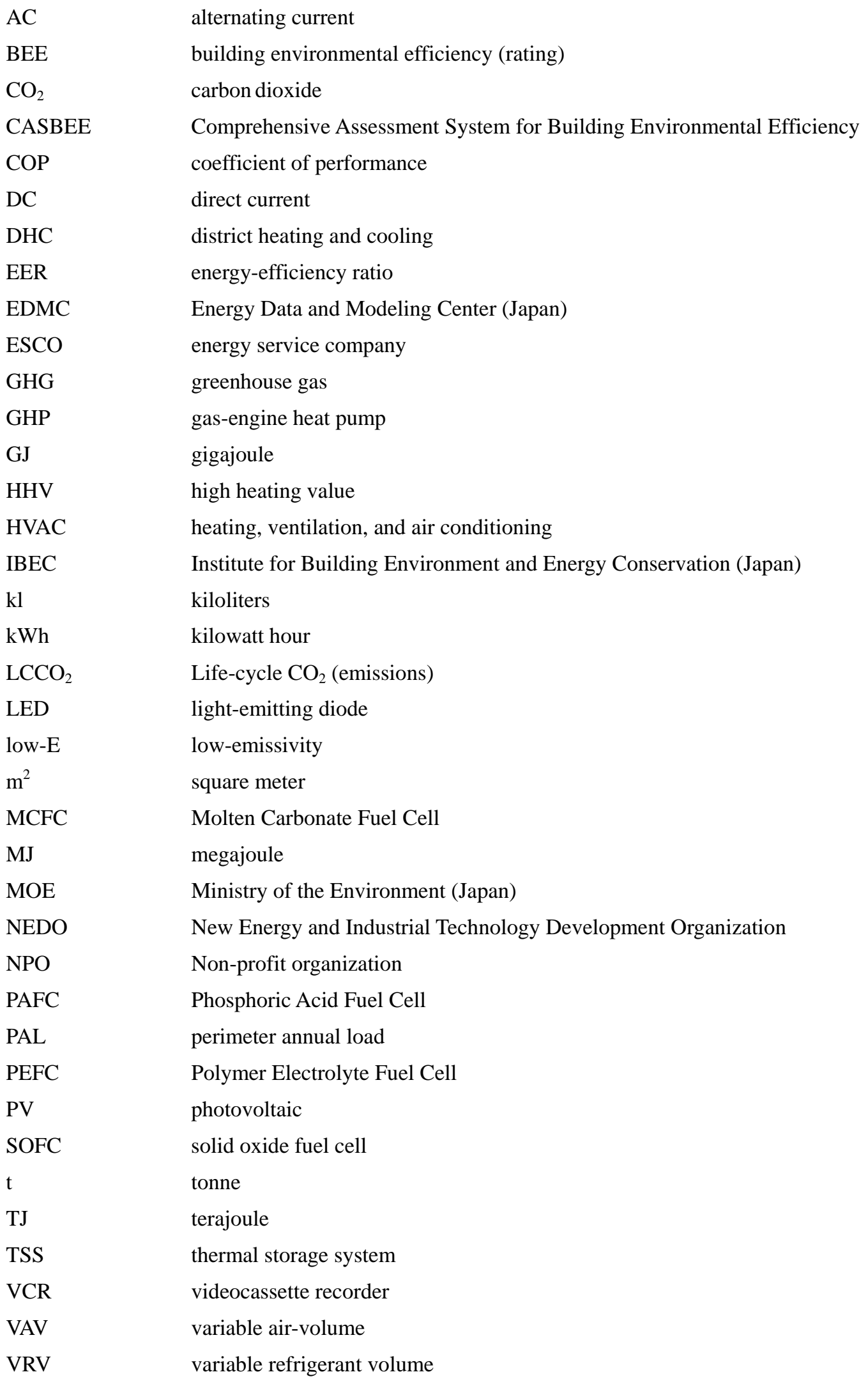


variable water-volume 


\section{Summary}

In response to the Kyoto Protocol for preventing global warming, signed in February 2005, the Kyoto Protocol Target Achievement Plan was developed in March 2006. In this plan, $\mathrm{CO}_{2}$ emission reduction targets to be achieved in FY 2010 was set in each sector (industrial, residential, commercial, transport, energy conversion, etc.) and $+6 \% \mathrm{CO}_{2}$ emission increase allowed for the residential sector and $+15 \%$ for the commercial and other sectors based on the standard of FY 1990. However, concerning the $\mathrm{CO}_{2}$ emission of FY 2002, those sectors must be reduced $22.8 \%$ and $16.7 \%$ respectively.

Since the primary due period of 2008-2012 is close at hand, specific measures for the prevention of global warming should be implemented in all areas. First, this report outlines energy consumption and greenhouse gas emission trends in the residential and commercial sectors in Japan. It indicates that they have increased by $24 \%$ and $28 \%$ respectively in 2000 compared to 1990 . The increase in residential energy consumption is caused by the widespread use of heating equipment, hot-water supply apparatus and other household electrical appliances. It also notes that residential energy consumption is much lower than in Western countries; heating, hot-water supply and other use each accounts for $1 / 3$, so heating use is as small as approximately $1 / 5$ of that in Western countries. The amount varies widely depending on region, and heating use accounts for 2/3 in cold Hokkaido. With respect to insulation for residential buildings, the report shows future projections for GHG emissions including fluorocarbon, which is used for insulation materials, and suggests that GHG emission can be reduced by just 0.6\% compared to 1990 if any measure for cutting fluorocarbon emissions is implemented in addition to the promotion of thermal insulation.

On the other hand, the report indicates that the increase in commercial energy use is caused by growth of the floor area of buildings. The energy consumption ratio per certain floor area is larger for hotels, hospitals and department stores, and smaller for schools. The report shows the future projections for $\mathrm{CO}_{2}$ emissions until 2050, and indicates that if the various energy conservation measures applicable are implemented, 59\% reduction can be achieved compared to 1990. It also indicates that, forecasting residential $\mathrm{CO}_{2}$ emissions by region, the promotion of thermal insulation and improvement of heating system efficiency are effective in Hokkaido, and solar shading and improvement of cooling system efficiency are effective in Okinawa.

Thermal insulation, sophisticated windows, heating/cooling ventilation apparatus, hot-water supply apparatus, and other household electrical appliances are called out by the report as the technologies for mitigation of global warming in the residential sector, and it notes that the efficiency of household electrical appliances such as air-conditioners, refrigerators and washing machines has been significantly improved recently. The report suggests that since residential energy consumption is greatly affected by lifestyle and behavior, the impact of behavior should be considered. It also suggests that the reduction effect of activities such as decreasing the preset temperature for heating, improving the use of hot-water supply apparatus, and unplugging equipment which is not in use, is larger than further improvement of insulation efficiency for houses with an already high insulation efficiency. It calls out technologies to 
mitigate global warming by commercial sector, including improving the efficiency of external materials such as the shielding of solar radiation, with the central focus on windows, various high-efficiency cooling systems, heat source equipment such as heat pump hot water systems and domestic cogeneration systems, lighting apparatus and BEMS (Building Energy Management Systems), and describes the future projections for implementing this equipment, and the effect on emissions reduction.

The report also describes political measures, including the building energy conservation standard, which has contributed significantly to energy saving, the Comprehensive Assessment System for Building Environmental Efficiency (CASBEE), which provides a comprehensive assessment of the mitigation of global warming and environmental performance, and the top-runner programs which contribute to the improvement of equipment efficiency. It discusses policies which offer financial incentives, including the premium financing system of the housing loan corporation which promotes household energy conservation, and the low interest loan from the Japan Development Bank to promote the implementation of energy conservation technologies for commercial buildings. It also describes the dissemination of Cool Biz as the adjustment measure for hot weather which significantly reduces air-conditioning load.

The report introduces examples of awareness-raising activities for mitigating global warming, including cases where energy conservation has been addressed in school education and has achieved power consumption reduction, and the case where the municipal government has returned regional currency to high performers according to the amount of individual environmental contribution to energy conservation and has achieved significant effect.

Lastly, it was concluded that since the substantial reduction of $\mathrm{CO}_{2}$ emissions is expected if measures using these technologies available at present are actually implemented, the aggressive promotion of political measures and awareness-raising activities is important. 


\section{Preface}

The Intergovernmental Panel on Climate Change (IPCC) is now developing the Assessment Report 4 (AR4). Activities related to the Working Group 3 (WG3) are receiving primary support from the Ministry of Economy, Trade and Industry in Japan. In relation to Chapter 6 of AR4, IPCC/WG3, "Buildings (including private equipment)," the Building Alleviation Policy Review Committee (Chairperson: Shuzo Murakami, Professor of Keio University and Director General of IBEC) consists of experts on the building environment, facilities, and equipment, from industry, government and academia. It was established in November 2004 with the cooperation of the Institute for Building Environment and Energy Conservation (IBEC), and the Global Industrial and Social Progress Research Institute (GISPRI) under the sponsorship of the Land, Infrastructure and Transportation Ministry and the Ministry of Economy, Trade and Industry. Collaborating with Dr. Mark Levine of Lawrence Berkeley National Laboratory, the working group has vigorously promoted research and studies on the measures for energy conservation in the building sector.

Numerous findings and achievements from these research projects and studies are reported, including those related to the future projections of $\mathrm{CO}_{2}$ emissions in the Japanese building sector, and surveys on the actual condition of residential energy consumption, the energy conservation benefits gained by lifestyle change, and activities to raise awareness of the prevention of global warming. Useful up-to-date information was gathered on the actual conditions of energy consumption, the technologies for the prevention of global warming and their effects, and the actual status of political actions. Since this is very precious information and is considered useful to researchers and government officials not only in Japan but also in other countries which are involved in investing in building energy efficiency for the prevention of global warming, we have the honor to publish this report at the request and with the cooperation of Dr. Levine.

The important part of these contents was reflected in the draft of Assessment Report 4 (AR4) of IPCC/WG3. We would like to deliver our sincere gratitude to all who offered their kind cooperation.

In addition to being an important input to the Intergovernmental Panel on Climate Change, this report is the first in a new series from Lawrence Berkeley National Laboratory. The series is a joint undertaking between the International Energy Studies and China Energy Groups. ${ }^{1}$ The series will consist of analyses performed by these two groups as well as notable studies that we have commissioned by colleagues in other institutions and often in other countries. We hope that the series will contribute to the public dialogue, addressing the following broad areas: technologies and practices to reduce greenhouse gas (GHG) emissions; policy options to reduce GHG emissions; analysis of individual countries; global and regional scenarios of GHG emissions; and special topics.

\footnotetext{
${ }^{1}$ Both groups are in the Energy Analysis Department of the Environmental Energy Technologies Division. They can be located from either website at LBNL.
} 
We are pleased to have this report on Japanese energy use and energy-related GHGs in Japan's building sector produced almost entirely by senior Japanese researchers as the first in this series. 


\section{Introduction}

$\mathrm{CO}_{2}$ emissions from the residential and commercial sector in Japan was $363 \mathrm{Mt}-\mathrm{CO}_{2}$ in FY 2002, which accounts for $29 \%$ (13\% from the residential sector and $16 \%$ from the commercial and other sectors) of total emission. Compared to that of FY 1990, the amount has increased by $28.8 \%$ for the residential sector and by $36.7 \%$ for the commercial sector and is expected to keep increasing. In response to the Kyoto Protocol in February 2005 for promoting the prevention of global warming, the Kyoto Protocol Target Achievement Plan was developed in March 2006 (Cabinet office, Government of Japan, 2005). In this plan, the reduction targets to be achieved in FY 2010 are set to 6\% for the residential sector and $15 \%$ for the commercial and other sectors based on the standard of FY 1990. However, based on the standard of FY 2002, those sectors must be reduced $22.8 \%$ and $16.7 \%$ respectively. Since the primary due period of 2008-2012 is close at hand, specific measures for the prevention of global warming should be implemented in all areas.

First, this report outlines energy consumption and greenhouse gas emissions trends from the residential and commercial sectors in Japan. Second, it describes the results of the $\mathrm{CO}_{2}$ emissions forecast for the building sector and future projections of $\mathrm{CO}_{2}$ emissions from households by prefecture. Third, the report discusses the technologies to mitigate global warming from both the residential and the commercial points of view respectively. In this section it describes the benefits gained by reducing residential energy through lifestyle changes. Fourth, it describes energy conservation standards, the assessment system and labeling, and financial measures as political mitigation policy. Lastly, it reports activities to raise awareness about the prevention of global warming.

\section{Overview of Energy Consumption and Greenhouse Gas (GHG) Emission Trends in Japanese Buildings}

This section reports energy consumption and carbon dioxide $\left(\mathrm{CO}_{2}\right)$ emissions data for residential and non-residential buildings in Japan, based on an extensive literature survey. We also present greenhouse gas (GHG) emission estimates for the period ending in 2012 for residential buildings; these calculations include fluorocarbon emissions from thermal insulation products for houses.

\subsection{Total Energy Consumption in Japan's Residential and Commercial Sectors}

Energy consumption in Japan's residential building sector was 2,228 $\times 10^{6}$ gigajoules (GJ) in 2000, an increase of 24 percent from the total in 1990. Energy consumption in commercial buildings was 1,934 x $10^{6} \mathrm{GJ}$ in 2000, an increase of 28 percent from the total in 1990. Table 1 shows these energy consumption data. 
Table 1. Energy consumption in Japan’s building sector (Unit: $10^{6} \mathrm{GJ}$ )

\begin{tabular}{|c|c|c|c|c|c|c|c|c|c|c|c|}
\hline Fiscal Year & 1990 & 1991 & 1992 & 1993 & 1994 & 1995 & 1996 & 1997 & 1998 & 1999 & 2000 \\
\hline \multirow{2}{*}{ Demand for residential use } & 1796 & 1833 & 1917 & 2006 & 2004 & 2144 & 2143 & 2139 & 2093 & 2161 & 2228 \\
\hline & $100 \%$ & $102 \%$ & $107 \%$ & $112 \%$ & $112 \%$ & $119 \%$ & $119 \%$ & $119 \%$ & $117 \%$ & $120 \%$ & $124 \%$ \\
\hline \multirow{2}{*}{ Demand for commercial use } & 1508 & 1633 & 1679 & 1633 & 1751 & 1804 & 1804 & 1846 & 1905 & 1918 & 1934 \\
\hline & $100 \%$ & $108 \%$ & $111 \%$ & $108 \%$ & $116 \%$ & $120 \%$ & $120 \%$ & $122 \%$ & $126 \%$ & $127 \%$ & $128 \%$ \\
\hline \multirow{2}{*}{$\begin{array}{l}\text { Total of residential \& commercial } \\
\text { energy }\end{array}$} & 3303 & 3467 & 3601 & 3638 & 3760 & 3948 & 3948 & 3982 & 4003 & 4065 & 4166 \\
\hline & $100 \%$ & $105 \%$ & $109 \%$ & $110 \%$ & $114 \%$ & $120 \%$ & $120 \%$ & $121 \%$ & $121 \%$ & $123 \%$ & $126 \%$ \\
\hline \multirow{2}{*}{$\begin{array}{l}\text { Energy intensity for household } \\
\text { use }\left(10^{3} \mathrm{kcal} / \text { household }\right)\end{array}$} & 43656 & 43953 & 45305 & 46557 & 46005 & 48471 & 47805 & 47026 & 45490 & 46130 & 46988 \\
\hline & $100 \%$ & $101 \%$ & $104 \%$ & $107 \%$ & $105 \%$ & $111 \%$ & $110 \%$ & $108 \%$ & $104 \%$ & $106 \%$ & $108 \%$ \\
\hline \multirow{2}{*}{$\begin{array}{l}\text { Energy intensity for commercial } \\
\text { use }\left(10^{3} \mathrm{kcal} / \mathrm{m}^{2}\right)\end{array}$} & 1174 & 1227 & 1228 & 1162 & 1203 & 1204 & 1181 & 1179 & 1189 & 1176 & 1170 \\
\hline & $100 \%$ & $105 \%$ & $105 \%$ & $99 \%$ & $103 \%$ & $103 \%$ & $101 \%$ & $100 \%$ & $101 \%$ & $100 \%$ & $100 \%$ \\
\hline
\end{tabular}

Source: The Institute of Energy Economics, Japan, Energy Data and Modeling Center (EDMC). 2006. Directory of Energy and Economic Statistics.

\subsection{Review of Energy Consumption by End Use in Japan's Residential Buildings}

The subsections below give an overview of Japan's residential energy consumption by end use, with a general comparison to energy use in other developed countries and regional breakdowns by geographic regions in Japan.

\subsubsection{Comparison to End-Use Energy Consumption in Other Developed Nations}

Figure 1 shows that energy consumption and end uses in Japanese households differ significantly from those in other developed nations (Nakagami et al., 2002). In particular, energy consumption for space heating is much lower in Japan than in western countries. Energy-efficiency measures related to space heating, such as use of thermal insulation and reduction of outside air infiltration are therefore unlikely to have as large an effect on residential energy consumption in Japan as they would have in western countries where space heating accounts for a major portion of energy consumption. Japan differs from western countries in its space-heating methods and practices, which reflects both differences in lifestyle and climate. This difference between Japan and western nations illustrates the principle that effectively reducing energy consumption requires careful attention to the actual conditions in the target country.

\subsubsection{Trends in Residential Energy Consumption in Japan}

Japan's average annual energy consumption is about 45 GJ/household per year in last dacade. As shown in Figure 2, this number has been increasing almost every year, reflecting continuing improvements in living conditions that are not offset by energy savings measures (Jyukankyo Research Institute, 2002). The most recent data show that 25 to 30 percent of all residential energy consumed in Japan is used for space heating/cooling, 35 to 40 percent is used for hot water (e.g., baths and showers), and 35 to 40 percent is used for lighting/other (e.g., refrigerators, TVs). Growth in hot water and lighting/other uses is 
more significant than growth in space heating/cooling energy use. Thus, hot water and lighting/other are the most promising areas to address in order to reduce total energy consumption.

Figure 2 suggests that the growth in space heating energy consumption is relatively small. This is largely a result of successful public promotion of thermal insulation and sealing of homes. However, thrifty space-heating use in most households (i.e., intermittent and partial use in rooms only when occupied) also contributes to the small increase. Continuous and whole-space heating require more energy, even in households that have significant thermal insulation. Although the largest portion of space heating/cooling energy is used for heating rather than cooling, and cooling energy remains very low, the growth in cooling has been rapid. This trend should be carefully monitored. (Bogaki et al, 1998a, b)

\section{Regional Differences in Japan}

Figure 3 shows the geographical pattern of energy consumption in Japan (Hasegawa and Inoue, 2004). In the northernmost area, Hokkaido, as space heating use is comparable to that in western countries, the total energy consumption is comparatively large. However, energy consumption for space heating in the southern districts (south of Tokyo) is less than 25 percent of the consumption of Hokkaido. The overall energy consumption in the southern districts of Japan is about two-thirds of the total in the Hokkaido area.

In warmer districts, thermal insulation and air-sealing practices prevent heat dissipation from indoors to outdoors in warmer months, which can increase the use of cooling and thus increase energy consumption. Houses in warmer areas should be designed to ensure maximum comfort by allowing for sufficient ventilation in spring and summer, employing enhanced thermal insulation in roofs and walls, keeping all openings large enough for use of cross-ventilation, and installing solar shading for all openings.

\section{End-Use Energy Consumption}

The subsections below examine specific end uses and contributors to end-use energy consumption.

\section{Hot Water}

Hot-water supply accounts for the largest proportion of energy consumed in Japanese households. This is a result of the typical Japanese lifestyle in which about 50 percent of all household members take a bath almost every day. As shown in Figure 4, although about 70 percent of households showed general willingness to save energy (answering "can do" and "can do somewhat" to almost all questions), only 30 percent showed willingness to reduce the frequency of baths to save energy. This result holds even among environmentally conscious households. Thus, it is suggested that, in Japan, hot-water energy savings should be encouraged through the use of solar energy and the introduction of an efficient hot-water supply system rather than through voluntary consumer behavior changes (Hasegawa and Inoue, 2004). 


\section{Influence of Household Size}

Household size is a factor in energy consumption. Figure 5 shows that per-capita energy consumption increases significantly with decreasing household size, with a single-person household using about 1.7 times the amount of energy used by a person in a four-person household. These results suggest that decreasing household size (caused by many factors, including a desire in some parts of the population to live independently, aging of the population, decline in the birthrate, and the trend toward the nuclear families) should be carefully observed because it will tend to result in an increase per-capita energy consumption (Hasegawa and Inoue, 2004, Inoue et al, 2006 and Mizutani et al., 2006).

\section{Efficiency of Home Appliances}

The efficiency of home appliances, such as air conditioners, refrigerators, and lighting, has improved significantly in recent years. The coefficient of performance (COP) of the latest domestic air conditioners is around 6.0, and a new efficient lighting system (high-frequency fluorescent lighting) has been developed. Despite these efficiency improvements, energy consumption in the typical home is still increasing. The number of electronic and plug-in devices, many of which consume energy even when in inactive modes, has increased dramatically in Japan during the past decades. In addition, the sizes of home appliances, such as refrigerators and TVs, are increasing, which also increases energy consumption. As shown in Figure 2, these devices account for a substantial portion of increased household energy consumption.

\subsubsection{Total Global-warming Impact from Daily-life Activities and Home Energy Consumption}

It is worth noting that overall energy consumption within a residence is not always the major contributor to global warming when compared to other daily-life activities of household members. Production of food, drink, and water which is consumed within the house as well as the production of waste in houses are estimated to result in greater emissions of greenhouse gas (GHG) emissions than direct energy consumption by the household. Figure 6 shows $\mathrm{CO}_{2}$ emissions related to various household "life-cycle" activities (using estimations based on field surveys, statistical data, and numerical analysis). $\mathrm{CO}_{2}$ emissions produced by daily life within a home, including emissions from energy consumption and from general daily activities, were found to contribute a large proportion of total $\mathrm{CO}_{2}$ emissions compared to emissions associated with the material manufacturing, building, maintenance, demolition, and disposal phases of a house's life cycle. It has also been shown that the level of $\mathrm{CO}_{2}$ emissions related to daily activities is almost as high as the level that is directly attributable to energy consumption (Chikada and Inoue, 2000, 2003).

Given the contribution of residences and household appliances to overall energy consumption, ongoing efforts should be made to improve their efficiency. Lifestyle and environmental awareness should also be addressed. 


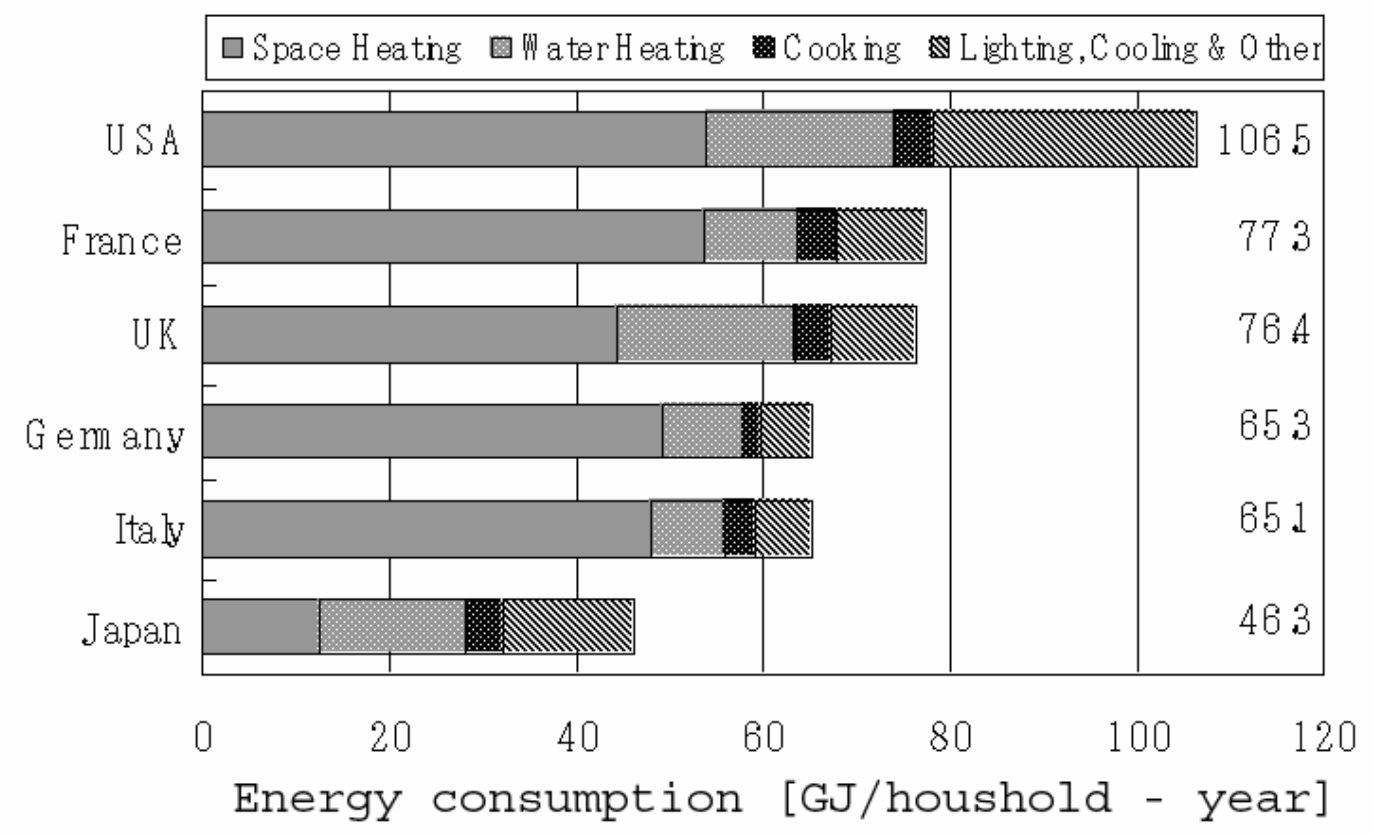

Figure 1. International comparison of energy consumption in housing (1998)

(Nakagami et al., 2002) Note: Germany’s data are for 1997

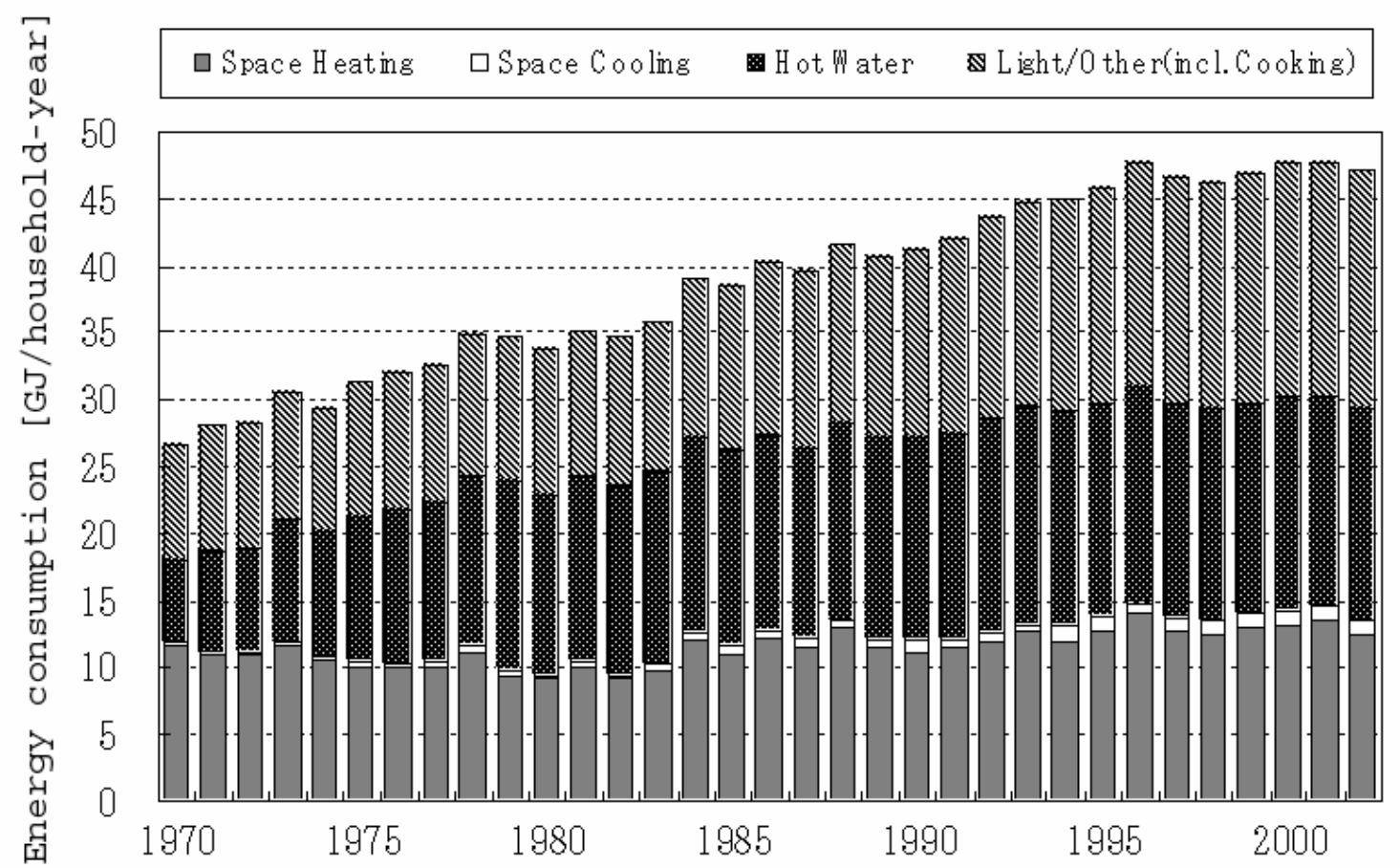

Figure 2. Trends in household energy consumption (Jyukankyo Research Institute, 2002) 


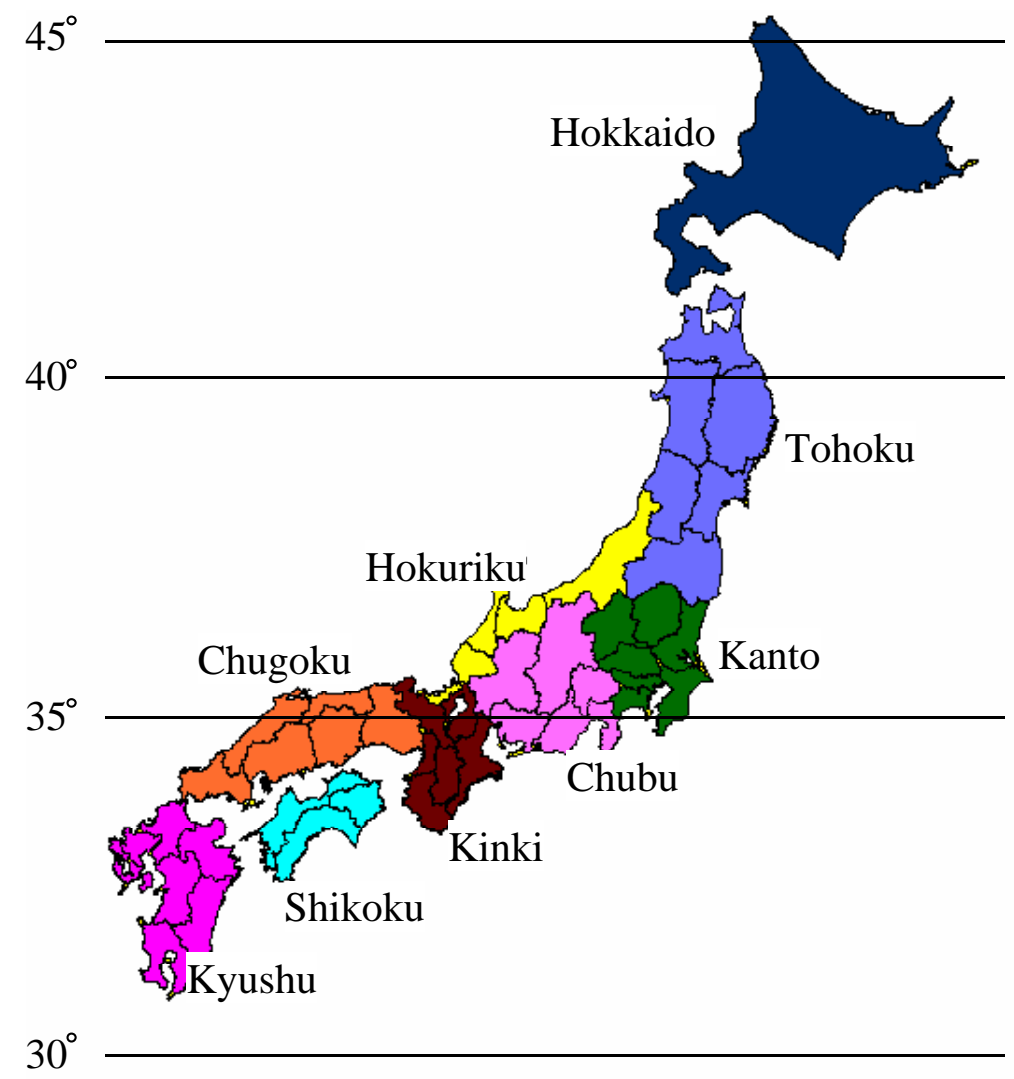

Hokkaido (N=102)

Tohoku ( $\mathrm{N}=98)$

Hokuriku $(\mathrm{N}=63)$

Kanto (N=1457)

Chubu ( $\mathrm{N}=379)$

Kinki $(\mathrm{N}=613)$

Chugoku ( $\mathrm{N}=108)$

Shikoku $(\mathrm{N}=41)$

Kyushu (N=111)

Okinawa $(\mathrm{N}=4)$

Average $(\mathrm{N}=2976)$

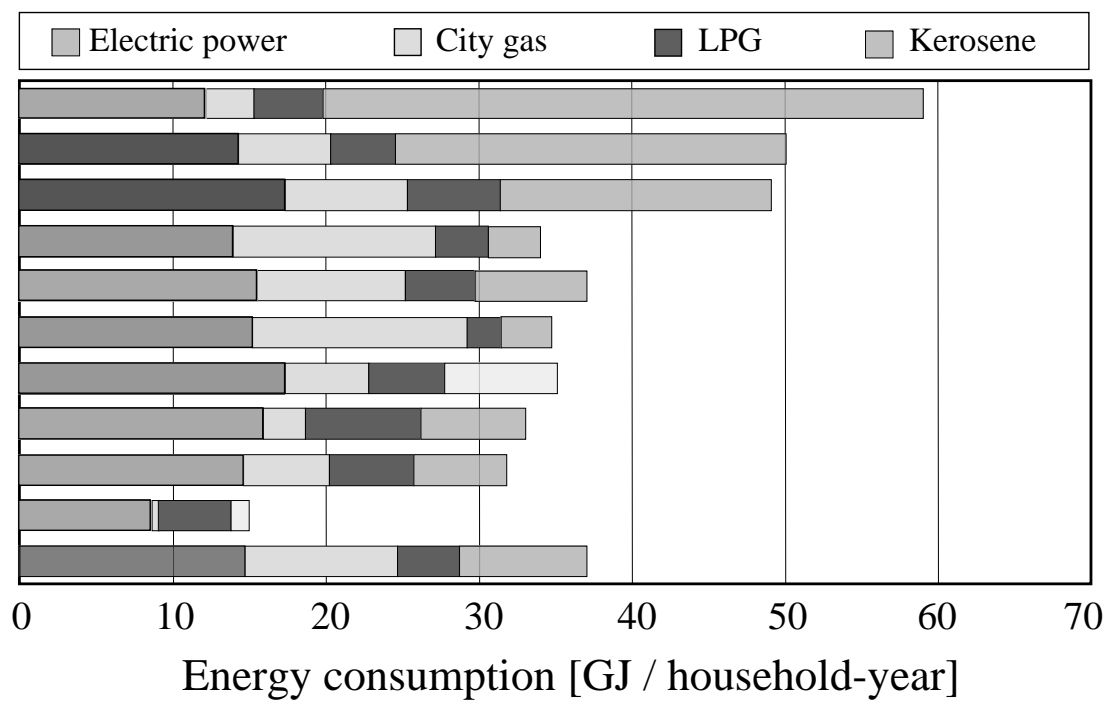

Figure 3. Regional energy consumption (Hasegawa and Inoue, 2004) Note: Includes single-person households 


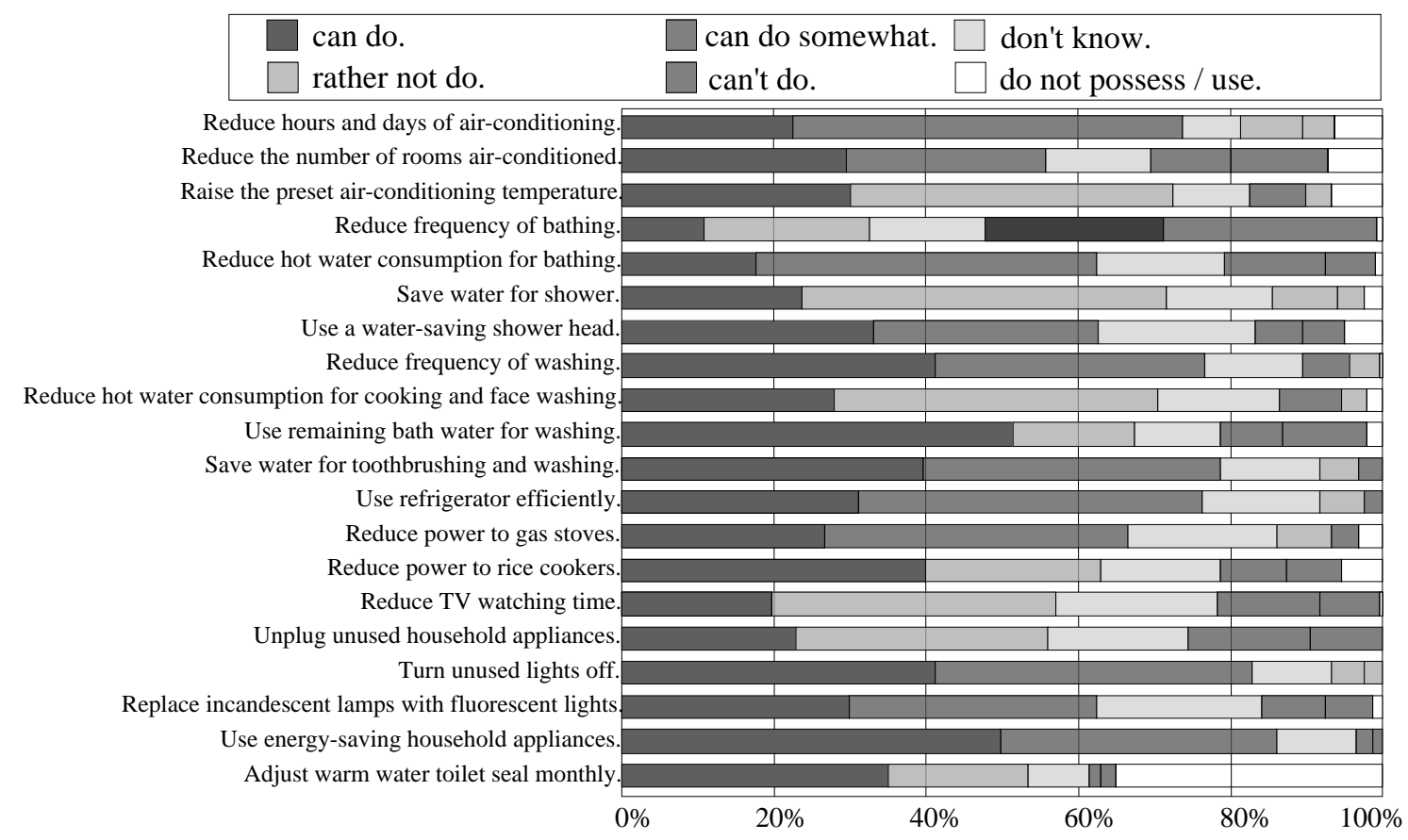

Figure 4. Concerns related to energy-saving actions (Hasegawa and Inoue, 2004)

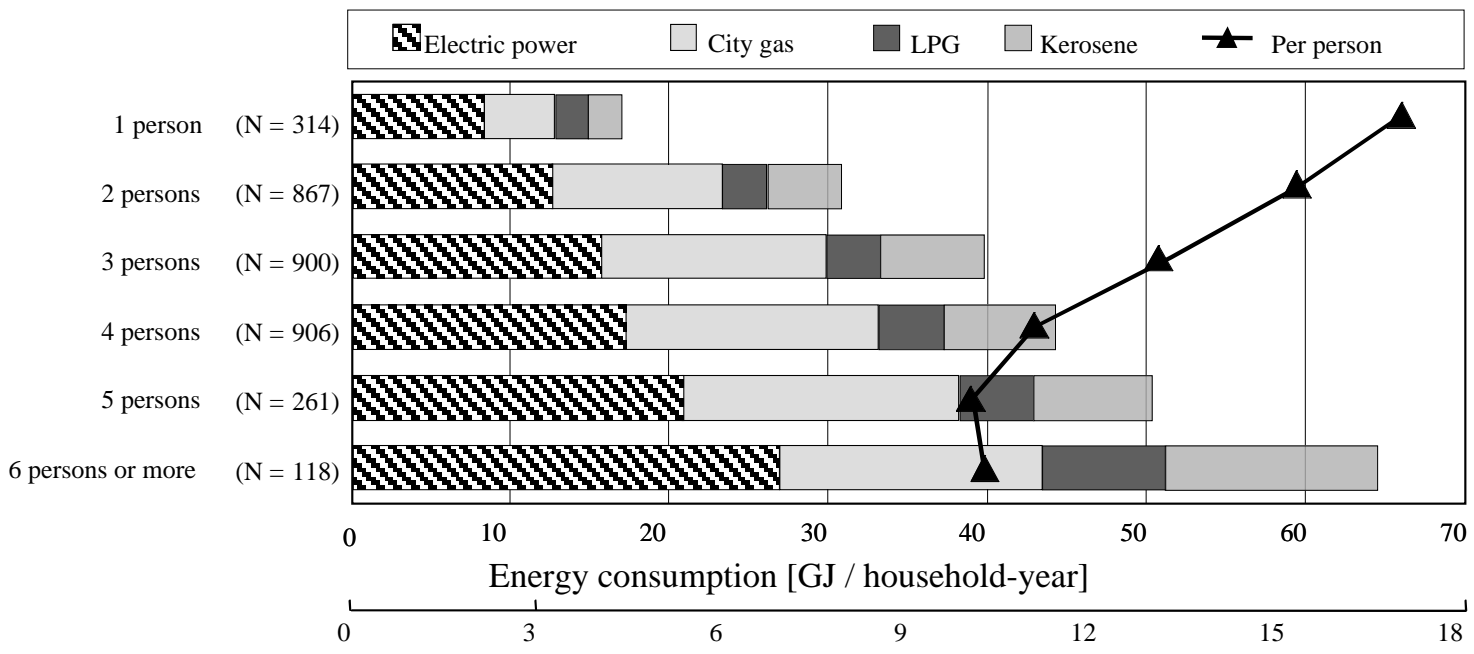

Per person energy consumption [GJ/person-year]

Figure 5. Relationship between family size and energy consumption (Hasegawa and Inoue, 2004) 


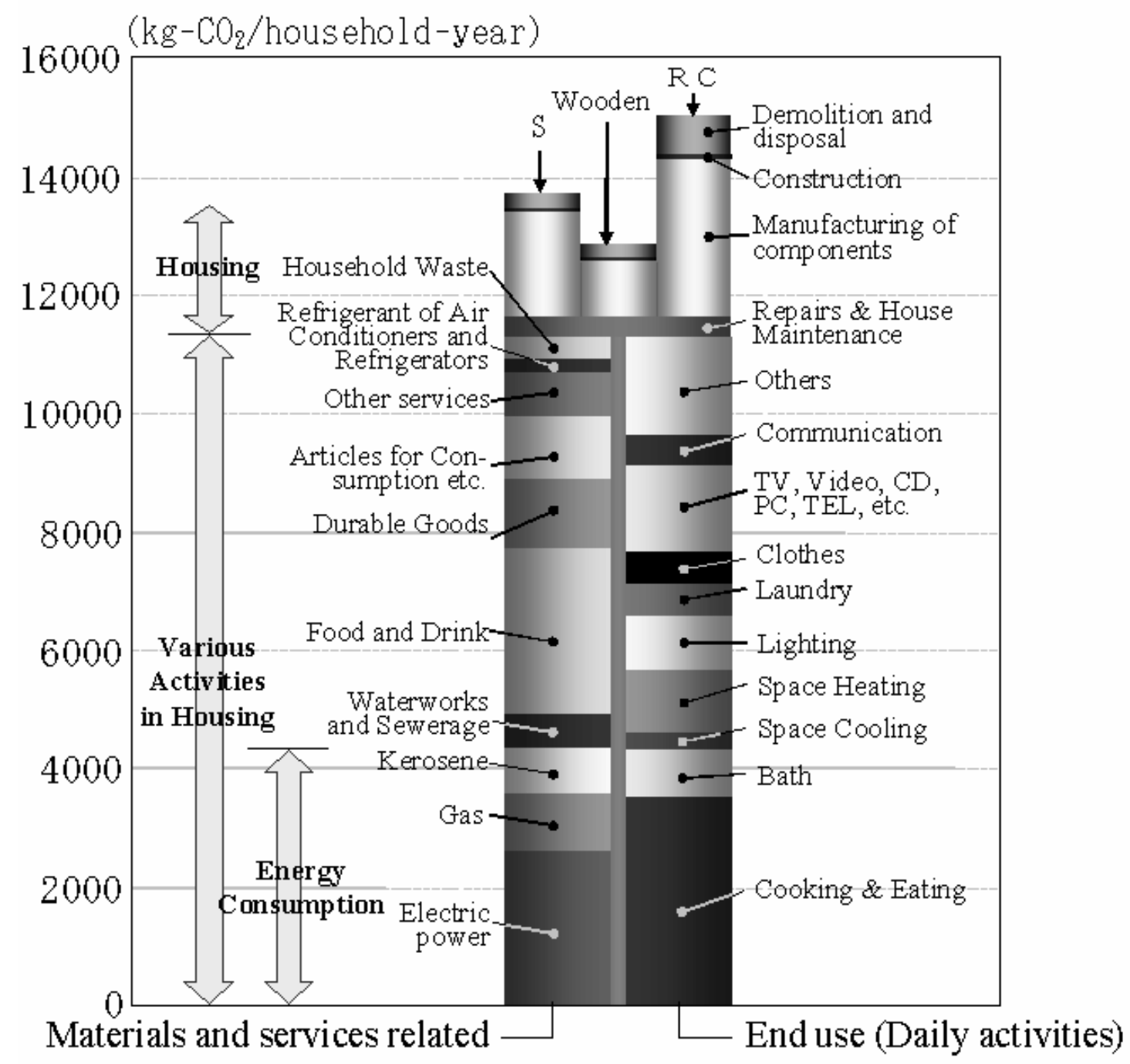

Figure 6. Breakdown of total $\mathrm{CO}_{2}$ emissions and end uses for daily-life activities in a detached house (Chikada and Inoue, 2003)

\section{3 $\mathrm{CO}_{2}$ Emissions from Energy Use in all Sectors in Japan}

Total $\mathrm{CO}_{2}$ emissions in 2000 were 1,237 million tons, an increase of 10.5\% from 1990 as shown in Table 2. (Global Environmental Bureau, Ministry of Environment, Japan, 2003) The breakdown of $\mathrm{CO}_{2}$ emissions in 2000 shows that $\mathrm{CO}_{2}$ emitted from residential, commercial, transportation, industrial and energy conversion sectors accounted for $93.3 \%$ of the total, $\mathrm{CO}_{2}$ from industrial processes accounted for $4.3 \%$, and $\mathrm{CO}_{2}$ from the waste sector accounted for $2.0 \%$. The industrial sector accounts for $40 \%$ of emissions of $\mathrm{CO}_{2}$ from fuel combustion, making it the single largest source of emissions. It is followed by the residential and commercial sector at $25.8 \%$ and the transport sector at $20.7 \%$.

$\mathrm{CO}_{2}$ emissions from the residential sector in 2000, whose share accounts for $13.5 \%$ of $\mathrm{CO}_{2}$ emissions, increased 20.4\% compared with 1990, as shown in Table 2. $\mathrm{CO}_{2}$ emissions from the commercial sector in 
2000, whose share accounts for $12.3 \%$ of $\mathrm{CO}_{2}$ emissions, increased $22.1 \%$ compared with $1990 . \mathrm{CO}_{2}$ emissions from the transportation sector in 2000, whose share accounts for $20.7 \%$ of $\mathrm{CO}_{2}$ emissions, increased 20.6\% compared with 1990. $\mathrm{CO}_{2}$ emissions from the industrial sector in 2000 increased $0.9 \%$ compared with 1990. $\mathrm{CO}_{2}$ emissions from the energy conversion sector in 2000 increased $11.4 \%$ compared with 1990 .

Table 2. Trends in $\mathrm{CO}_{2}$ emissions in each sector in Japan [Mt-CO${ }_{2}$ (Global Environmental Bureau, Ministry of Environment, Japan, 2003)

\begin{tabular}{|c|c|c|c|c|c|c|c|c|c|c|c|c|}
\hline & 1990 & 1991 & 1992 & 1993 & 1994 & 1995 & 1996 & 1997 & 1998 & 1999 & 2000 & $\begin{array}{c}\text { Share in } \\
2000\end{array}$ \\
\hline \multirow{2}{*}{ Residential } & 138.2 & 140 & 147.5 & 148 & 155.2 & 160 & 159 & 155.6 & 150.9 & 159.8 & 166.4 & \multirow{2}{*}{$13.50 \%$} \\
\hline & $100.00 \%$ & $101.30 \%$ & $106.70 \%$ & $107.10 \%$ & $112.30 \%$ & $115.80 \%$ & $115.10 \%$ & $112.60 \%$ & $109.20 \%$ & $115.60 \%$ & $120.40 \%$ & \\
\hline \multirow{2}{*}{ Commercial } & 124.5 & 131.9 & 137 & 129.3 & 143.6 & 143.3 & 142.9 & 142.8 & 144.7 & 149.5 & 152 & \multirow{2}{*}{$12.30 \%$} \\
\hline & $100.00 \%$ & $105.90 \%$ & $110.00 \%$ & $103.90 \%$ & $115.30 \%$ & $115.10 \%$ & $114.80 \%$ & $114.70 \%$ & $116.20 \%$ & $120.10 \%$ & $122.10 \%$ & \\
\hline \multirow{2}{*}{ Transportation } & 212.3 & 221.9 & 227.2 & 228.9 & 240.2 & 247 & 253.5 & 257.9 & 257.2 & 261.4 & 256.1 & \multirow{2}{*}{$20.70 \%$} \\
\hline & $100.00 \%$ & $104.50 \%$ & $107.00 \%$ & $107.80 \%$ & $113.10 \%$ & $116.30 \%$ & $119.40 \%$ & $121.50 \%$ & $121.10 \%$ & $123.10 \%$ & $120.60 \%$ & \\
\hline \multirow{2}{*}{ Industrial } & 490.1 & 487.3 & 476.4 & 470.4 & 488.6 & 489.8 & 496.8 & 494.1 & 474.4 & 495.4 & 494.6 & \multirow{2}{*}{$40.00 \%$} \\
\hline & $100.00 \%$ & $99.40 \%$ & $97.20 \%$ & $96.00 \%$ & $99.70 \%$ & $99.90 \%$ & $101.40 \%$ & $100.80 \%$ & $96.80 \%$ & $101.10 \%$ & $100.90 \%$ & \\
\hline \multirow[t]{2}{*}{ Energy Conversion } & 77.2 & 78.4 & 79.5 & 78.7 & 82.7 & 82.7 & 81.6 & 83.3 & 83.6 & 86.3 & 86 & \multirow{2}{*}{$7.00 \%$} \\
\hline & $100.00 \%$ & $101.60 \%$ & $103.00 \%$ & $101.90 \%$ & $107.10 \%$ & $107.10 \%$ & $105.70 \%$ & $107.90 \%$ & $108.30 \%$ & $111.80 \%$ & $111.40 \%$ & \\
\hline \multirow{2}{*}{ Industrial Processes } & 56.6 & 58.2 & 58.8 & 58.2 & 59.2 & 59.1 & 59 & 57.6 & 52.3 & 51.9 & 53.2 & \multirow[b]{2}{*}{4.3} \\
\hline & $100.00 \%$ & $102.80 \%$ & $103.90 \%$ & $102.80 \%$ & $104.60 \%$ & $104.40 \%$ & $104.20 \%$ & $101.80 \%$ & $92.40 \%$ & $91.70 \%$ & $94.00 \%$ & \\
\hline \multirow{2}{*}{ Waste } & 15.4 & 16 & 17.5 & 17.8 & 20.6 & 21.6 & 22.3 & 23.5 & 24 & 23.9 & 24.2 & \multirow{2}{*}{$2.00 \%$} \\
\hline & $100.00 \%$ & $103.90 \%$ & $113.60 \%$ & $115.60 \%$ & $133.80 \%$ & $140.30 \%$ & $144.80 \%$ & $152.60 \%$ & $155.80 \%$ & $155.20 \%$ & $157.10 \%$ & \\
\hline \multirow{2}{*}{ Others } & 5.1 & 4.8 & 5 & 5.1 & 4.8 & 4.5 & 4.4 & 4.7 & 4.5 & 4.5 & 4.5 & \multirow{2}{*}{$0.40 \%$} \\
\hline & $100.00 \%$ & $94.10 \%$ & $98.00 \%$ & $100.00 \%$ & $94.10 \%$ & $88.20 \%$ & $86.30 \%$ & $92.20 \%$ & $88.20 \%$ & $88.20 \%$ & $88.20 \%$ & \\
\hline \multirow{2}{*}{ Total } & 1119.3 & 1138.5 & 1148.9 & 1136.4 & 1194.8 & 1208 & 1219.4 & 1219.4 & 1191.7 & 1232.8 & 1237.1 & \multirow{2}{*}{$100.00 \%$} \\
\hline & $100.00 \%$ & $101.70 \%$ & $102.60 \%$ & $101.50 \%$ & $106.70 \%$ & $107.90 \%$ & $108.90 \%$ & $108.90 \%$ & $106.50 \%$ & $110.10 \%$ & $110.50 \%$ & \\
\hline
\end{tabular}

* Consumption of lime stone, etc.

\subsection{Global-warming Impact of Fluorocarbons used in Thermal Insulation of Japanese Homes}

Enhancing thermal insulation in houses is an effective strategy for reducing GHG emissions because increased insulation can significantly reduce energy consumption. However, $\mathrm{CO}_{2}$ is also emitted during the production of insulation materials, and fluorocarbons are used as the primary foaming agents in the manufacture of foam insulation; the global warming potential of fluorocarbons is enormous; for example, the global-warming impact of the leakage of one kilogram of fluorocarbons is equivalent to the emission of several hundred to several thousand kilograms of $\mathrm{CO}_{2}$.

The subsections below discuss GHG emissions, including fluorocarbon leakage resulting from enhanced thermal insulation of houses, specifically focusing on the life-cycle $\mathrm{CO}_{2}\left(\mathrm{LCCO}_{2}\right)$ emissions of insulators formed using fluorocarbon agents (Murakami et. al. 2004).

Figure 7 (1) shows $\mathrm{LCCO}_{2}$ emissions for a detached house in Tokyo insulated with hydrocholorofluorocarbon (HCFC) 141b in hard urethane foam. This house meets Japan's thermal insulation standards adopted in 1992, which are considered the model for new houses. Figure 7 (1) shows that, since the 1999 thermal insulation standards were implemented and for the period during which HCFC141b continued to be used as the foaming agent (i.e., until 2004), $\mathrm{LCCO}_{2}$ emissions increased by 14 percent because of leakage of HCFC 141b from foam insulation. When HFC 245fa, (which was substituted for HCFCs from 2004 on) replaced HCFC 141b, $\mathrm{LCCO}_{2}$ emissions increased by 42 percent. In 
contrast, when foam insulation is produced using hydrocarbon, one of the non-fluorocarbon foaming agents, $\mathrm{LCCO}_{2}$ emissions can be cut by 62 percent. Similarly, if housing complexes convert from using HCFC to non-fluorocarbon foaming agents and implement Japan's 1999 thermal insulation standards, $\mathrm{LCCO}_{2}$ emissions could be reduced 58 percent, as shown in Figure 7 (2)(Murakami et al. 2004).

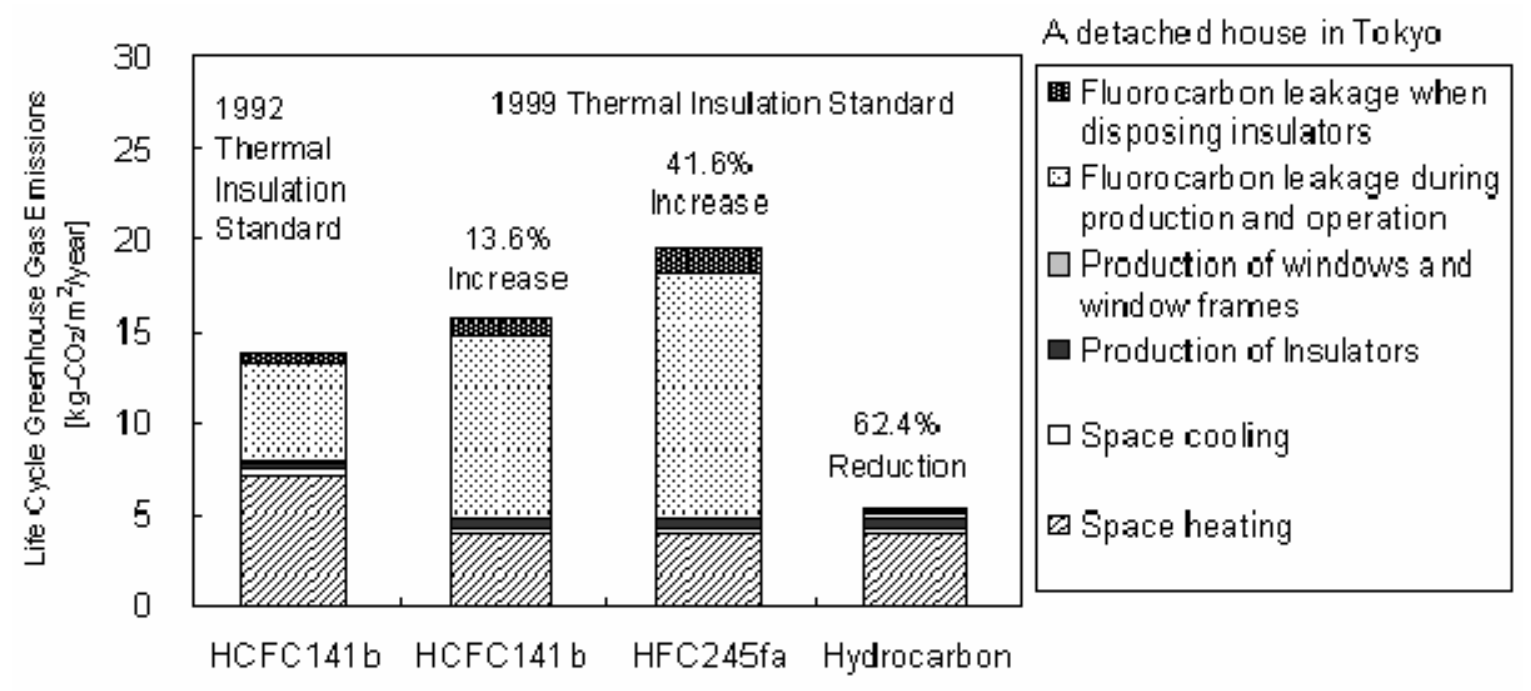

(1) A detached house

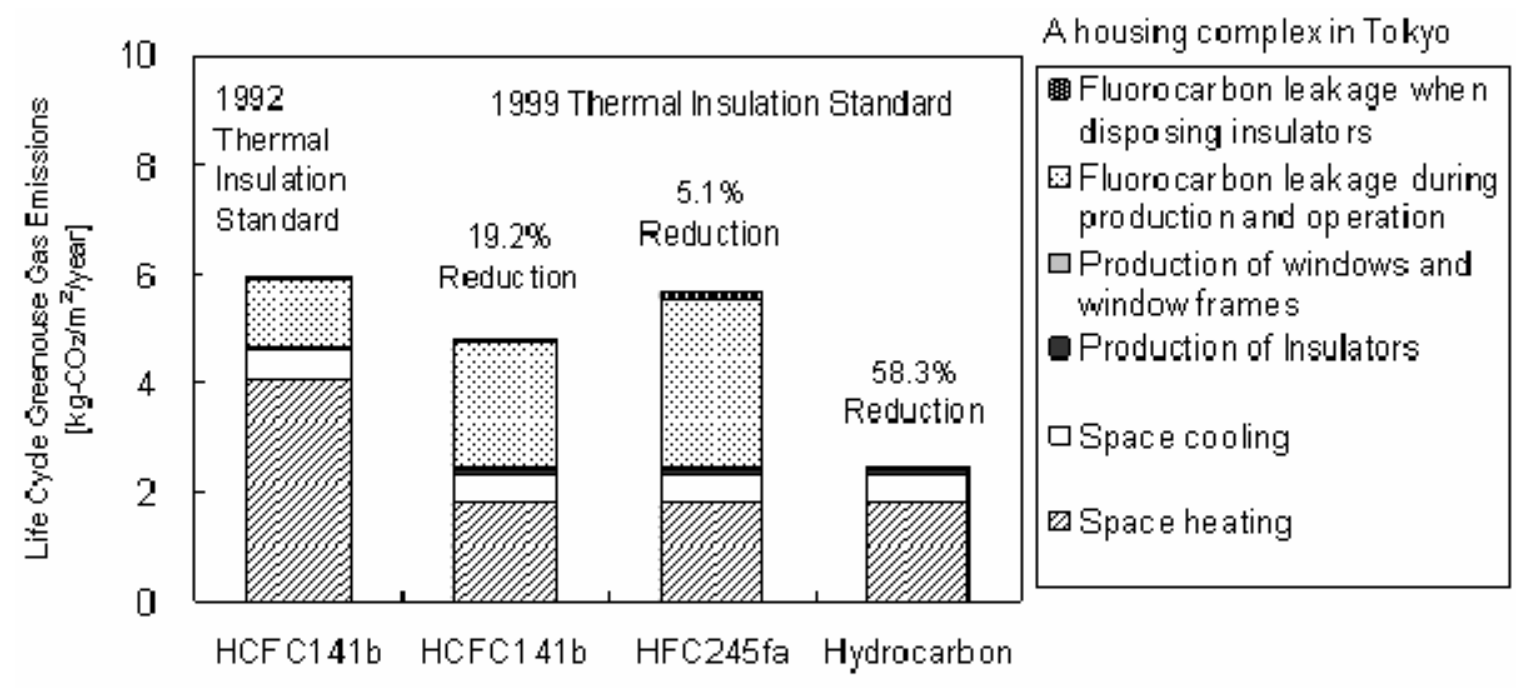

(2) A housing complex

Figure 7. The effect on $\mathrm{LCCO}_{2}$ emissions from reductions of non-fluorocarbon foaming agents used for foam insulation (Murakami et al., 2004) 


\subsubsection{Projection of GHG Emissions in 2012 from All Japanese Houses}

Representative values of $\mathrm{LCCO}_{2}$ emissions were determined for each of six climate regions in Japan, based on the insulation standards in each region and standard models for detached houses and housing complexes. These values were then multiplied by the gross floor space (broken down by the time of construction for houses in each region) to estimate yearly GHG emissions from all houses in Japan. GHG emissions were calculated as follows: 1) Number of houses, broken down by prefecture and time of construction; 2) Percentage of houses, broken down by prefecture and construction method; 3) Average gross floor space, broken down by time of construction and construction method; 4) Percentage of construction space, broken down by time of construction and type of insulation; 5) Percentage implementation of insulation standards for new houses, broken down by time of construction; and 6) Emissions of $\mathrm{LCCO}_{2}$, broken down by region and type of insulation. (Ikaga et. al. 2002)

Figure 8 shows $\mathrm{CO}_{2}$ emissions from space heating and cooling (in gray) and the production of home insulation materials (in white) for all houses in Japan up to the year 2012. For Case 1 (which is defined as only 15 percent of new houses complying with 1999 thermal insulation standards in 2010), total $\mathrm{CO}_{2}$ emissions associated with space heating and cooling and production of insulation materials were 33.1 million t- $\mathrm{CO}_{2}$ in 1990 and 38.1 million t- $\mathrm{CO}_{2}$ in 2000, which is an increase of 15 percent.

If the insulation levels in new houses remain unchanged after 2003, total annual average $\mathrm{CO}_{2}$ emissions from 2008 through 2012 come to 36.4 million t- $\mathrm{CO}_{2}$, an increase of 9.9 percent from 1990 (Case 1 in Figure 8). In contrast, if measures are adopted so that 90 percent of houses implement the 1999 thermal insulation standards by 2010 , total $\mathrm{CO}_{2}$ emissions are estimated at 36.1 million $\mathrm{t}-\mathrm{CO}_{2}$ during the period 2008-2012, an increase of 9.1 percent from 1990 (Murakami et al., 2004).

GHG emissions from all houses in Japan, including leakage of fluorocarbons from foam insulators (shown in black) as well as $\mathrm{CO}_{2}$ emissions from space heating and cooling, are shown in Fig.8. Case 1 in Figure 8 also shows that GHG emissions (were 38.7 million t- $\mathrm{CO}_{2}$ in 1990, 14 percent of which was fluorocarbon leakage. Assuming that the current scenario for insulation improvement measures remains unchanged, total GHG emissions during the period 2008-2012 will increase 14.4 percent from 1990 figures. If the insulation measures specified by the 1999 thermal insulation standards are implemented for 90 percent of new houses by 2010, emissions of greenhouse gases during the period 2008-2012 will increase by an estimated 18.7 percent compared to 1990 (Case 2 in Figure 8). However, if measures to cut fluorocarbon emissions (such as replacing foaming agents used in new houses with non-fluorocarbon types and recovering 50 percent of fluorocarbons during the demolition of existing houses) are implemented, in addition to the insulation measures, total GHG emissions during the period 2008-2012 can be reduced by 0.6 percent compared with 1990 levels, as shown in Case 3 in Figure 8. (Murakami et al., 2004) 


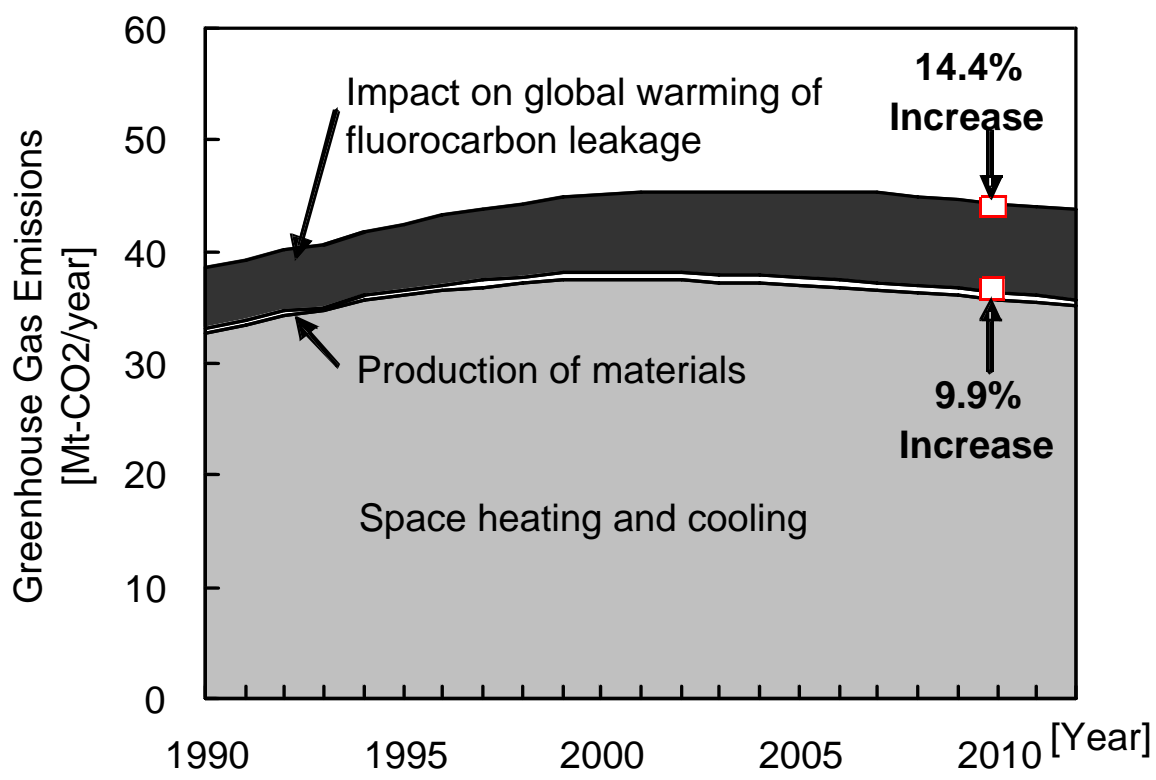

Case 1: 15 percent of new houses in 2010 comply with 1999 thermal insulation standards

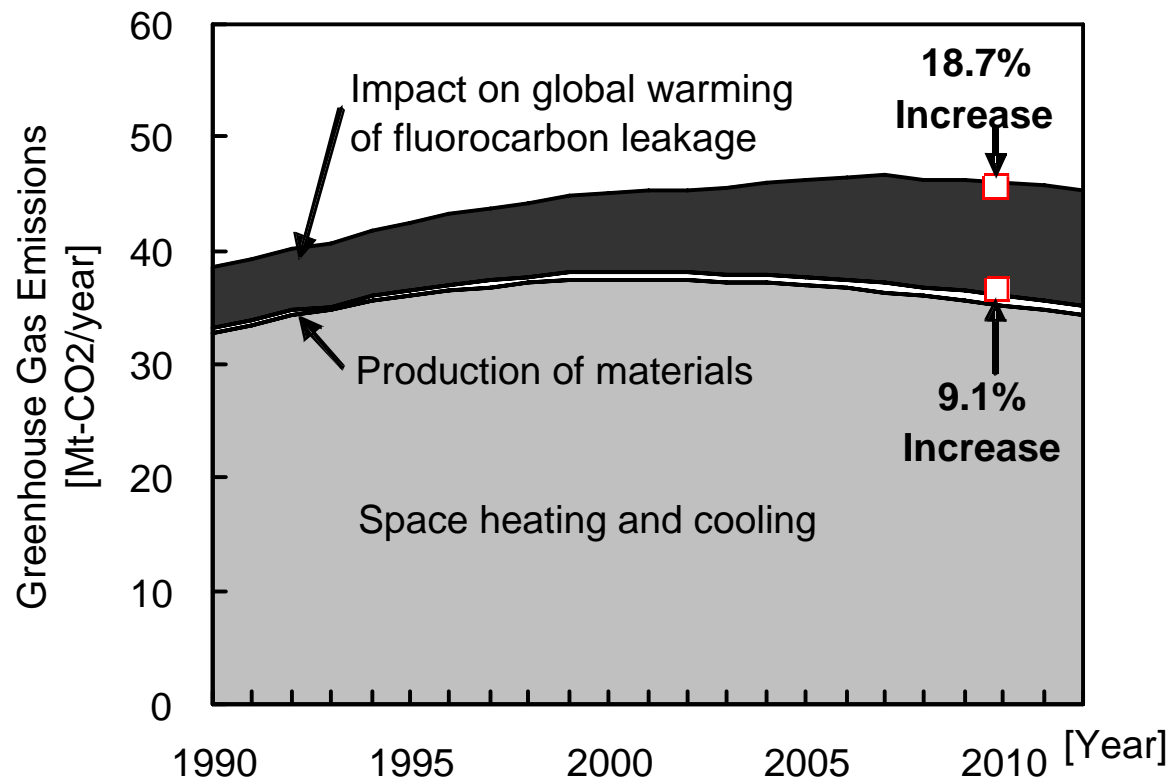

Case 2: 90 percent of new houses in 2010 comply with 1999 thermal insulation standards 


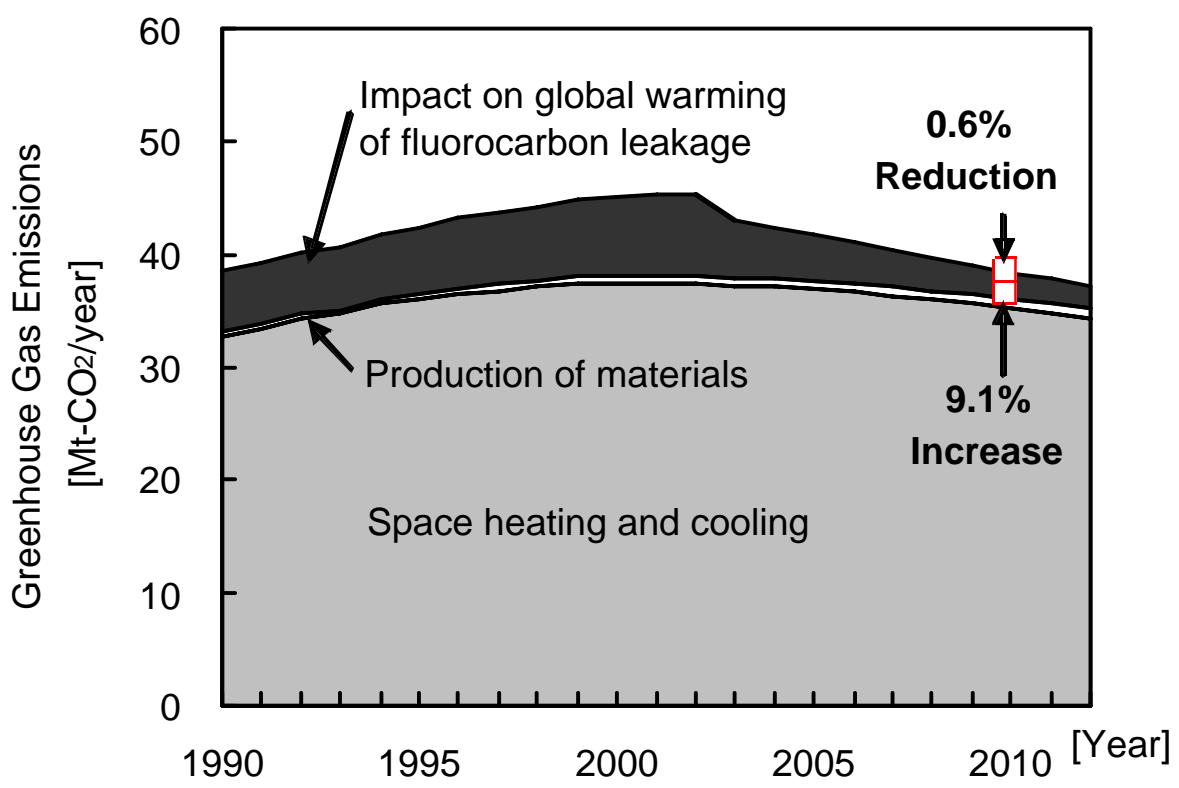

Case 3: Case 2 with adoption of non-fluorocarbon-foamed insulation for new houses and recovery of 50 percent of fluorocarbons during demolition of existing houses

Figure 8. Projection to 2012 of GHG emissions from all houses in Japan (Murakami et al., 2004)

\subsection{Key Drivers of Energy Consumption in Japanese Non-residential Buildings}

Total energy consumption trends for the Japanese commercial building sector are shown in Figure 9 (Institute of Building Environment and Energy Conservation, 2004). Although energy consumption intensity is relatively stable, the total amount of energy consumed is increasing at a rapid rate. Figure 10 (Building-Energy Manager's Association of Japan, 2002) also shows a slight upward trend, but the increase in energy consumption intensity in each type of building is not as marked as the increase in total energy consumption in the commercial sector, shown in Figure 9. These data suggest that the increase in commercial sector energy consumption is mainly caused by the increase in the total floor area of commercial buildings.

As shown in Figures 10 and 11 (Institute of Building Environment and Energy Conservation, 2004), energy consumption and end uses vary greatly among different types of commercial buildings (e.g., offices, hotels, hospitals, stores and schools).

Figure 11 shows that the energy consumption intensity for offices, which account for the largest floor area in the commercial sector, is about 1,900 megajoules per square meter $\left(\mathrm{MJ} / \mathrm{m}^{2}\right)$ per year, of which about 50 percent is for air conditioning, 30 percent is for lighting and office equipment, and 20 percent is for elevators, hot-water supply, and other uses. 
Air conditioning is necessary in offices (except in cold regions) because of the amount of heat generated by office equipment, lighting, and occupants. Only about half of the energy for air-conditioning is used for heating and cooling. The rest of energy is consumed by the fans, pumps, etc. associated with the air-conditioning system.

In hotels and hospitals, by contrast, the hot-water supply accounts for the majority of total energy consumed. Total energy consumption for hotels and hospitals is about 1.5 to 2 times greater than energy consumption for offices; energy consumption of schools and residences is relatively small.

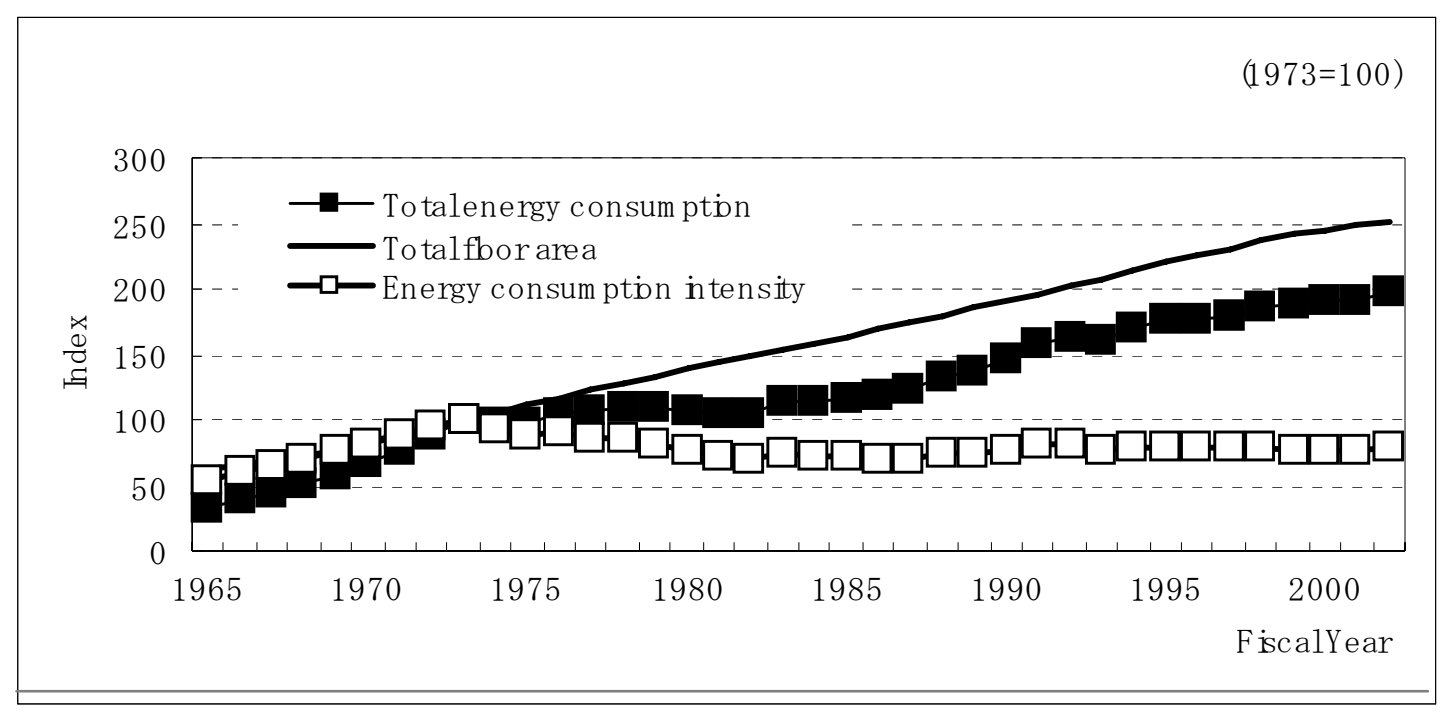

Figure 9. Total energy consumption trends in the Japanese non-residential building sector (Institute of Building Environment and Energy Conservation, 2004) 


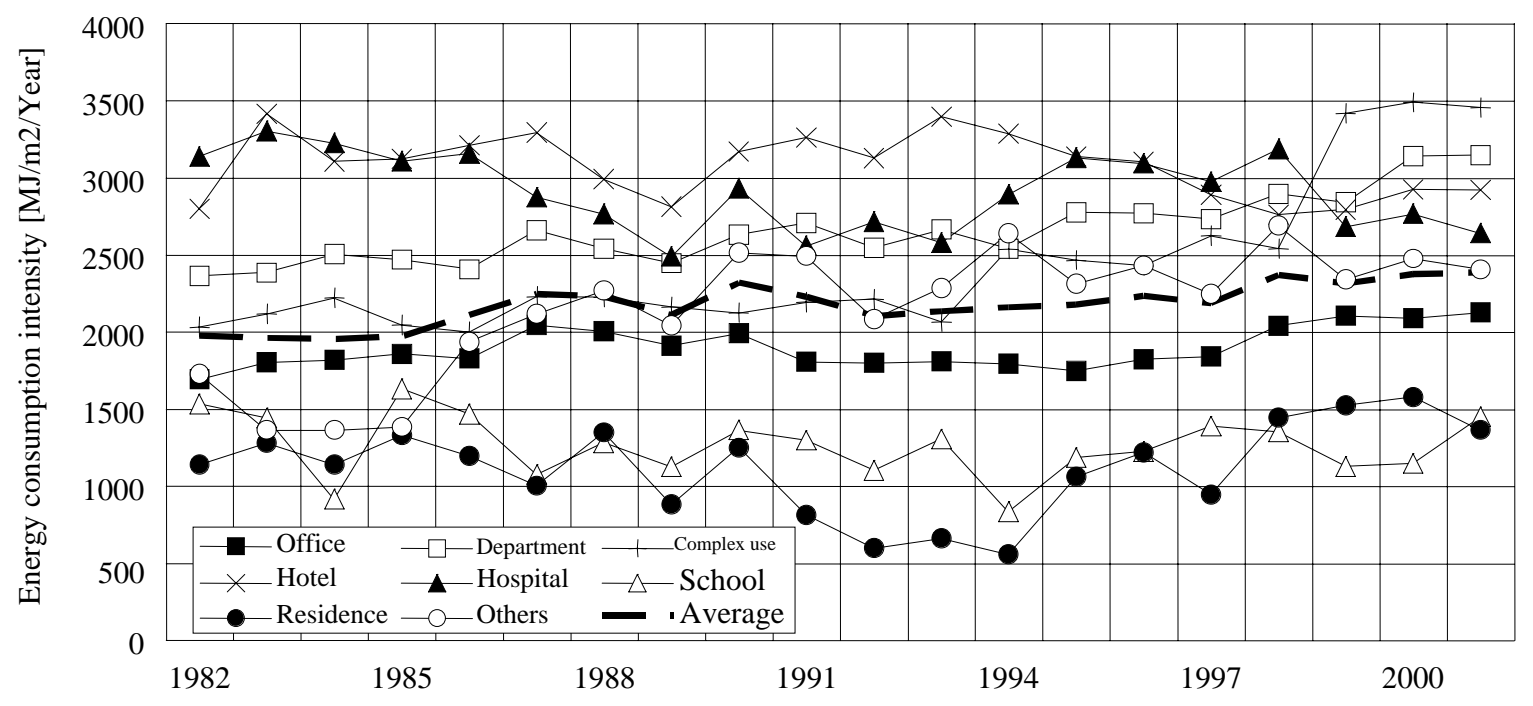

Figure 10. Energy consumption intensity trends in Japanese non-residential buildings (Building-Energy Manager's Association of Japan, 2002)

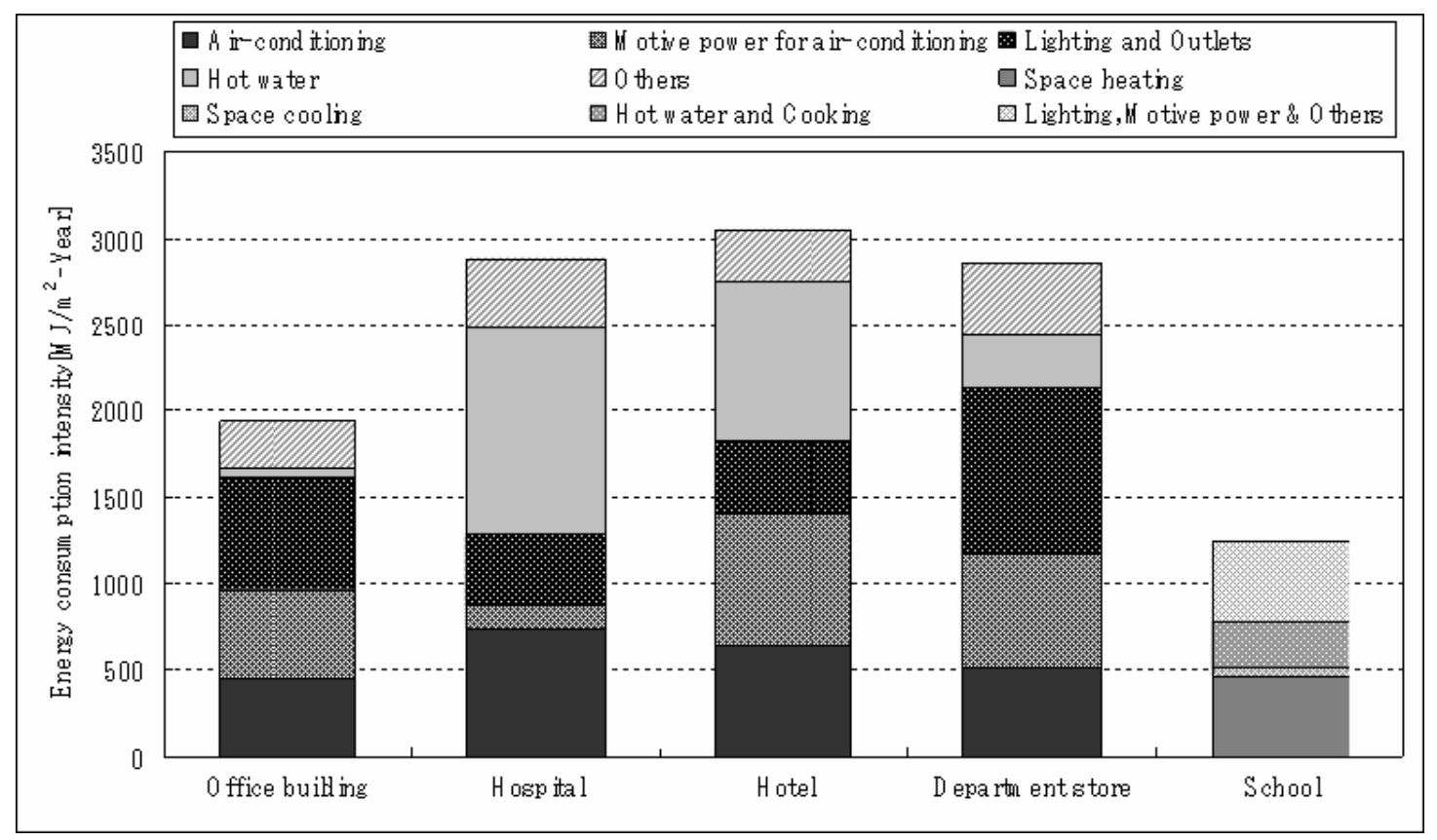

Figure 11. Energy consumption intensity and end uses in Japanese commercial buildings (Institute of Building Environment and Energy Conservation, 2004)

\section{Future Scenarios for $\mathrm{CO}_{2}$ Emissions from the Japanese Building Sector}

The subsections below describe projected $\mathrm{CO}_{2}$ emissions from Japanese buildings through the year 2050 and the impact of energy-conservation measures on emissions projections. 


\subsection{Projection of $\mathrm{CO}_{2}$ Emissions from the Japanese Building Sector through 2050}

Table 3 shows projected $\mathrm{CO}_{2}$ emissions from construction, renovation, and operation of buildings in Japan through the year 2050 (Ikaga et al., 2000).

Several scenarios were modeled for future $\mathrm{CO}_{2}$ emissions based on different assumptions about future emissions-reduction and energy-conservation measures.

Figure 12 shows projections for Scenario 1-a, which assumes that no emissions-reduction/ energy-conservation measures are adopted. Under this scenario, annual $\mathrm{CO}_{2}$ emissions from the construction, renovation and operation of buildings will be 470 million tons of $\mathrm{CO}_{2}$ in 2010, a 15 percent increase from 1990 levels. Japan's population is expected to decrease beginning in 2010; as a result, the total floor area of buildings will gradually decline. Because of this projected decline, building-related $\mathrm{CO}_{2}$ emissions under Scenario 1-a are projected to decrease in 2050 by 10 percent from 1990 levels.

Figure 13 shows Scenario 5-c-X, which assumes that $\mathrm{CO}_{2}$ emissions from electricity use are reduced in accordance with targets set for emissions-reduction/energy-conservation measures that were begun in the Japanese building sector in 1998. Annual $\mathrm{CO}_{2}$ emissions in 2010 will be 390 million tons, a decrease of 20 million tons or 6 percent from 1990 levels. Annual $\mathrm{CO}_{2}$ emissions in 2050 will be reduced to 40 percent of 1990 levels.

Scenario 5-c-Y, shown in Table 3, assumes that emissions-reduction/energy-conservation measures are undertaken by the Japanese building sector starting 2001. For this scenario, $\mathrm{CO}_{2}$ emissions in 2010 are expected to decrease by 3 percent relative to 1990 levels. If emissions reductions are implemented starting in 2006, (Scenario 5-c-Z), $\mathrm{CO}_{2}$ emissions will increase by 1 percent in 2010.

Scenario 5-b-X in Table 3 is a case in which the unit $\mathrm{CO}_{2}$ emissions from electricity are only reduced by 10 percent by 2010. In this case, $\mathrm{CO}_{2}$ emissions from the building sector will only be reduced by 1 percent in 2010. Furthermore, $\mathrm{CO}_{2}$ emissions from the building sector in 2010 will increase by 2 percent if unit $\mathrm{CO}_{2}$ emissions from electricity remain at 1990 levels (Scenario 5-a-X, Table 3) (Ikaga et al., 2000). 
Table 3. Projected Japanese-building-sector $\mathrm{CO}_{2}$ emissions ratios through 2050 compared with 1990 Levels (Ikaga et al., 2000)

\begin{tabular}{|c|c|c|c|c|c|c|c|c|}
\hline \multirow{2}{*}{ Scenarios } & \multirow{2}{*}{$\begin{array}{l}\text { Countermeasures by the Building } \\
\text { sector }\end{array}$} & \multirow{2}{*}{$\begin{array}{l}\text { Countermeasures in } \\
\text { power supply industry }\end{array}$} & \multicolumn{2}{|c|}{ X: start in 1998} & \multicolumn{2}{|c|}{ Y: start in 2001} & \multicolumn{2}{|c|}{ Z: start in 2006} \\
\hline & & & 2010 & 2050 & 2010 & 2050 & 2010 & 2050 \\
\hline $1-\mathrm{a}$ & \multirow{3}{*}{ 1. No countermeasures } & Case a. $(-0 \%)$ & 1.15 & 0.9 & 1.15 & 0.9 & 1.15 & 0.9 \\
\hline 1-b & & Case b. $(-10 \%)$ & 1.12 & 0.78 & 1.12 & 0.78 & 1.12 & 0.78 \\
\hline $1-\mathrm{c}$ & & Case c. (-20\%) & 1.06 & 0.64 & 1.06 & 0.64 & 1.06 & 0.64 \\
\hline $2-\mathrm{a}$ & \multirow{3}{*}{$\begin{array}{l}\text { 2. } 20 \% \text { energy conservation in } \\
\text { new construction work, } 10 \% \text { in } \\
\text { renovation work }\end{array}$} & Case a. $(-0 \%)$ & 1.09 & 0.8 & 1.11 & 0.8 & 1.14 & 0.8 \\
\hline 2-b & & Case b. $(-10 \%)$ & 1.06 & 0.69 & 1.08 & 0.7 & 1.11 & 0.7 \\
\hline 2-c & & Case c. (-20\%) & 1.01 & 0.57 & 1.02 & 0.57 & 1.05 & 0.58 \\
\hline 3-a & \multirow{3}{*}{$\begin{array}{l}\text { 3. In addition to Scenario 2, a } \\
\text { threefold increase in durability } \\
\text { plus the use of eco-materials }\end{array}$} & Case a. $(-0 \%)$ & 1.05 & 0.65 & 1.07 & 0.66 & 1.1 & 0.69 \\
\hline 3-b & & Case b. $(-10 \%)$ & 1.02 & 0.56 & 1.04 & 0.57 & 1.07 & 0.59 \\
\hline 3-c & & Case c. (-20\%) & 0.97 & 0.45 & 0.99 & 0.46 & 1.01 & 0.48 \\
\hline $4-\mathrm{a}$ & \multirow{3}{*}{$\begin{array}{l}4.30 \% \text { energy conservation in new } \\
\text { construction work, } 15 \% \text { in } \\
\text { renovation work }\end{array}$} & Case a. $(-0 \%)$ & 1.07 & 0.75 & 1.1 & 0.75 & 1.14 & 0.76 \\
\hline 4-b & & Case b. $(-10 \%)$ & 1.04 & 0.66 & 1.07 & 0.66 & 1.11 & 0.66 \\
\hline 4-c & & Case c. $(-20 \%)$ & 0.99 & 0.54 & 1.01 & 0.55 & 1.05 & 0.55 \\
\hline $5-a$ & \multirow{3}{*}{$\begin{array}{l}\text { 5. In addition to Scenario } 4 \text {, a } \\
\text { threefold increase in durability } \\
\text { plus the use of eco-materials }\end{array}$} & Case a. $(-0 \%)$ & 1.02 & 0.59 & 1.05 & 0.61 & 1.1 & 0.64 \\
\hline 5-b & & Case b. $(-10 \%)$ & 0.99 & 0.51 & 1.02 & 0.52 & 1.07 & 0.55 \\
\hline 5-c & & Case c. (-20\%) & 0.94 & 0.41 & 0.97 & 0.42 & 1.01 & 0.45 \\
\hline
\end{tabular}

Note 1: Relative values of $\mathrm{CO}_{2}$ emissions from construction, renovation, and operation of buildings compared with 1990 Levels (410 million tons $\mathrm{CO}_{2} /$ year as 1.0), Note 2: Figure for 2010 is a mean value for the period 2008-2012, Note 3: Case a= $\mathrm{CO}_{2}$ emissions per kilowatt hour (kWh) in 2010 are the same as in 1990, Case b= $\mathrm{CO}_{2}$ emissions per kWh in 2010 are reduced by 10 percent from 1990 levels, Case c $=\mathrm{CO}_{2}$ emissions per kWh in 2010 decrease by 20 percent from 1990 levels.

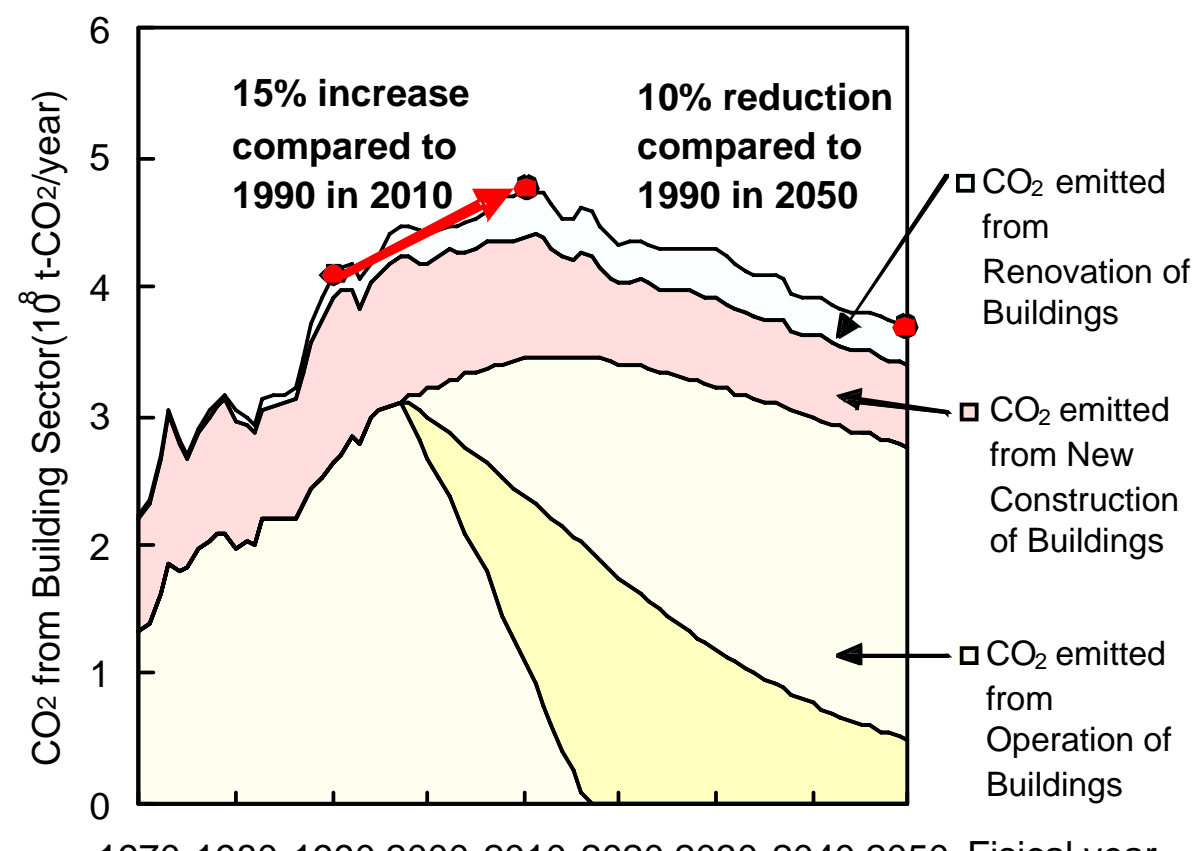

197019801990200020102020203020402050 Fisical year

Figure 12. Scenario 1-a (no emissions-reduction measures) projection of Japanese-building-sector $\mathrm{CO}_{2}$ emissions (Ikaga et al., 2000) 


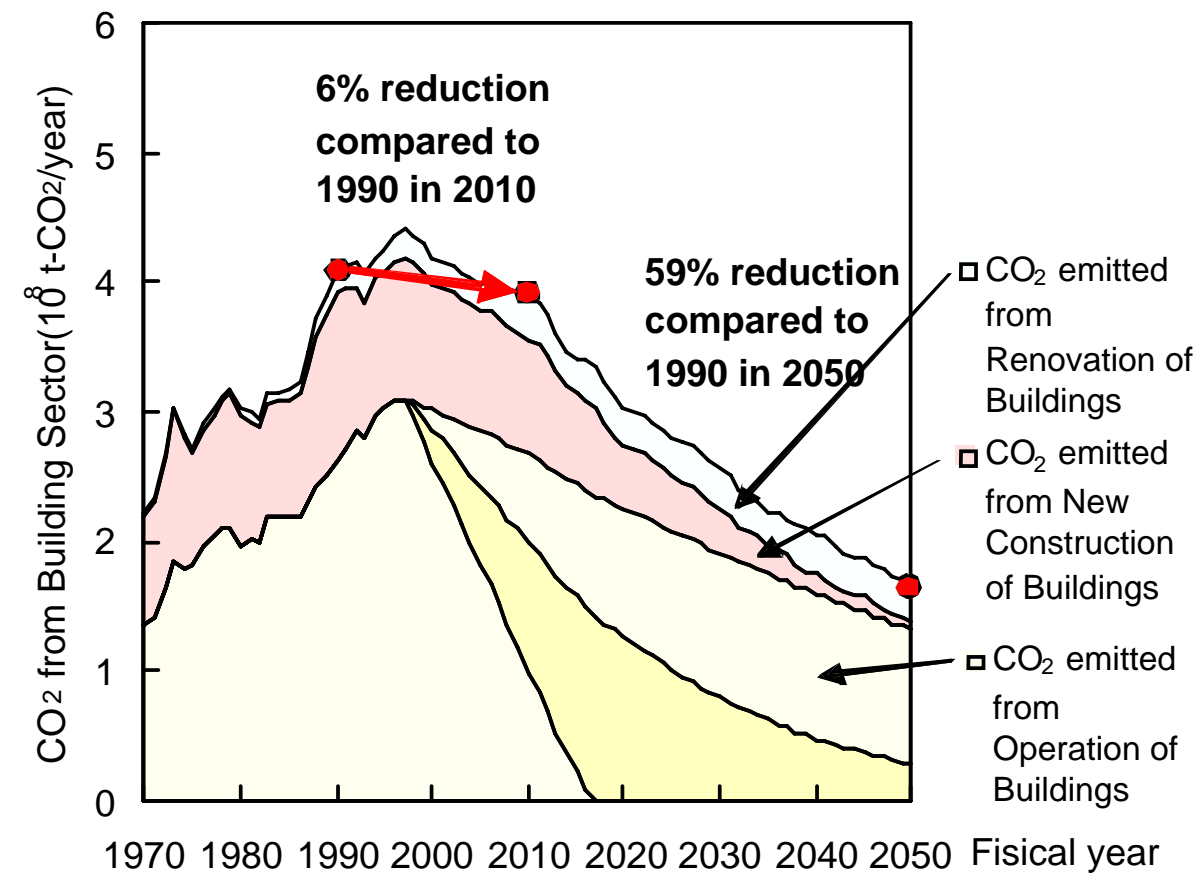

Figure 13. Scenario 5-c-X (emissions-reduction measures beginning in 1998) projection of Japanese-building-sector $\mathrm{CO}_{2}$ emissions (Ikaga et al., 2000)

\subsection{Future Residential $\mathrm{CO}_{2}$ Emissions in Japan}

The subsections below summarize the methods by which future residential $\mathrm{CO}_{2}$ emissions in Japan were estimated based on end uses and demographics and adoption of energy-conservation measures in the residential sector.

\subsubsection{Background}

$\mathrm{CO}_{2}$ emissions from household energy consumption in Japan increased by 20 percent from 1990 to 2000, making the residential sector an important target for emissions-reductions policies to ensure that the country will meet the target reductions specified in the Kyoto Protocol (a total 6 percent reduction from 1990 levels, achieved by 2012 at the latest). The emissions reduction targets set by the Kyoto Protocol are only a first step toward what emissions levels should be further in the future, however; some European countries, for example, are implementing policies that call for 50- to 80-percent reductions from 1990 levels by 2050. For this reason, our estimates cover the period through 2050.

Because residential $\mathrm{CO}_{2}$ emissions vary significantly depending on factors such as climate, family composition, and lifestyle, we break down household energy consumption by prefecture and family 
composition into end-use categories: heating \& cooling; hot-water supply; and "other," which includes energy used in kitchen activities, home entertainment, information technology, housework, hygiene-related activities, and lighting. Seven family types are considered: 1) households with an elderly single person only, 2) other households with a single member, 3) households with an elderly married couple only, 4) other households with a married couple only, 5) households with parents and a child or children, 6) households with a single parent and a child or children, and 7) other households. This level of detail allows us to identify the emissions-reduction/energy-conservation measures that will be most effective in the residential sector.

\subsubsection{Nationwide Data on Japanese Households and Reduction of $\mathrm{CO}_{2}$ Emissions through Energy-Conservation Measures}

Energy consumption estimation method was shown in Figure 14. The estimated number of households in Japan by family type is shown in Figure 15. The numbers through 2025 are from the National Institute of Population and Social Security Research; numbers from 2026 on were obtained by extrapolating the trend through 2025. Between 2015 and 2020, the total number of households will increase by 24 percent compared with 1990 levels and then begin to decrease. The respective proportions of households with a single member and with elderly members are expected to increase from 1990 through 2050. Based on these statistics, nationwide $\mathrm{CO}_{2}$ emissions were broken down according to the purpose of residential energy use and estimated through 2050. The energy conservation measures used in this study were shown in Table 4. The results are shown in Figure 16. The results are annual household emissions of 1.4 billion tonne- $\mathrm{CO}_{2}$ in 1990 and 1.7 billion tonne- $\mathrm{CO}_{2}$ in 2000 (a 20-percent increase). In the no emission-reduction-measures case, it was estimated that emissions will increase by 26 percent in 2010 compared with 1990 levels. Even with emissions-reduction/energy-conservation measures, including reinforcement of thermal insulation for new and existing houses, promotion of the most efficient household equipment for replacements, promotion of solar thermal collectors and photovoltaics (PVs), and promotion of energy-saving lifestyle changes, emissions will still increase in the short term, by 11 percent in 2010, compared with 1990 levels. However, if all of these measures are implemented, a 64 percent reduction in emissions will be achieved by 2050, as shown in Figure 17.

Japan aims to reduce approximately 80 percent of 1990 emissions by 2050. Therefore, measures that will result in reductions exceeding the levels shown in Figure 17 will be required. (Ikaga et.al., 2005)

\subsubsection{Residential $\mathrm{CO}_{2}$ Emissions Reductions (by Prefecture) from Energy-Conservation Measures}

Figure 18 shows the estimated increase, compared to 1990 levels, in household $\mathrm{CO}_{2}$ emissions by prefecture during the first commitment period of the Kyoto Protocol for the no-emission-reduction-measures case. Emissions increase by 1.4 times 1990 levels in two prefectures: Saitama and Shiga. In more than 70 percent of prefectures, emissions increase by at least 1.2 times 1990 levels. 
Figure 19 shows the results when the energy-conservation measures listed in Table 4 are implemented. The maximum growth in emissions is 1.3 times 1990 levels. In approximately 15 percent of prefectures, the growth rate is less than 1.0. As the first commitment period of the Kyoto Protocol draws near, these results show the importance of promoting energy-conservation measures while taking into account differences among prefectures, numbers of households, weather, lifestyle, etc.

Tokyo, Hokkaido, and Okinawa Prefecture are examples why it is important to take local details into account when designing emissions-reduction strategies.

The total number of households in the Tokyo metropolitan area is expected to increase by 31 percent (compared with 1990 levels) by approximately 2005 and then start to decrease. The proportion of households with only elderly members (i.e., households with only a single elderly person or an elderly married couple) will continue to increase from 1990 through 2050. $\mathrm{CO}_{2}$ emissions in Tokyo were 13.0 million t- $\mathrm{CO}_{2}$ in 1990, as shown in Figure 20, and 17.0 million t- $\mathrm{CO}_{2}$ in 2005, a 31 percent increase. In the no-emission-reduction-measures case, emissions will still increase by 28 percent over 1990 levels by 2010, but a 39 percent reduction will be achieved by 2050. With the energy-conservation measures listed in Table 4, $\mathrm{CO}_{2}$ emissions will still increase by 13 percent over 1990 levels in 2010, but a 59 percent reduction will be achieved in 2050 .

The total number of households in Hokkaido is estimated to increase by 17 percent over 1990 levels in 2010 and then start to decrease to 18 percent or less of 1990 levels by 2050. Figure 21 shows an estimate of $\mathrm{CO}_{2}$ emissions by end use in Hokkaido through 2050, assuming the above population changes. Heating accounts for half of $\mathrm{CO}_{2}$ emissions, which suggests the importance in this region of emissions-reduction measures such as improvements in thermal insulation and heating-system efficiency. Annual $\mathrm{CO}_{2}$ emissions in the Hokkaido region were 11 million t- $\mathrm{CO}_{2}$ in 1990 and 14.0 million t-CO 2005 (a 28 percent increase). In the no-emission-reduction-measures case, it is estimated that emissions in 2010 will increase by 35 percent over 1990 levels but decrease by 53 percent relative to 1990 levels in 2050. In contrast, with the additional energy-conservation measures listed in Table 4, it is estimated that emissions will increase by 7 percent from 1990 levels by 2010 but decrease by 61 percent relative to 1990 levels by 2050.

The total number of households in Okinawa Prefecture is expected to continue to increase through 2030 to a total of 54 percent more than the number of households in 1990, the same trend as in Saitama Prefecture. Figure 22 shows the estimate of $\mathrm{CO}_{2}$ emissions broken down by end use in Okinawa Prefecture through 2050, based on these population data. Unlike in other prefectures, $\mathrm{CO}_{2}$ emissions in Okinawa attributable to cooling are very high, which indicates the importance of energy-conservation measures such as solar insulation shielding and high-efficiency cooling systems. Annual $\mathrm{CO}_{2}$ emissions were 1.0 million $\mathrm{t}-\mathrm{CO}_{2}$ in 1990 and 1.4 million $\mathrm{t}-\mathrm{CO}_{2}$ in 2005 (a 32-percent increase). In the no-emission-reduction-measures case, emissions will increase by an estimated 33 percent over 1990 levels by 2010 but decrease by 29 percent by 2050. In contrast, with the additional energy-conservation 
measures listed in Table 4, it is estimated that emissions will increase by 18 percent by 2010 compared with 1990 levels but decrease by 57 percent by 2050. (Ikaga et. al. 2005)

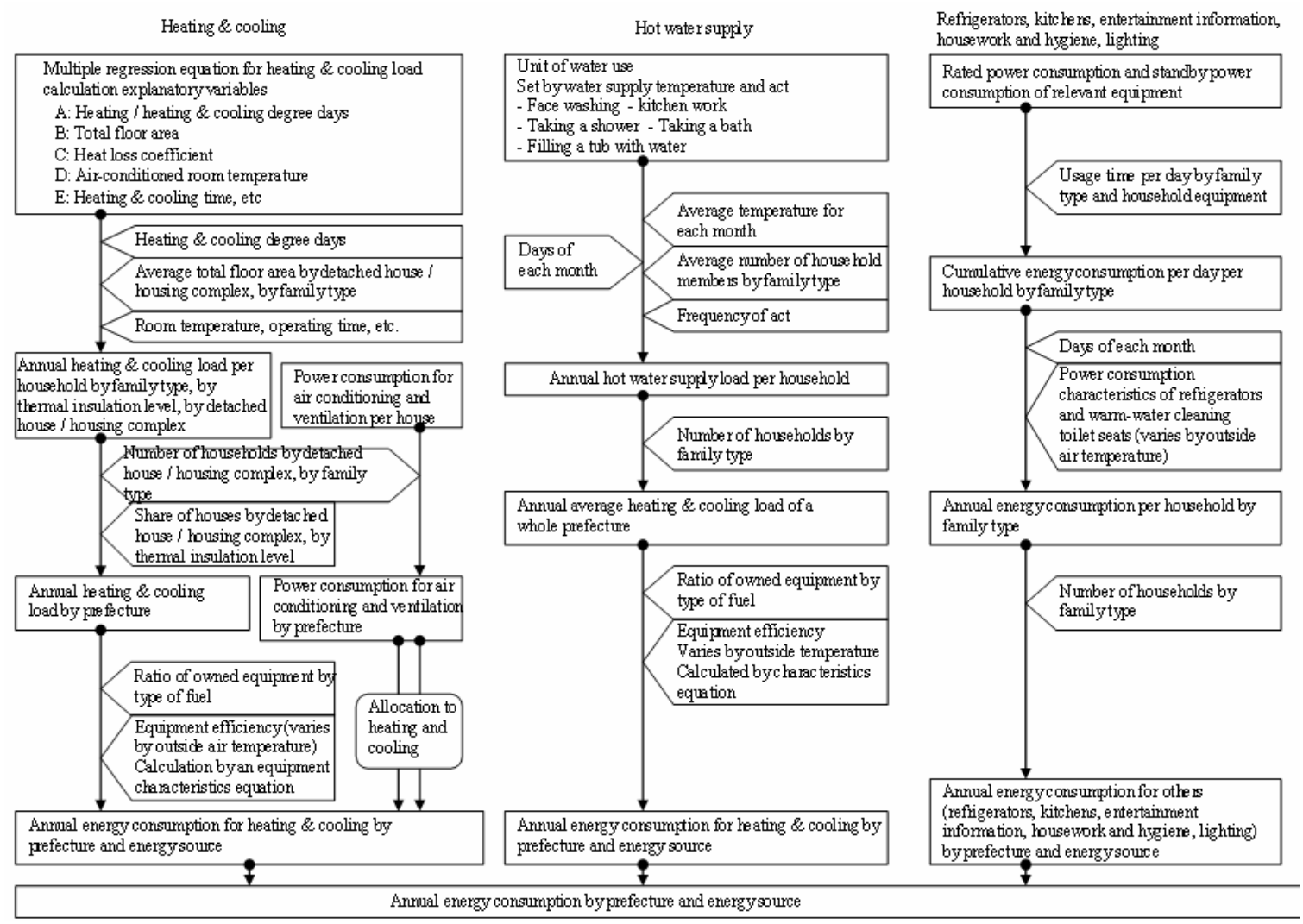

Figure 14. Energy consumption estimation method 
Table 4. Outline of assumed energy-conservation measures

\begin{tabular}{|c|c|}
\hline & Specifics of energy saving measures \\
\hline \multirow{6}{*}{$\begin{array}{l}\text { Heating \& } \\
\text { cooling }\end{array}$} & $\begin{array}{l}\text { Improvement of thermal insulation for new houses (assuming that, by 2020, all new houses meet the Next } \\
\text { Generation Standard as a Revision of Japanese Housing Energy Efficiency Standard) }\end{array}$ \\
\hline & $\begin{array}{l}\text { Renovation of thermal insulation for existing houses (assuming that } 1.0 \% \text { of all houses are renovated to meet the } \\
\text { Next Generation Standard as a Revision of Japanese Housing Energy Efficiency Standards starting in 2005) }\end{array}$ \\
\hline & $\begin{array}{l}\text { Promotion of the purchase of energy saving air conditioners for replacement (assuming that the heating COP } \\
\text { increases from } 3.0 \text { to } 6.0 \text { and the cooling COP increases from } 4.0 \text { to } 6.0 \text {, on average, for all households by } 2020 \text {, } \\
\text { and the heating COP increases from } 4.0 \text { to } 8.0 \text { and the cooling COP increased from } 6.0 \text { to } 8.0 \text {, on the average, for } \\
\text { all households by 2050) }\end{array}$ \\
\hline & $\begin{array}{l}\text { Promotion of the purchase of electric heating equipment to replace kerosene units (assuming that the } \\
\text { electrification rate is } 1.5 \text { times and } 3 \text { times in } 2020 \text { and 2050, respectively, compared with 2005) }\end{array}$ \\
\hline & $\begin{array}{l}\text { Energy saving activities to decrease thermostats by } 2 \text { degrees } C \text { for heating and increase thermostats by } 1 \\
\text { degrees } C \text { for cooling (assuming that } 30 \% \text { of households are implemented by 2020) }\end{array}$ \\
\hline & $\begin{array}{l}\text { Energy saving activities to reduce the total heating and cooling operation time by } 25 \% \text { (assuming that } 30 \% \text { of } \\
\text { households are implemented by 2020) }\end{array}$ \\
\hline \multirow{4}{*}{$\begin{array}{l}\text { Hot water } \\
\text { supply }\end{array}$} & $\begin{array}{l}\text { Promotion of the purchase of heat pump water heaters to replace electric water heaters (assuming that the COP } \\
\text { of the heat pump water heater increases to } 6.0 \text { by 2050) }\end{array}$ \\
\hline & Promotion of purchasing condensing boiler for replacement (assuming that the efficiency 1.2 times by 2020) \\
\hline & $\begin{array}{l}\text { Promotion of the purchase electric water heaters to replace kerosene units (assuming that the electrification rate } \\
\text { is } 1.5 \text { times and } 3 \text { times in } 2020 \text { and 2050, respectively, compared to the base year of 2005) }\end{array}$ \\
\hline & $\begin{array}{l}\text { Promotion of energy saving activities (assuming the following energy saving activities are implemented by } 50 \% \\
\text { of all households in } 2020 \text { and this level stays flat afterward; (1) reduction of hot water supply temperature by } \\
1 \text { degree C, (2) reduction of the frequency of taking a bath, reducing water supply to bath, using water saving } \\
\text { shower heads, (3) reduction hot water use for face washing and kitchen work and using cold water for face } \\
\text { washing and kitchen work in summer, etc.) }\end{array}$ \\
\hline \multirow{3}{*}{$\begin{array}{l}\text { Household } \\
\text { electric } \\
\text { equipment }\end{array}$} & $\begin{array}{l}\text { Promotion of the purchase of energy saving refrigerators for replacement (assuming that the power consumption } \\
\text { of refrigerators is reduced by } 60 \% \text { in } 2020 \text { and by } 70 \% \text { in } 2050 \text { compared to the base year of 2005) }\end{array}$ \\
\hline & $\begin{array}{l}\text { Promotion of the purchase of the energy saving TVs for replacement (assuming that the power consumption of } \\
\text { TVs is reduced by } 50 \% \text { in } 2020 \text { and by } 75 \% \text { in } 2050 \text { compared to the base year of 2005) }\end{array}$ \\
\hline & $\begin{array}{l}\text { Promotion of energy saving activities (assuming the following energy saving activities are implemented by } 50 \% \\
\text { of all households in } 2020 \text { and the level stays flat afterward; (1) unplugging electric equipment when not in use, } \\
\text { (2) using the water left in a bath tub for washing clothes, (3) only washing clothes when you have a large load } \\
\text { and using speed course mode, (4) replacing light bulbs in hall ways, a bath room, and a washroom with bulb-type } \\
\text { fluorescent lamps, (5) closing the lid of warm-water cleaning toilet seats and adjusting the temperature setting } \\
\text { depending on the season, etc.) }\end{array}$ \\
\hline \multirow{2}{*}{$\begin{array}{l}\text { Solar heat / } \\
\text { light }\end{array}$} & $\begin{array}{l}\text { Wide use of solar water heaters (assuming the use of solar water heaters with } 4 \mathrm{~m}^{2} \text { / household by } 20 \% \text { of } \\
\text { detached houses and with } 2 \mathrm{~m}^{2} \text { / household by } 2 \% \text { of housing complexes by } 2020 \text {, and by } 40 \% \text { of detached } \\
\text { houses and } 4 \% \text { of housing complexes by 2050) }\end{array}$ \\
\hline & $\begin{array}{l}\text { Solar power generation (assuming the use of solar power generation with } 4 \mathrm{~kW} \text { / household by } 10 \% \text { of detached } \\
\text { houses and with } 0.5 \mathrm{~kW} / \text { household by } 1 \% \text { of housing complexes in by } 2020 \text {, and by } 20 \% \text { of detached houses } \\
\text { and } 2 \% \text { of housing complexes by 2050) }\end{array}$ \\
\hline
\end{tabular}

Note: In addition, the effort of electric power companies is incorporated into the assumption by setting the unit $\mathrm{CO}_{2}$ emissions from electricity in 2010 to a voluntary target of the Federation of Electric Power Companies of Japan, $0.34 \mathrm{~kg}-\mathrm{CO}_{2} / \mathrm{kWh}$ (reduced by $20 \%$ vs. 1990). Since no announced value is available for after 2010 , the assumption is made that measures are being promoted for the reduction by $60 \%$ by 2050 compared to 1990 . 


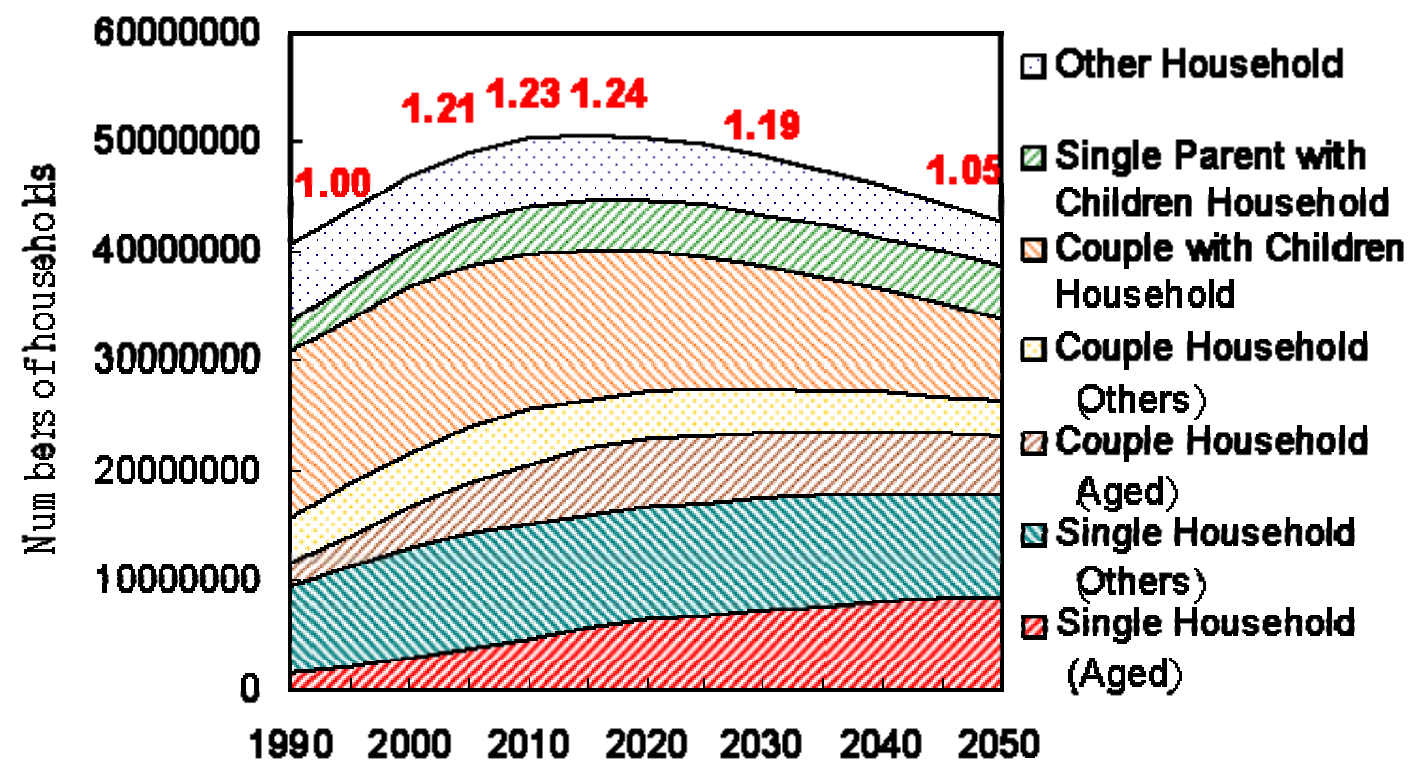

Figure 15. Estimate of number of households in Japan by family type, through 2050

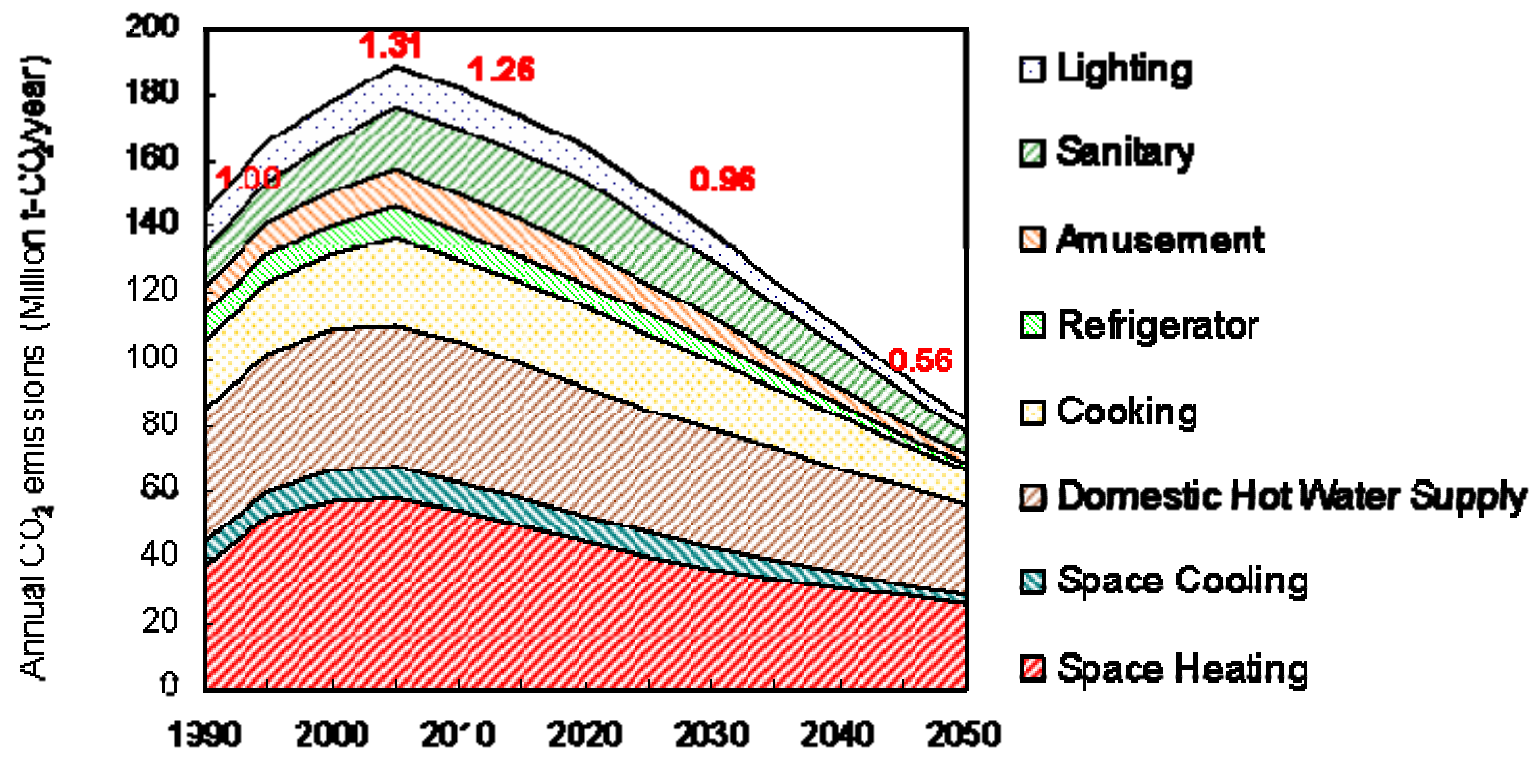

Figure 16. Estimate of $\mathrm{CO}_{2}$ emissions from all households in Japan, through 2050 (with no energy-conservation measures) 


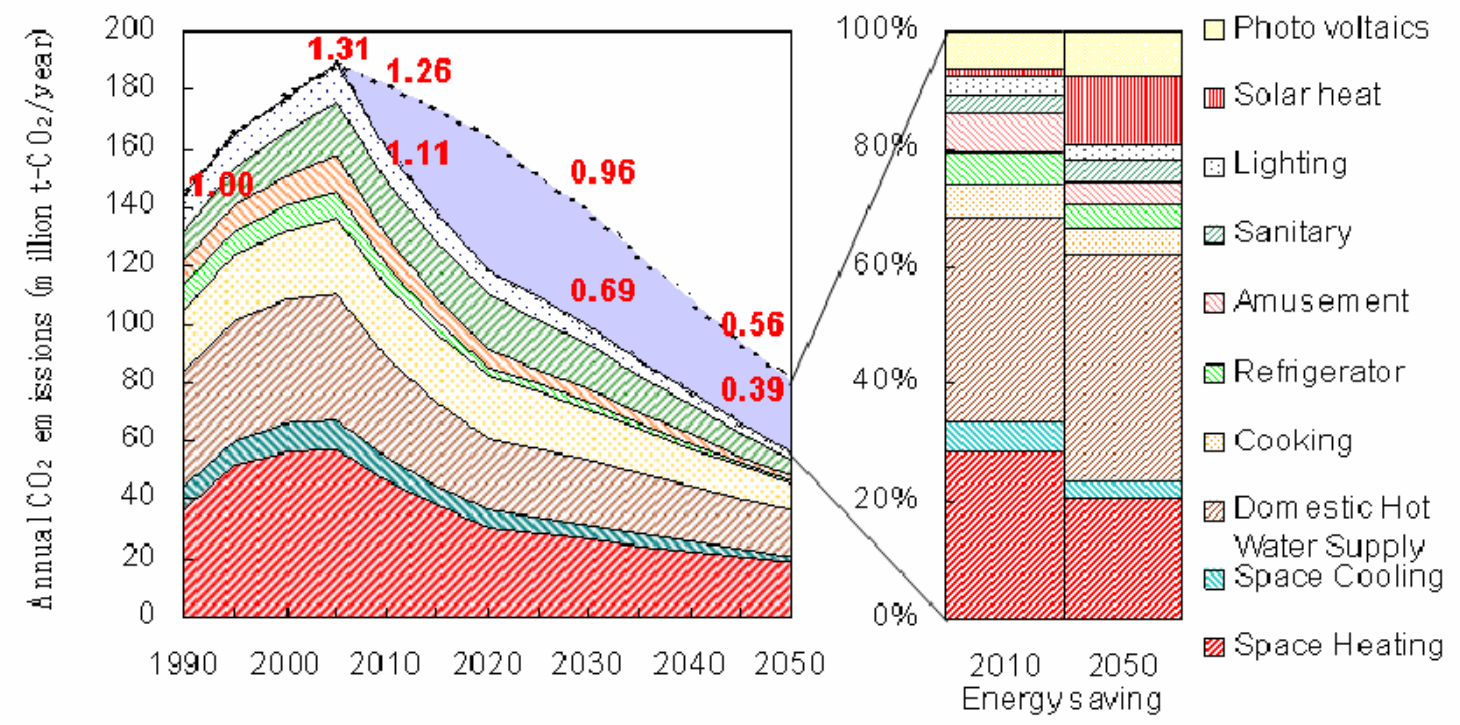

Figure 17. Estimate of $\mathrm{CO}_{2}$ emissions from all households in Japan, through 2050 (with energy-conservation measures)

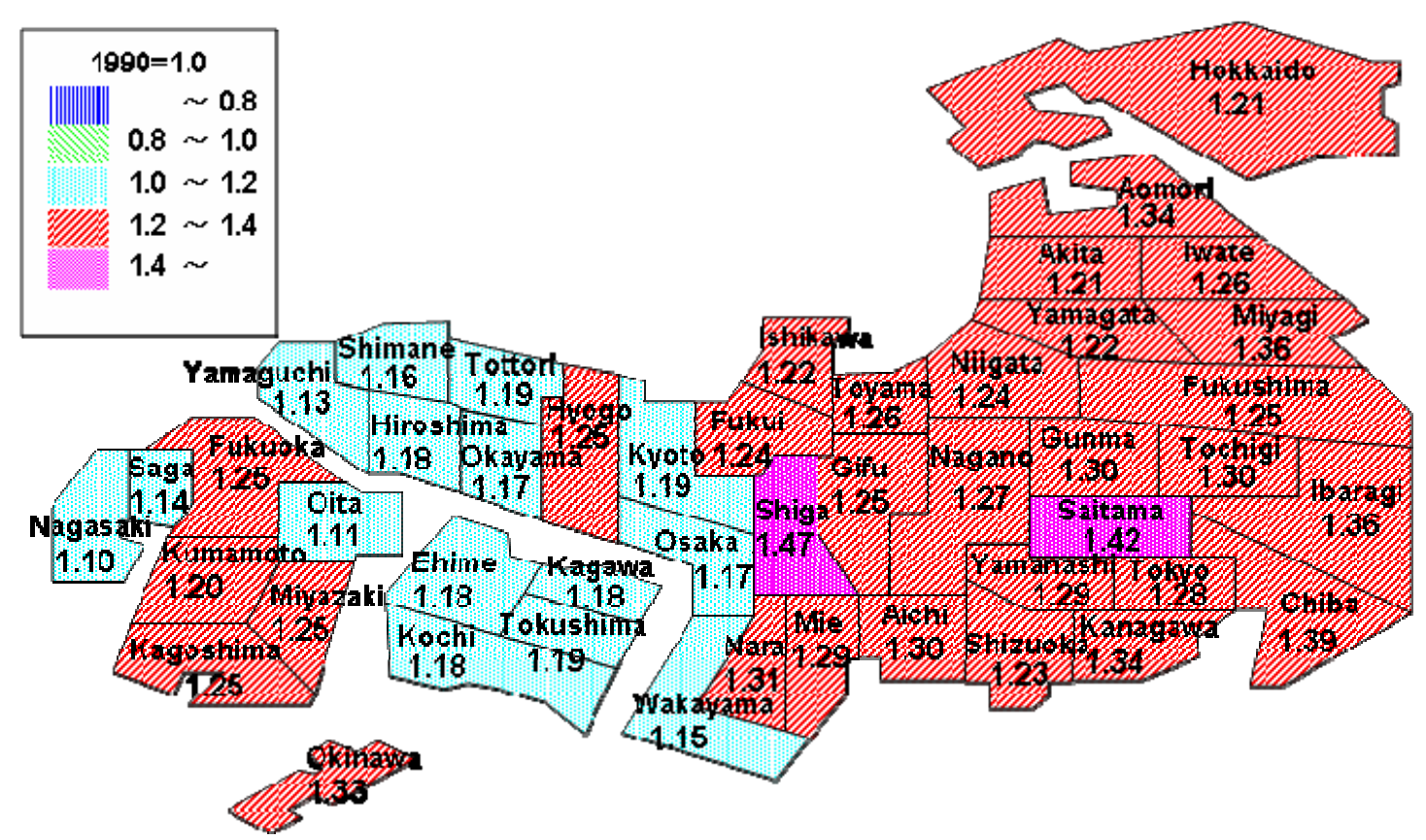

Figure 18. Growth in residential $\mathrm{CO}_{2}$ emissions in 2010, compared to 1990 levels, by prefecture (no energy-conservation measures) 


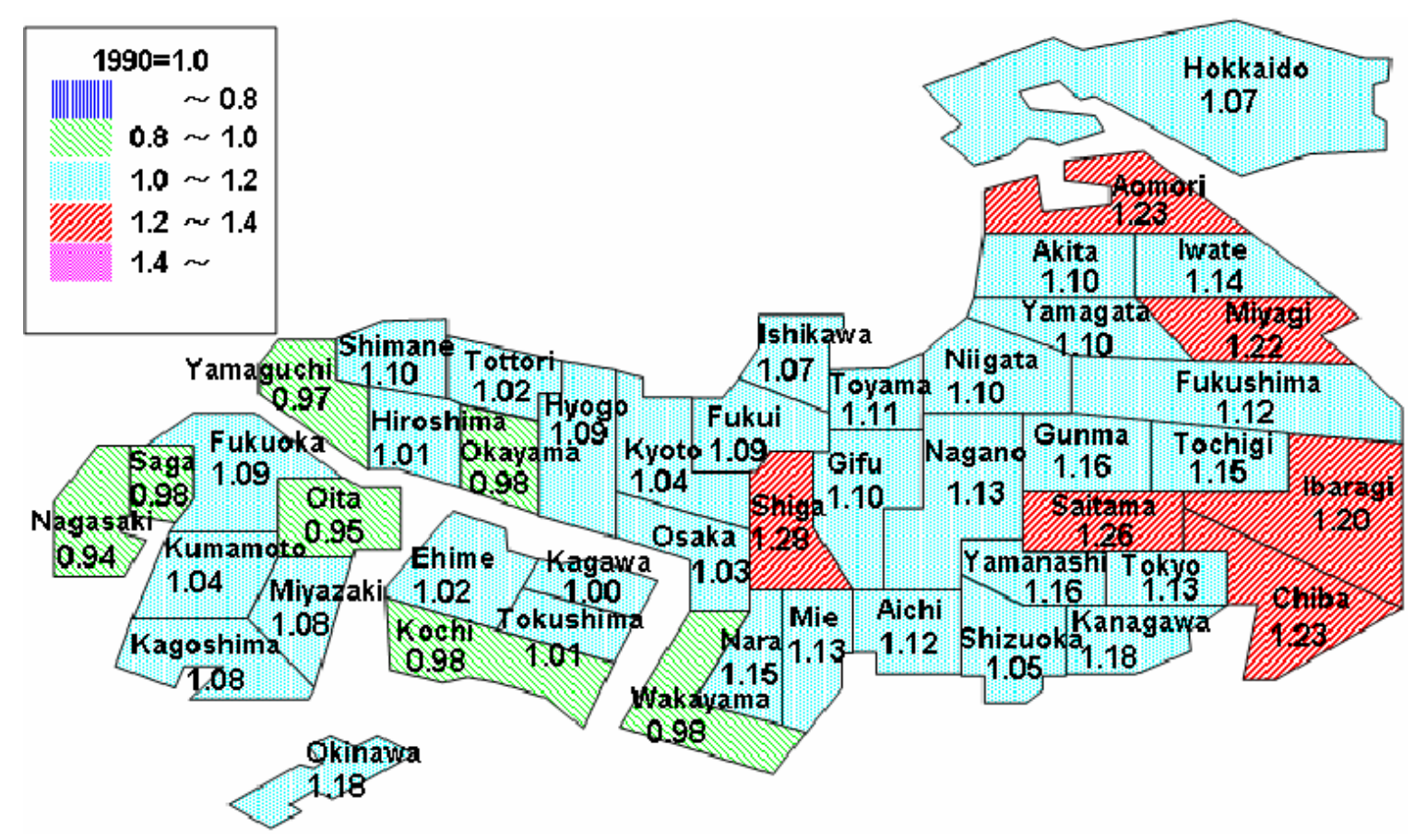

Figure 19. Growth in residential $\mathrm{CO}_{2}$ emissions in 2010, compared to 1990 levels, by Prefecture (with energy-conservation measures)
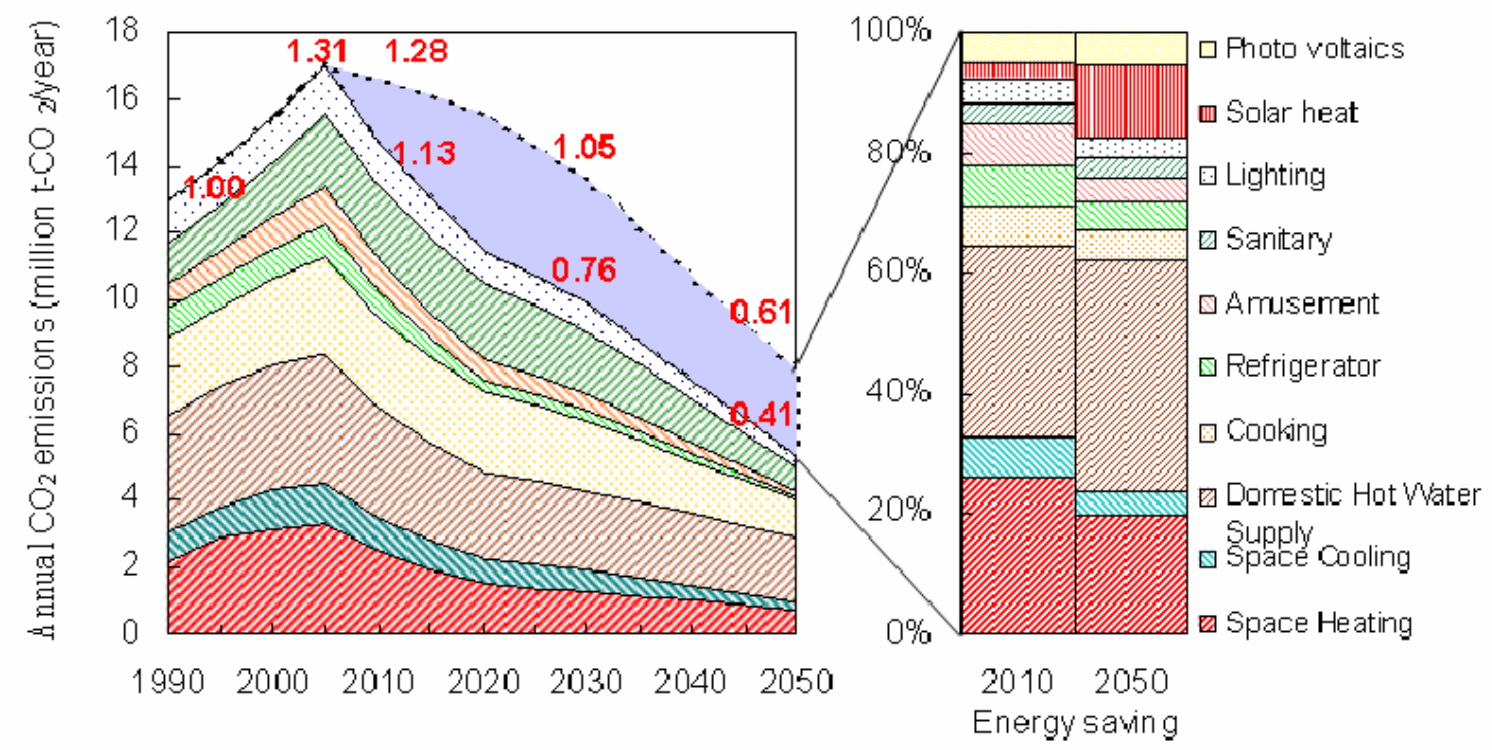

Figure 20. Estimated future residential-sector $\mathrm{CO}_{2}$ emissions in the Tokyo Metropolitan area (with energy-conservation measures) 


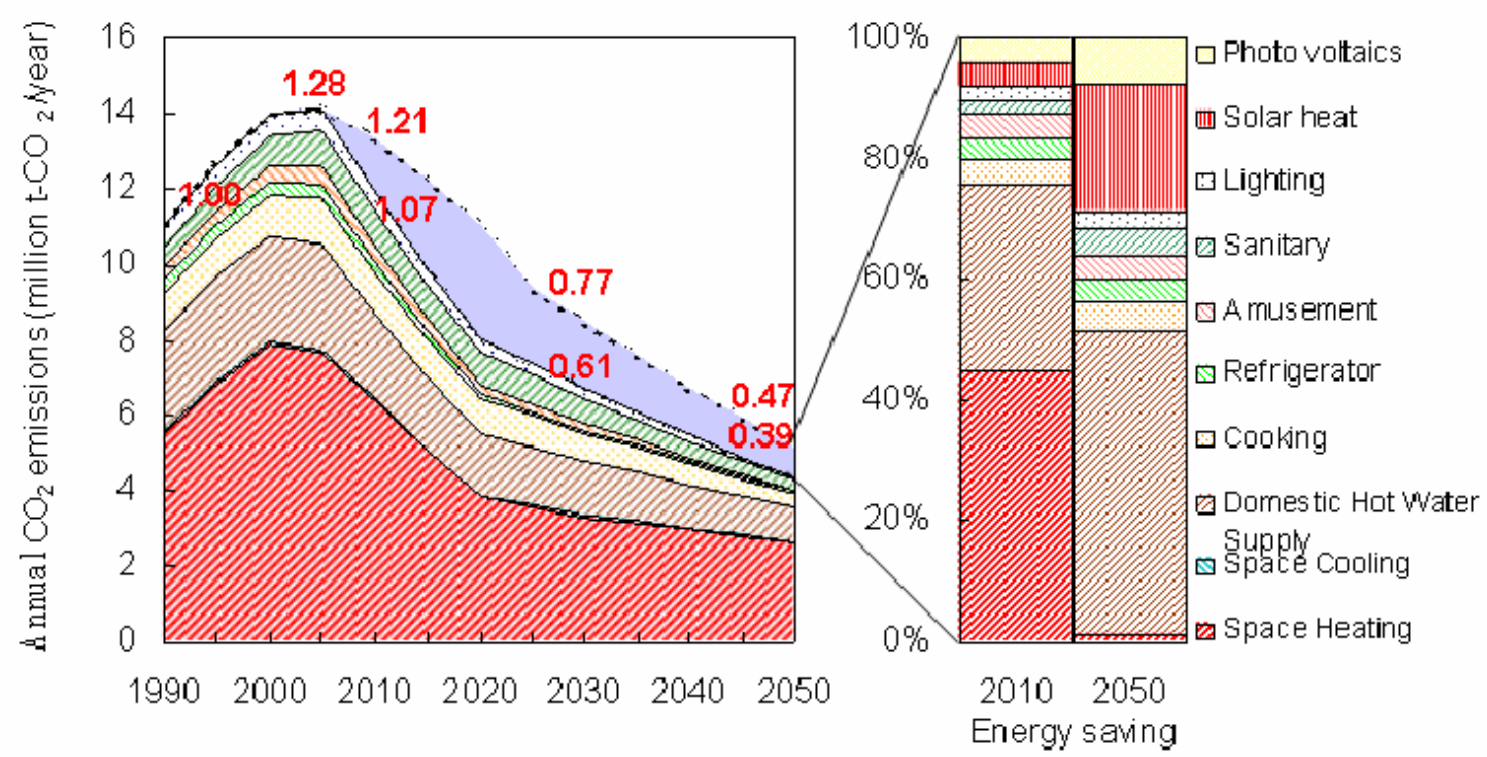

Figure 21. Estimated future residential-sector $\mathrm{CO}_{2}$ emissions in Hokkaido (with energy-conservation measures)

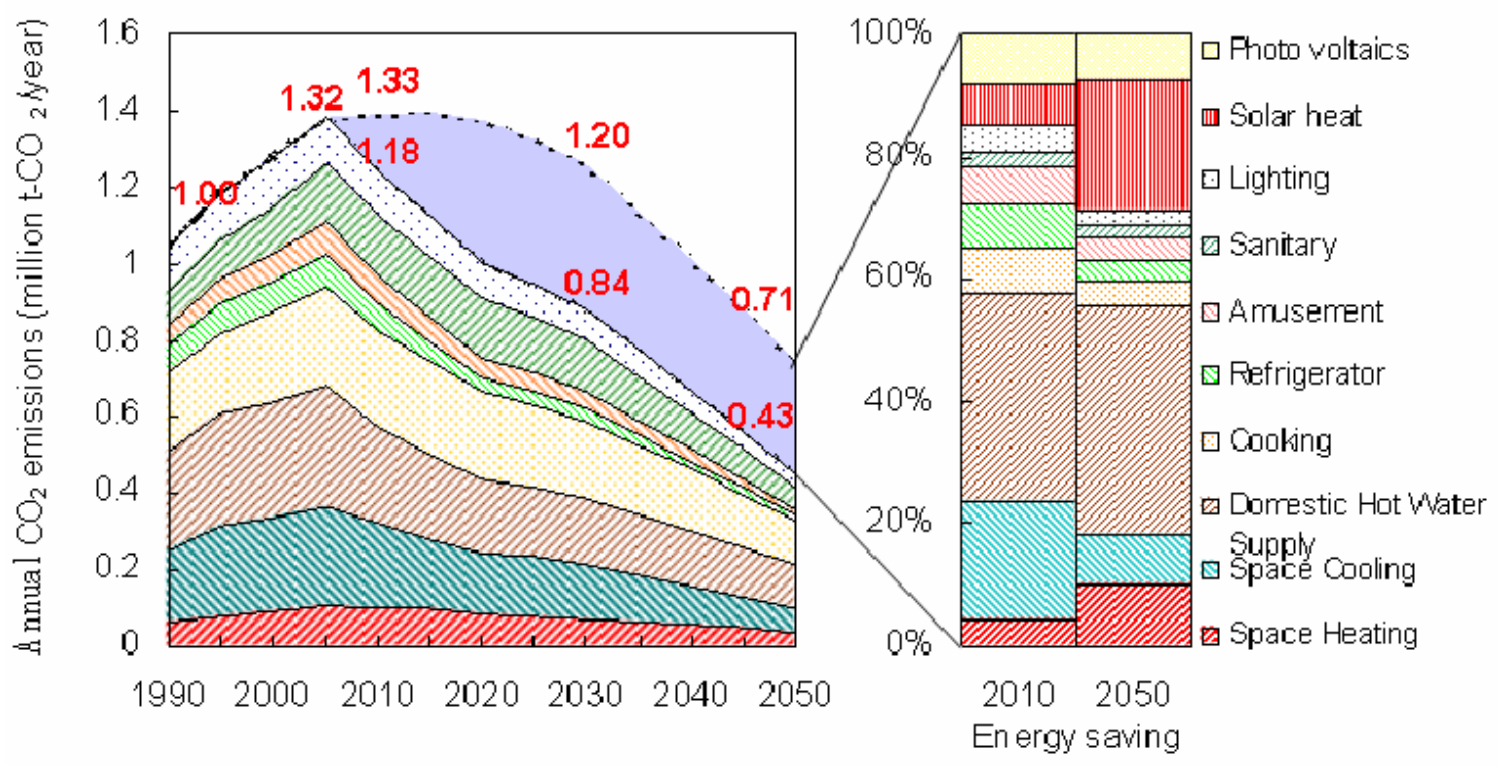

Figure 22. Estimated future residential-sector $\mathrm{CO}_{2}$ emissions in Okinawa Prefecture (with energy-conservation measures)

\section{Current Technologies and Energy-Conservation/GHG Mitigation Strategies for Japanese Buildings}

The subsections below describe technologies currently associated with different end uses in Japanese buildings. When available, information is included on energy-conservation technologies and practices to reduce GHG emissions in the present or in the future. 


\subsection{Taking Regional Climate into Account}

As described in Section 2.2 above, one-fourth of energy consumed by the residential sector in Japan is used for space heating, and the proportion of energy used for space heating is increasing in cold climate regions such as Hokkaido, Tohoku and Hokuriku districts. Therefore, in Japan, energy-conservation activities targeting space heating are important measures concerning building envelopes to reduce emissions associated with global warming, Japan's energy consumption for space cooling is very small at the present, but this consumption is expected to increase. Space cooling energy use in summer contributes to peak electricity load.

Because the amount of energy consumed for space heating and cooling depends heavily on the design of buildings, it is essential to design with energy conservation in mind, emphasizing use of renewable energy sources such as solar and wind that do not generate GHG emissions. Fundamental concepts of building design are discussed below with attention to designing for renewable energy.

Japan is blessed with four distinct seasons and a variety of climate conditions. In winter, in the area of the Sea of Japan, the daylight hours are very short and cold air from the Asian continent brings significant snow accumulation. By contrast, in the Pacific coast area of Japan, and the weather may be sunny and dry in winter. In the Hokkaido area, the climate is very cold; on the Pacific coast in Kyushu and Shikoku, the weather is mild. In summer, much of Japan outside of Hokkaido is very hot and humid with a rainy season.

Traditional Japanese homes feature a room with a large opening facing south and are designed to admit a significant amount of sunshine in winter. On sunny winter days, indoor temperatures are so warm that no heating is required in most regions. However, indoor temperatures drop sharply when the sun goes down and reach outdoor temperature levels by morning if no heating is used. Effective use of solar heat in winter requires strategies, such as insulation/air sealing and thermal storage, to trap solar heat gains. To ensure cool interiors in summer, proper shading with plantings and well-designed openings for ventilation are effective strategies. The transpiration effect of green plants lowers temperatures; plants also serve as a windbreak in winter.

To build homes that use renewable energy sources effectively and in an environmentally friendly manner are, designers must consider: 1) insulation/air sealing, 2) daylighting and daylighting control, and 3) ventilation. Underground thermal storage, utilization of atmospheric radiation, and evaporative cooling can be considered. Because a large amount of indoor heat is generated in office buildings, as described earlier, various passive techniques can decrease air-conditioning load in these buildings, e.g., including using a chimney effect for ventilation; and using light shelves, louvers, and other shading strategies such as cool tubes, rooftop planting, etc. For active renewable energy use, many buildings employ solar thermal water heaters or PV power generation. Solar thermal collectors are not widely used in Japan, the total energy consumption for these types of systems is currently less than 1 percent. 


\subsection{Technologies for Residential Buildings in Japan}

The subsections below describe specific technologies and practices that are commonly employed in residential buildings in Japan, with observations about energy-conservation or GHG-emissions-reduction issues where relevant.

\subsubsection{Walls and Windows}

There is a saying in a 700-year-old classical Japanese essay Tsurezuregusa (Yoshida, 1331); "It is important to make it a principle to consider the summer season as the main factor in building a house.“ For residential buildings in Japan, this precept has been followed; greater emphasis has been placed on the measures to address hot and humid seasons than on measures to address the cold. Large canopies to block solar radiation, large openings for cross-ventilation, and high floor levels to guard against moisture have long been characteristics of traditional Japanese houses. Conversely, thermal insulation and air tightness, which would reduce the impact of cold weather, have largely been neglected. Since the first oil crisis of 1973, these winterproofing measures have gotten attention as means of reducing energy consumed by heating. Law Concerning the Rational Use of Energy (a.k.a. the "Energy Conservation Law”, 1979) prescribes insulation/air tightness standards for different regions and house types. The Energy Conservation Law was amended in 1992 and 1999 to tighten these standards, and both technologies have been improved so that they are now comparable to practices in Europe and the U.S.

Japanese houses are traditionally constructed of wood; half of all new houses today are wood (post and beam construction). Prefabricated houses account for 20 or 30 percent of all residential buildings in Japan. Construction methods include RC (Reinforced Concrete) system, S (Steel) system, and wooden system. Insulation/air tightness technologies have been employed in all of these construction methods. To allow for both thermal insulation and air tightness in winter and cross ventilation in other seasons, large windows with significant insulation properties are installed, which can be opened and closed as circumstances demand. Double glazing has become more common in recent years (installed in more than 80 percent of all newly built detached houses in 2004). At the same time, other types of glazing are also being used, including low-emissivity (low-E), vacuum sealing, and combinations. With regard to solar shading performance, the prevalence of rainfall and strong winds (including typhoons) in Japan means that outdoor shading and awnings are not very popular. Instead, large eaves/canopies or solar shading glass are generally used. The solar shading advantages of bamboo blinds (Sudare) and the natural light utilization effect of paper sliding doors (Shoji) have recently been re-evaluated.

\subsubsection{Space Heating}

A number of heating technologies are used in Japan: passive solar, total heat exchanger, traditional Japanese Kotatsu, heat pump, gas/kerosene fan, and biomass-fueled stove. 


\section{Passive Solar}

Currently, not many houses in Japan have passive solar systems, but efforts are being made to increase the penetration of passive solar technology. Passive solar houses that employ daylighting and solar thermal collectors and houses with PV systems have been certified as "solar houses" by IBEC (Institute for Building Environment and Energy Conservation). A total of 25,000 OM Solar Houses, which use the heated air that inhaled at edge of eaves and moved into ridge to collect incident solar heat on roof for hot water supply and heating, are constructed for the past 15 years in whole the country.

\section{Kotatsu (Traditional Japanese Heating Units)}

In traditional Japanese homes, fire pits or charcoal braziers were generally used to warm the body. The “Kotatsu,” a direct body-warming apparatus unique to Japan, was common in Japanese houses. A kotatsu is a low table covered with a futon (a heavy quilted cover) placed on a tatami. The inside of the futon is warmed by an electric heater attached to the bottom surface of the table. People sitting on the tatami put their feet under the table for direct body warming. People can live comfortably in a room using a kotatsu even if the room air temperature is low; in many cases, rooms equipped with a kotatsu are heated only to a low temperature, or no heating is used at all. According to a detailed survey on residential energy consumption, the annual energy consumption of a house that uses a kotatsu as the main heating apparatus is approximately 40 percent less than the average consumption of all the houses studied (Sugihara et al. 2003). At present, Japanese residence has been changing from low energy direct body-warming system such as kotatsu to space heating system. This is one reason that the energy consumption in Japanese residential sector has been increasing.

\section{Heat-Pumps}

Heat-pump air conditioners are widely used as one of the heating equipment in Japan outside the coldest areas. Of the total shipment of domestic air conditioners in 2005, 7,400,000 units (99 percent) were heat-pump units. As shown in Figure 24, heating COP of the most of present residential room air conditioners exceeds 5.0, which has highest energy efficiency among residential heating equipments.

\section{Gas Fan Heaters}

The market share of gas and kerosene fan heaters in Japan is increasing compared with the market shares of other heating appliances, such as stoves. Recent-model fan heaters have a combustion rate that is closely controlled by adjustments in the room thermostat. Some models automatically lower the temperature by 1 degree $\mathrm{C}$ every 30 minutes, and a maximum of 2 degree $\mathrm{C}$ when the set temperature level is exceeded. These features have improved the energy-saving performance of the gas fan heater.

\section{Biomass Stoves}

The biomass pellet stove, which is not widely used in Japan, is expected to be one of the $\mathrm{CO}_{2}$ mitigation technologies in space heating. Burning biomass can be a part of the carbon cycle.(i.e., this fuel is carbon neutral). Therefore biomass stoves using pellet fuel do not add significantly to global warming gases. Some pellet and wood chip boilers are operated in the Tohoku (northeast) region of Japan where forest 
resources are abundant and the climate is comparatively cool. There are 14 pellet manufacturing facilities in Japan, and supply currently exceeds demand. There was $\mathrm{CO}_{2}$ emissions reduction of 9 to 27 percent in homes where a pellet stove for room heating was installed. As the quantity of pellets used substitute for fossil fuels can be counted as a non $\mathrm{CO}_{2}$ emitter compared with conventional kerosene stove. (Miura, 2005)

\subsubsection{Cooling}

Air conditioners widely used in Japan differ from the central air conditioning that is common in the U.S. The most common Japanese air conditioner in is the "mini-split" type, consisting of an outdoor and an indoor unit connected with refrigerant/drain piping. These devices are designed only to provide cooling, dehumidification, and heating; ventilation is provided separately from the air conditioner. One outdoor mini-split unit is installed for each indoor unit in each room, and efficiency in partial load is high because most apparatuses use variable speed control for the compressor. Almost all the air conditioners are the heat-pump type, as mentioned in Section 4.2.2 above.

Figure 23 shows the number of air conditioners sold in Japan during the past 20 years. The Japanese Institute of Energy Economics estimates that there are an average of about 2.5 room air conditioners per household in Japan. It is believed that main living areas, such as living rooms and bedrooms, are usually equipped with air conditioners. The energy-efficiency standard for air conditioners is the so-called Top Runner Standard to be described as section 5.2.3, and the mean value of the cooling-rated COP (load factor 100 percent, ambient temperature 35 degree C, room air temperature 27 degree C) and heating-rated COP (load factor 100 percent, ambient temperature 7 degree C, room air temperature 20 degree C) must be 5.27 for the models with cooling capacity of less than $2.5 \mathrm{~kW} ; 4.90$ for those with capacity of 2.5 - $3.2 \mathrm{~kW}$; and 3.65 for those with capacity of 3.2 - $4.0 \mathrm{~kW}$. Figure 24 shows the distribution of cooling and heating COPs in actual air conditioners of cooling capacity $2.8 \mathrm{~kW}$ on the Japanese market as of October 2005. As the figure shows, all air conditioners have satisfied the standard, and some of them exceed the cooling and heating COP value of 6.0. 


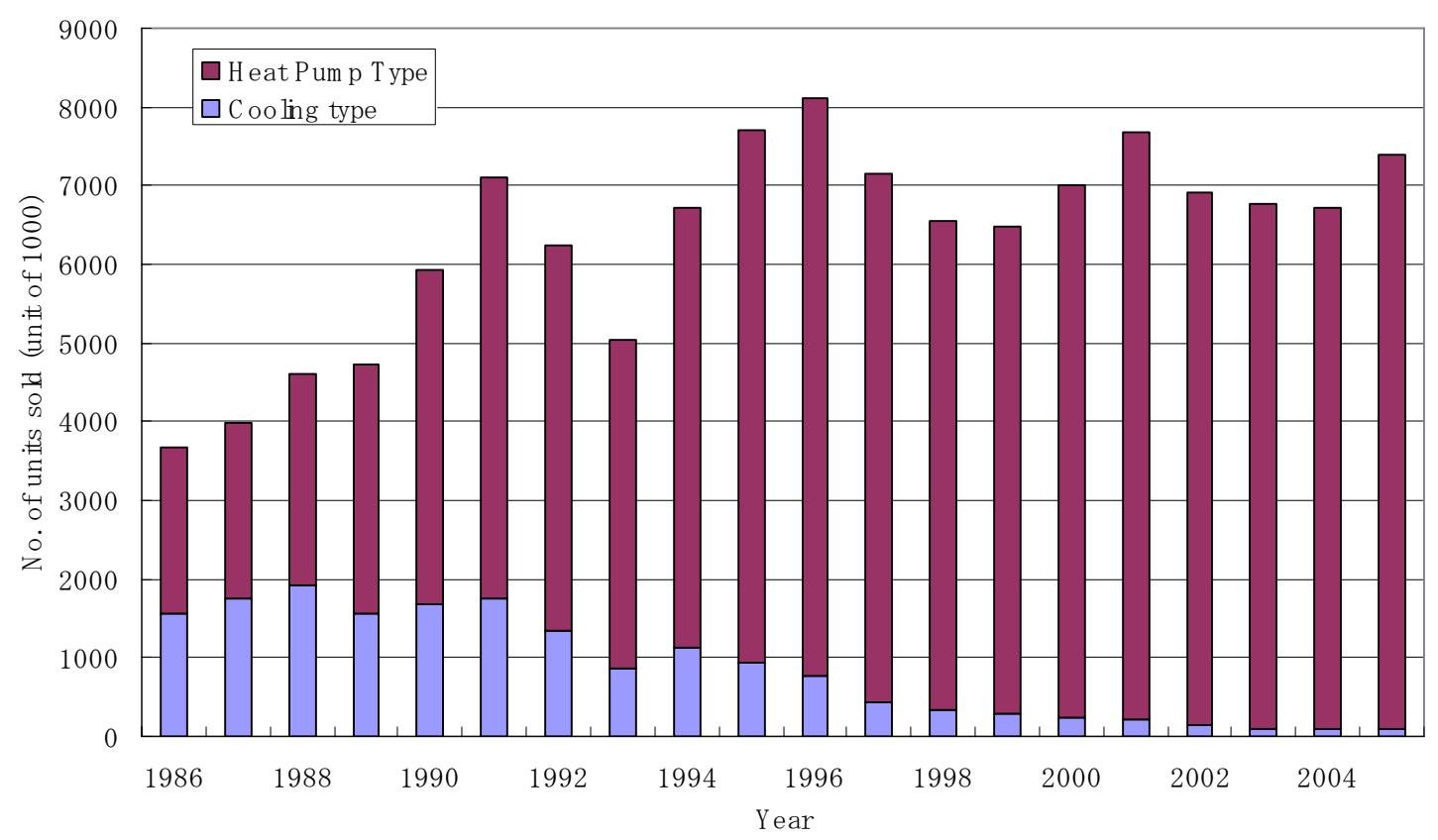

Figure 23. Change in number of domestic room air conditioners sold in Japan (The Japan Refrigeration and Air Conditioning Industry Association, 2006)

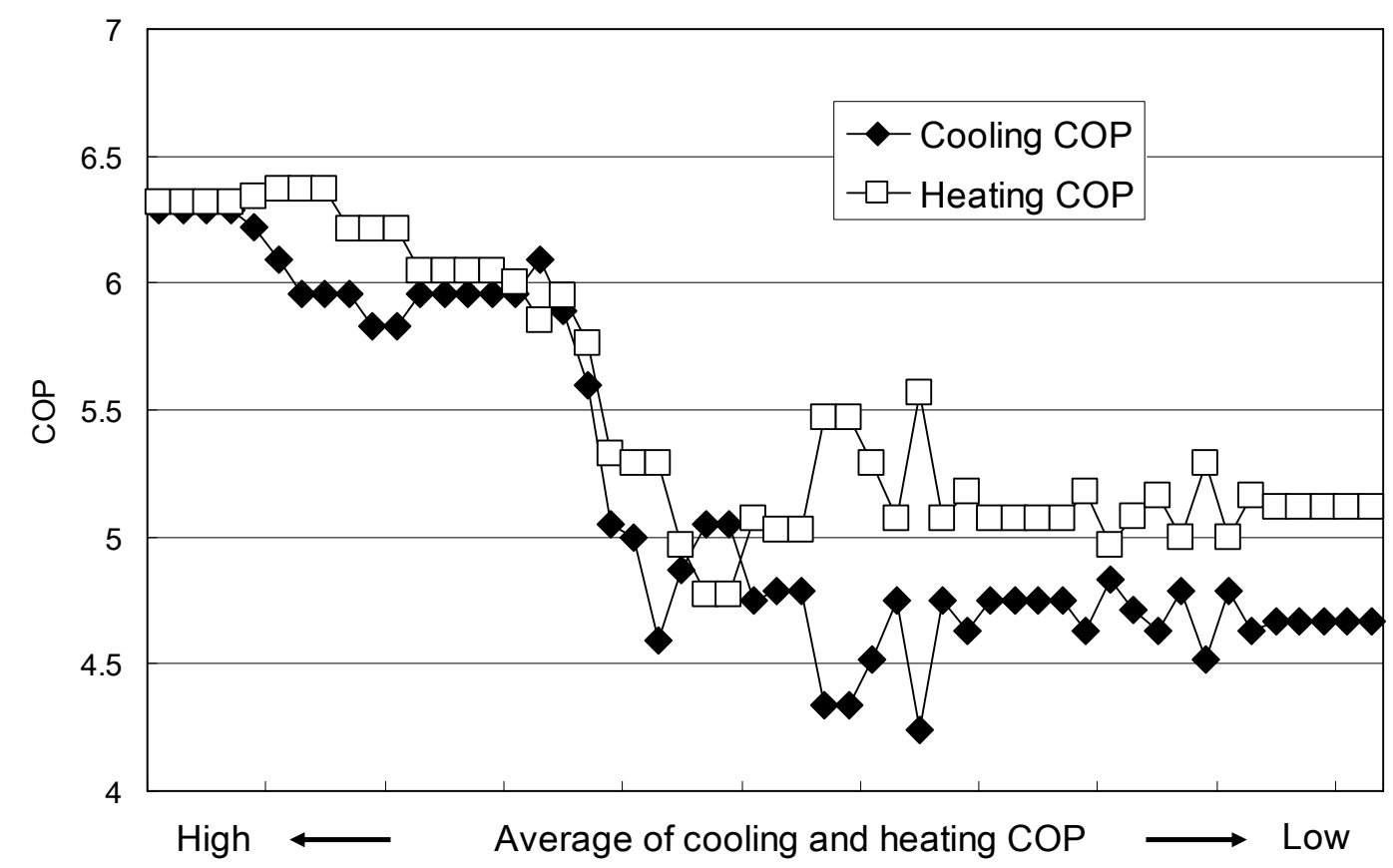

The residential room air conditioners sold in Japan in 2006 were sorted in descending order of average COP

Figure 24. COPs of residential room air conditioners (The Energy Conservation Center, Japan, 2006) 


\subsubsection{Hot Water}

Several different devices related to hot water usage are found in Japanese homes.

Water-saving Showerheads

Water-saving showerheads can save about 15 percent relative to water consumption of non-water-saving devices, without impairing showering comfort. The water-saving showerhead has a simple ON/OFF button valve. The shower head button in turned off while hair is being soaped and only turned on to rinse. Consumption of water and gas for hot water heating are each reduced by 32 percent per month relative to consumption with a standard showerhead, and $\mathrm{CO}_{2}$ emissions are also reduced by 32 percent to $25.8 \mathrm{~kg}$, from $37.9 \mathrm{~kg}$. In the Kyoto Protocol Target Achievement Plan, reduction of fuel consumption by means of water-saving showerheads on a nationwide basis will be about 11,000 terajoules (TJ) in 2010. This is estimated to be equivalent to an emissions reduction of about 590 kt $\mathrm{CO}_{2}$ (TOTO, 2004).

\section{Solar Water Heaters}

In 1990, 8.1 percent of energy for residential hot-water supply in Japan was provided by solar water heaters, according to the Institute of Energy Economics, and in 1999, 11.5 percent of homes used solar water heaters. In recent years solar water heater usage has decreased by half because of the difficulty of maintenance and the spread of PV.

\section{$\mathrm{CO}_{2}$-refrigerant Heat-Pump Water Heater}

Hot water accounts for about 34 percent of residential-sector energy consumption in Japan. In 2001, a residential $\mathrm{CO}_{2}$-refrigerant heat-pump water heater was put on the market. The $\mathrm{CO}_{2}$-refrigerant heat-pump water heater has a COP of approximately 4.9. The Japanese government set a diffusion target of 5.2 million by 2010, making the $\mathrm{CO}_{2}$-refrigerant heat-pump water heater the primary global-warming protection measure in the residential hot water market. In 2002, the government instituted a subsidy program that pays $¥ 50,000$ to $¥ 80,000$ (approximate $\$ 400$ to $\$ 700$ ) for the installation of the $\mathrm{CO}_{2}$-refrigerant heat-pump water heater unit. In addition, depending on the end user's contract and region, his/her electric utility bill may be lowered by as much as 30 percent compared with the bill that would apply for a conventional electric water heater (Yatabe, 2006).

\section{Condensing Water Heaters}

A condensing boiler is a kind of hydronic boiler which achieves enhanced efficiency by incorporating an additional heat exchanger. This uses the heat in the exhaust gases from the boiler to preheat the water as it enters the boiler, and so recaptures energy that would otherwise be lost. The condensing boiler has a second stainless steel heat exchanger (highly resistant to corrosion) placed downstream from the primary heat exchanger. This design improves hot-water supply efficiency by 95 percent (from 80.7 percent to 95.2 percent) over conventional water heaters. Comparing the efficiency of the condensing boiler and the conventional water heater, (in terms of hot-water supply and heating load in a general household model), 
we find that the condensing boiler saves 13 percent more energy and reduces $\mathrm{CO}_{2}$ emissions by 13 percent.

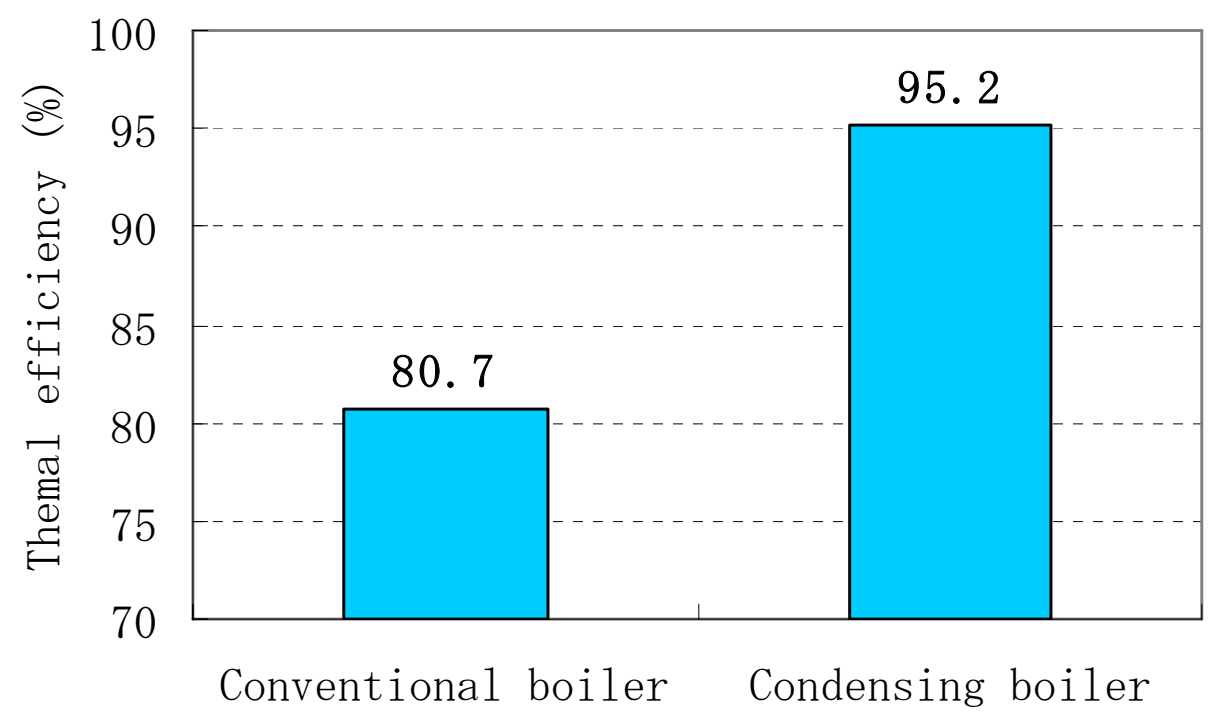

Figure 25. Thermal efficiency of conventional and condensing boiler (Japan Industrial Association of Gas and Kerosene Appliances, 2006)

\subsubsection{Residential Power Generation}

In the following section, we will highlight the energy efficient generation method for residential use.

\section{Photovoltaic (PV) Power}

At the end of March 2004, PV power accounted for approximately 860 MW in Japan. A PV promotional program carried out by the New Energy Foundation Japan is responsible for approximately 595 MW part of the 860 MW quoted above. The Foundation provides a 20,000 kW (appx.\$170) subsidy for PV systems smaller than $10 \mathrm{~kW}$. An average household consumes approximately 3,600 kWh, which can be supplied by a 3- to 4- kW rated-output PV system. PV systems generate maximum output during sunny days. PV system owners have the ability to sell power back to utilities, which helps reduce power consumption during the hot summer when the demand for power is greatest. A PV system costs approximately $66 \mathrm{kWh}$ (55cents/kWh) for a residential system and $73 \mathrm{kWh}(60 \mathrm{cents} / \mathrm{kWh})$ for a non-residential system. Figure 26 shows numbers of residential PV systems installed in Japan (New Energy Foundation, 2006). 


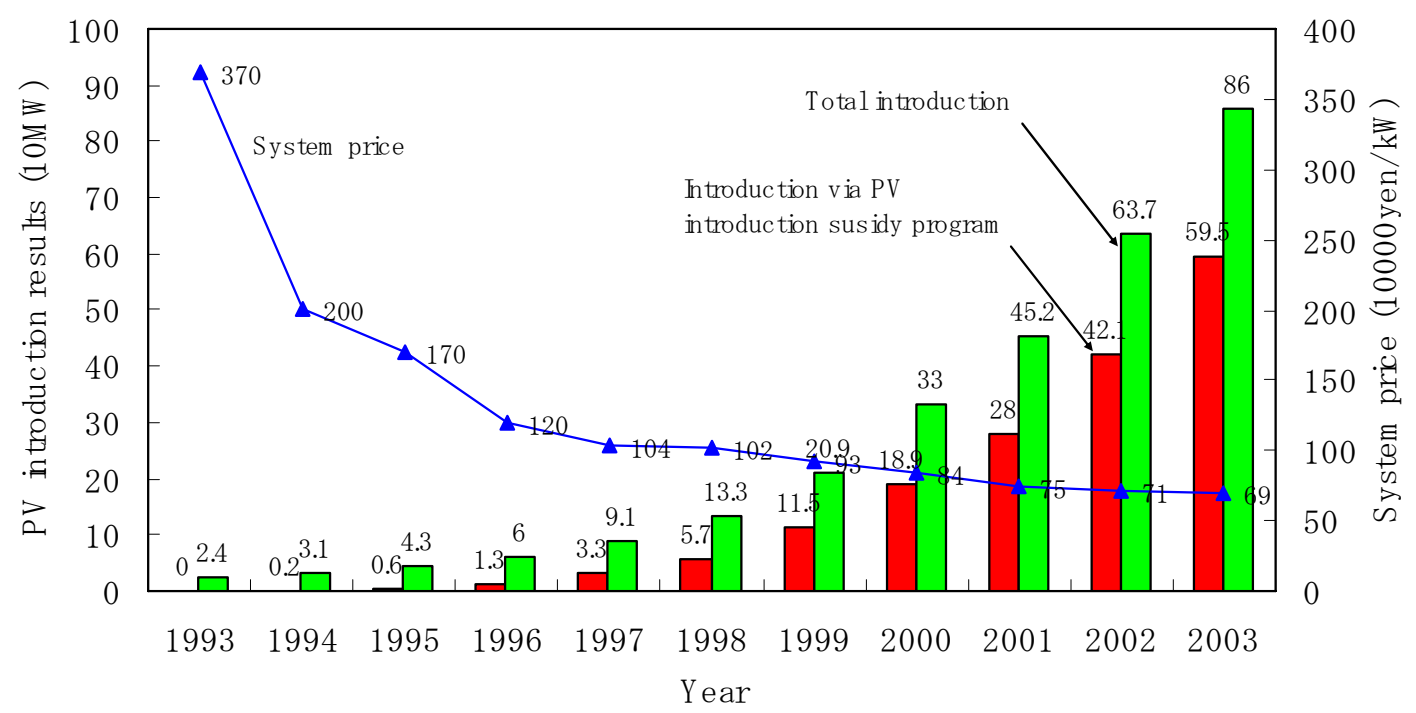

Figure 26. Numbers of residential PV systems installed in Japan (New Energy Foundation, 2006)

\section{Cogeneration Systems}

Cogeneration utilizes exhaust heat from systems such as air conditioning and water heating. Cogeneration reduces the user's overall operational costs while saving energy and resources, thus making a significant contribution to global environmental protection. Until recently, cogeneration was only used in large-scale facilities such as factories and office buildings; however, a small-scale (1-kW) residential gas engine cogeneration system was introduced to the market in 2003. The residential gas engine cogeneration system uses a gas engine as an electric generator and exhaust heat from power generation is used for water heating. The generating efficiency is 20.3 percent (Higher heating value (HHV) bases), exhaust heat recovery efficiency is 56.9 percent (HHV), and total efficiency is 77.2 percent (HHV). This system can reduce primary energy consumption by about 22 percent and $\mathrm{CO}_{2}$ emissions by about 32 percent compared to values for a comparable household without a cogeneration system (Osaka Gas, 2007).

Test marketing began in 2005 for a fuel-cell cogeneration system for home. A Polymer Electrolyte Fuel Cell (PEFC) is used as the electric generator in this system. As with the gas engine cogeneration system, exhaust heat from power generation is used for water heating. The generating efficiency is 33 percent (HHV), exhaust heat recovery efficiency is 45 percent (HHV), and total efficiency is 78 percent (HHV). This system can reduce primary energy consumption by about 26 percent and $\mathrm{CO}_{2}$ emissions by about 40 percent relative to the values for a comparable household without the cogeneration system.

A solid oxide fuel cell (SOFC) cogeneration system is currently being developed for residential use. This system uses solid oxide fuel cells for electric generators. Experimental units have been installed in apartment buildings, and the system is planned to reach the market in 2008. The target generating efficiency is 41 percent (HHV), exhaust heat recovery efficiency is 27 percent (HHV), and total efficiency 68 percent (HHV). The Kyoto Protocol Target Achievement Plan calls for installation of 2,200,000 kW in 
stationary fuel cells by 2010, with about 1,200,000 kW in the residential sector (PEFC) and about 1,000,000 kW in the commercial sector (PEFC, SOFC, Molten Carbonate Fuel Cell (MCFC), and Phosphoric Acid Fuel Cell (PAFC)).

\subsubsection{Lighting}

Fluorescent lamps are subject to Japan's Top Runner Standard for lighting. Highly efficient devices that achieve the Top Runner Standard values are labeled with an energy-saving symbol. One of the primary lighting conservation strategies in Japan is to shift from using incandescent bulbs to fluorescent lamps. This switch reduces power consumption by two-thirds, and the investment cost is recovered in approximately nine months. About 16 percent of all residential energy consumption goes to lighting. Currently, fluorescent lighting is being promoted for every room of the home, especially fluorescent lamps installed directly on the ceiling, which contributes to making the room look two-thirds bigger than its actual size (The Energy Conservation Center, Japan, 2005).

\subsubsection{Consumer Appliances}

In Japan, consumer appliances whose energy consumption can be reduced to help reduce GHG emissions include: refrigerators, washing machines, dishwashers, televisions and videocassette recorders, and cooking devices.

\section{Refrigerators}

Japan is pursuing energy conservation and GHG emission reduction in refrigerators by promoting non-CFC refrigerants and high-efficiency refrigerators using a variable speed compressor and a vacuum-heat insulating material. Energy savings of 55.2 percent have been achieved in comparison with the refrigerator shipped in 1998 as an effect of the Top Runner Standard (The Energy Conservation Center, Japan, 2006).

\section{Washing Machines}

High-efficiency washing machines are being developed by using variable speed controls for the motor and for reduction of standby power consumption. Figure 27 shows average water and electricity consumption of typical Japanese washing machines. Standard washing machines in 1995 used $240 \mathrm{Wh}$ per load (The Energy Conservation Center, Japan, 2006). New, high-efficiency washers use 54 Wh per load, a savings of more than 75 percent over the 240 Wh per load documented for standard washers in 1999. New high-efficiency washing machines with 7- kilogram (kg) load capacity consume 52-135 Wh per load. Water savings of more than 35 percent over 1995 levels have been achieved through the adoption of a water-saving tub and a "shower rinse" function that uses less water than traditional rinse cycles. 


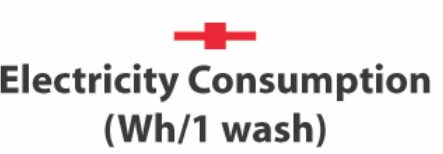

Water Consumption

(Wh/1 wash)

(Wh/1 wash)

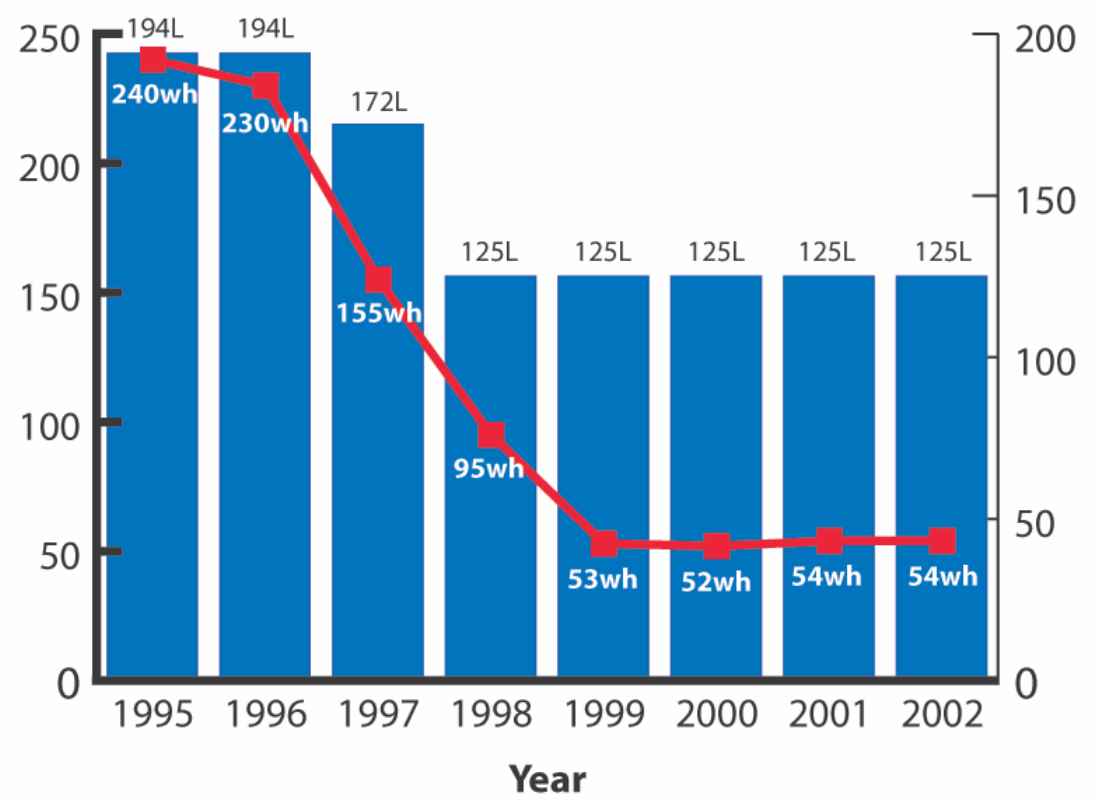

Figure 27. Average water and electricity consumption of typical Japanese washing machines

\section{Dishwashers}

Dishwashers circulate only a small amount of hot water that is stored in a rotary drum. Dishwashers use about 12 liters of water to clean a load of dishes that would take about 108 liters water when washed by hand; in other words, dishwashers use about one-ninth the amount of water consumed by hand washing. This reduced water consumption also translates to less hot-water heating-energy consumed, which, in turn, reduces $\mathrm{CO}_{2}$ emissions by approximately one-half, from $171.57 \mathrm{~kg}$ for hot water for hand washing to 87.4 kg for dishwasher use. (The Energy Conservation Center, Japan, 2006)

\section{Televisions and Videocassette Recorders (VCRs)}

Based on the requirement of Japanese Top Runner Standard, energy consumption of today's TV sets are 25.7 percent below the models shipped in 1997. Sales of large, liquid-crystal/plasma televisions are growing rapidly, so new Top-Runner Standard including these models was set in 2005. Regarding liquid crystal TV sets and plasma TV sets, approximately 15.3\% improvement is expected in 2008 compared to that for Fiscal 2004. Energy consumption of VCRs is reduced by 73.6 percent from the 1997 model based on the Top Runner Standard. (The Energy Conservation Center, Japan, 2006)

\section{IH Cooking Heater (Induction Heating Stovetop)}

The thermal efficiency of conventional electrical cooking heaters, such as the sheathed heater is approximately 70 percent. The efficiency of the IH cooking heater has improved up to approximately 90 percent because it generates heat only on the bases of pots and pans through magnetic lines of energy. 
Moreover, its superior characteristics allow users to cook in a cool environment and make the air conditioner work better in summer since there is no burning part like burners Also, this device starts up faster and more efficiently than other electrical cooking heaters. Its benefits are due to the smaller amount of radiant heat that it generates.

Domestic sales of IH cooking heaters have been solid. A total of 290,000 units were sold in the first half of FY2004, and the IH cooking heater has maintained a double- digit sales percentage increase during recent years. This growth in sales results from:

- Social change, including the rapid aging of the population and a focus on safety;

- The development of "all-electric" housing;

- New types of IH cooking heaters that allow the use of aluminum pans have come onto the market; and

- Easy care and maintenance; cleaning requires only wiping the top plate.

\section{Gas Cookstove}

The gas cookstove is one of the devices specified in Japan's Law Concerning Rational Use of Energy (a.k.a. Energy Conservation Law). Gas cookstove efficiency was approximately 40 percent in the 1990s. Energy efficiency is now 56.3 percent, which meets the energy-saving standard specified for gas cookstoves. Increased efficiency has been achieved by reducing the diameter of inner the flame burner and lowering the flame aperture angle.

\subsection{Energy Savings from Lifestyle Changes in Japan}

Energy-conservation strategies involve not only technical measures, such as adding thermal insulation to buildings and improving the efficiency of equipment, but also non-technical, lifestyle changes such as moderating temperature settings for space heating and cooling and reducing the duration and frequency of use of appliances. The effectiveness of non-technical measures depends heavily on actual conditions and usage in the home, which may be totally different in different countries. Although it is difficult to predict the energy savings from daily-life behavioral/operational changes, it is possible to quantify savings through case studies, analysis, and simulation. This section presents case studies of energy savings from lifestyle changes in residential buildings in Japan.

Energy savings resulting from lifestyle changes adopted by participants using the 74-item "Save-energy Menu” were investigated by Yuasa et al., 2005, and Yoshino et al., 2005. The Save-energy Menu included moderating temperature settings for space heating and cooling and reducing use of home appliances. Residents followed the menu for one week each in each season. The energy savings were determined by comparing the energy consumption for that week with the consumption for the previous week. The test residences were six single apartments in Tokyo and 6 detached houses and two apartments in cities in Tohoku District. Energy consumption was measured at 15-minute intervals in each home. The study was conducted in 2003-2004. In case of single apartments in Tokyo, energy consumption was found to decrease by up to 47 percent, with an average decrease of 21.5 percent in summer, 17.3 percent in autumn 
and 26.5 percent in winter. In the case of houses in Tohoku District, energy consumption was found to decrease by up to $17.4 \%$, with an average decrease of 5.5 percent in spring and 5.1 percent in summer. But in one house, energy consumption increased because of increased air-conditioner use as a result of hot weather during the test period. In winter, due to decrease of the outdoor temperature in the week in which the occupants followed the menu, the energy consumption was increased by $9.8 \%$ in average.

In another study, Chiba, Yoshino et al., 2004, the actual energy consumption of each household appliance in a detached house was measured throughout a year, and energy savings were simulated for this house. Space heating and cooling loads were estimated by dynamic simulation, and household energy consumption was calculated hourly throughout the year. The researchers then confirmed that the calculated estimates for energy consumption were nearly equal to the actual measured values for the whole year. Next, changes in daily-life behavioral/operational parameters (e.g., temperature settings for space heating and cooling, hot water supply temperature, time and frequency of household appliance use) were defined for three different cases, as shown in Table 5: the "energy-saving," "baseline," and "energy-wasting daily-life" cases. The calculated results are shown in Figure 28 (including two additional cases that varied thermal insulation levels for the baseline case; in one, the thermal insulation thickness was doubled, and in the other, it was halved.) (Chiba et al., 2004).

The results indicate that energy consumption in the energy-saving case was reduced by 38 percent, relative to the baseline case and that lifestyle changes were more effective than increasing the thickness of thermal insulation as a means to save energy.

The effects of adopting energy-saving behaviors have been clearly shown by the above investigation and simulation. The question remains: how to provide incentives for the populace to adopt these lifestyle changes. 
Table 5. Description of energy-saving behavioral/operational lifestyle changes (Chiba et al., 2004)

\begin{tabular}{|c|c|c|c|c|c|c|}
\hline \multicolumn{2}{|c|}{ Item } & \multirow{2}{*}{\multicolumn{2}{|c|}{$\begin{array}{c}\text { Condition } \\
\text { Operation time }\end{array}$}} & Energy-saving & Baseline & Energy-wasting daily-life \\
\hline \multirow{5}{*}{ 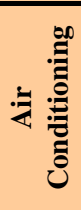 } & \multirow[b]{2}{*}{ Heating } & & & morning and night & at occupaucy & all day \\
\hline & & \multicolumn{2}{|c|}{ Temperarure } & $2^{\circ} \mathrm{C}$ down & $\begin{array}{l}\text { living room } 20^{\circ} \mathrm{C} \\
\text { Eur. room A } 19^{\circ} \mathrm{C}\end{array}$ & $2^{\circ} \mathrm{C}$ up \\
\hline & \multirow{3}{*}{ Cooling } & \multicolumn{2}{|c|}{ Operation time } & 12:00 16:00 & at occupaucy & all day \\
\hline & & \multirow{2}{*}{\multicolumn{2}{|c|}{$\begin{array}{c}\text { Temperature } \\
\text { Window }\end{array}$}} & $1^{\circ} \mathrm{C}$ up & living room $27^{\circ} \mathrm{C}$ & $1^{\circ} \mathrm{C}$ down \\
\hline & & & & open at no AC & open at no AC & closed \\
\hline \multirow{5}{*}{\multicolumn{2}{|c|}{ 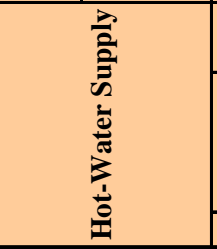 }} & \multicolumn{2}{|c|}{ Frequency of bathing } & $\begin{array}{l}\text { bath and shower } \\
\text { every other day }\end{array}$ & bath everyday & bath everyday \\
\hline & & \multirow{3}{*}{ 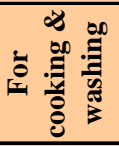 } & $\begin{array}{c}\text { Hot or cold } \\
\text { (Win./Mid./ Sum.) }\end{array}$ & $\begin{array}{c}\text { hot-water/ } \\
\text { water/water }\end{array}$ & hot/hot/hot & hot/hot/hot \\
\hline & & & Temp. & $1^{\circ} \mathrm{C}$ down & present & $1^{\circ} \mathrm{C}$ up \\
\hline & & & Amount & 1L/time down & present & 1L/time up \\
\hline & & \multicolumn{2}{|c|}{ Hot water volume in bathing } & $350 \mathrm{~L}$ & $400 \mathrm{~L}$ & $450 \mathrm{~L}$ \\
\hline \multicolumn{2}{|c|}{ Lighting } & \multicolumn{2}{|c|}{ Using duration time } & $\begin{array}{l}1 \text { h. short(morning } \\
\text { and night) }\end{array}$ & present & $\begin{array}{l}1 \mathrm{~h} \text {. long(morning } \\
\text { and night) }\end{array}$ \\
\hline \multirow{6}{*}{ 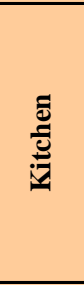 } & \multirow{4}{*}{ 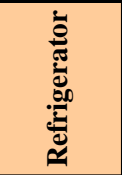 } & \multicolumn{2}{|c|}{ Temperatrue setting } & middle & $\begin{array}{l}\text { Dec. } \sim \text { Aug. strong } \\
\text { Sep. } \sim \text { Nov. middle }\end{array}$ & strong \\
\hline & & \multicolumn{2}{|c|}{ Inside stuff } & normal & normal & congested \\
\hline & & \multicolumn{2}{|c|}{ Space from wall } & $2 \mathrm{~cm}$ & $2 \mathrm{~cm}$ & no space \\
\hline & & \multicolumn{2}{|c|}{ Door leakage } & no leakage & no leakage & more leakage \\
\hline & \multirow{2}{*}{$\begin{array}{c}\text { Electric } \\
\text { water pot }\end{array}$} & \multicolumn{2}{|c|}{ Times of boiling } & 2 times & 1 time & 1 time \\
\hline & & \multicolumn{2}{|c|}{ Keeping warm } & no & $\begin{array}{c}\text { keeping } 98^{\circ} \mathrm{C} \text {, } \\
\text { pull when sleeping }\end{array}$ & keeping $98^{\circ} \mathrm{C}$ all day \\
\hline \multirow{7}{*}{ 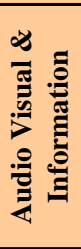 } & \multirow{2}{*}{ TV set } & \multicolumn{2}{|c|}{ Usage duration time } & \begin{tabular}{|c|}
$1 \mathrm{~h}$. short \\
\end{tabular} & present & $1 \mathrm{~h}$. long \\
\hline & & \multicolumn{2}{|c|}{ At no use } & disconnected to outlet & remote-OFF & remote-OFF \\
\hline & \multirow{2}{*}{ Stereo } & \multicolumn{2}{|c|}{ Usage duration time } & \begin{tabular}{|c|} 
present \\
\end{tabular} & present & $1 \mathrm{~h}$. long \\
\hline & & & At no use & disconnected to outlet & \begin{tabular}{|l|} 
always connected \\
\end{tabular} & always connected \\
\hline & \multirow{2}{*}{ PC } & \multicolumn{2}{|c|}{ Usage duration time } & \begin{tabular}{|c|}
1 h. short \\
\end{tabular} & \begin{tabular}{|c|} 
present \\
\end{tabular} & $1 \mathrm{~h}$. long \\
\hline & & \multicolumn{2}{|c|}{ At no use } & disconnected to outlet & always connected & always connected \\
\hline & Video & & It no use & disconnected to outlet & always connected & always connected \\
\hline & Washing & & requency & 1 time every 2 days & 1 time every 2 days & everyday \\
\hline ప్ర & Washing & Remaint & d water of a bath & use for washing & no use & no use \\
\hline 苋 & Vacuum & Ope & ration mode & Depend on situation & always high mode & always high mode \\
\hline
\end{tabular}




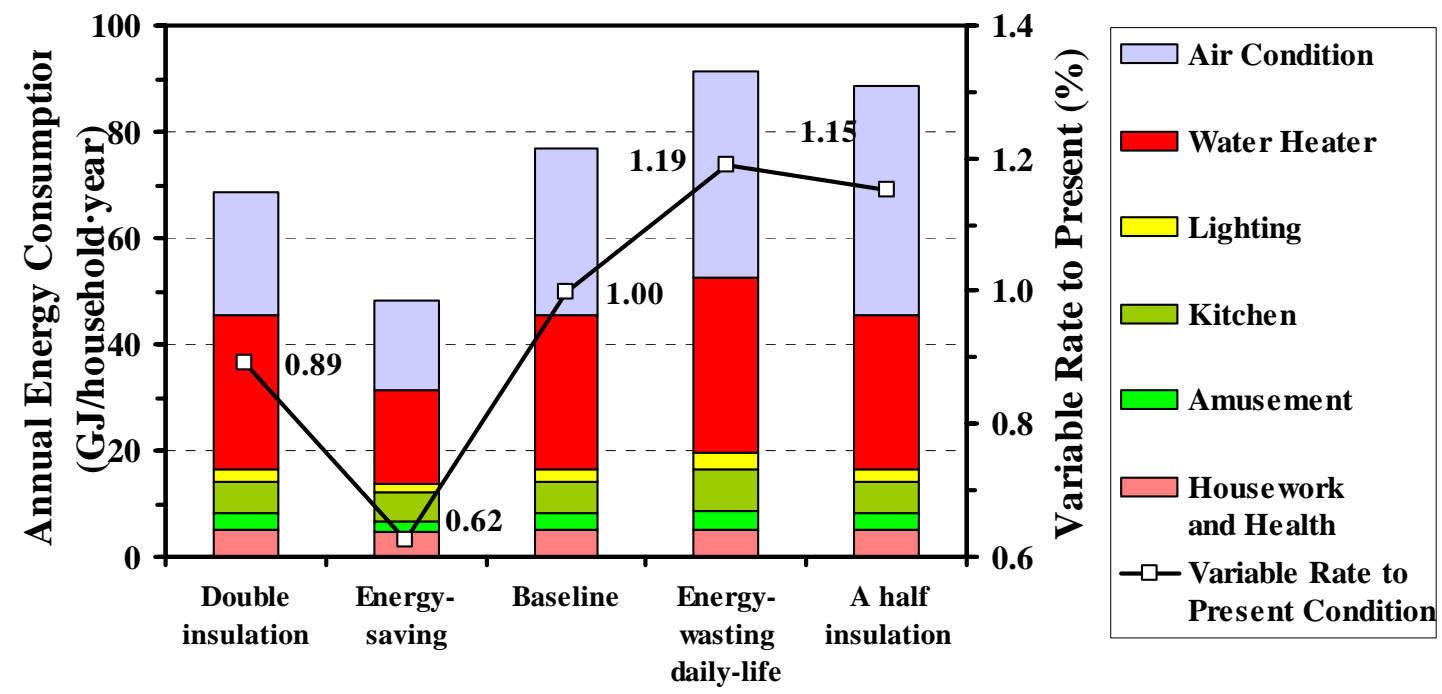

Figure 28. Calculated energy consumption results for different energy consumption behavior cases ("Double insulation" and "half insulation" indicate different thicknesses of thermal insulation with the same conditions as the "present daily-life" case) (Chiba et al., 2004)

\subsection{Technologies for Non-residential Buildings in Japan}

The subsections below summarize the building practices and materials used in non-residential buildings in Japan that are relevant to energy conservation and GHG emissions reductions.

\subsubsection{Walls and Windows}

The Japanese standard for building envelope thermal performance is based on perimeter annual load (PAL), which represents annual heat load per unit of perimeter floor space, according to the type of the building. To meet this standard, designers must carefully choose building shape and orientation, window specifications, air-conditioning zoning, and many other elements, as well as paying careful attention to thermal insulation of the envelope and use of energy-efficient window glass, solar shading, etc. As noted earlier, in most regions of Japan energy consumption for cooling in office buildings is greater than for heating; as a result, solar shading, thermal insulation, and building tightness are extremely important in efficient office building designs. Windows' perform significantly less well than other building components (e.g., roofs, walls) in the area of solar shading and have a significant impact on cooling and heating loads. Various measures, such as double glazing and window shading are employed to address the thermal impacts of windows.

\section{Glazing}

Double glazing is generally desirable for insulation purposes. Using heat-absorbing/reflecting glass or ceramic-printed glass for outer pane provides solar shading as well as thermal insulation. Special 
double-glazed units that have blinds, prisms, or Japanese paper between the panes are also used for additional solar shading. Solar shading low-E glass with a low-E layer in the outer pane offer comparatively effective solar shading with a high transmission coefficient in the visible range, i.e., the unit offers relatively natural visibility to occupants while selectively reducing transmission of infrared radiation. Other advanced solar-shading glass products that are used include units with a transparent low-E film between panes and thermotropic glass which becomes cloudy at a given temperature, a kind of switchable glass (Watanabe, 1998 and Inoue, 2003).

For enhancing space-heating performance, vacuum glass and double glazing with a transparent, heatgenerating layer are also available (Inoue et al., 2004). However, it is difficult to satisfy the energy-performance requirements for windows without combining advanced window products with other strategies, such as the window accessories described in the next subsection below as well as particular air conditioning/ventilation system features, etc.

\section{Window Accessories}

Generally, for building openings such as windows, window shades or curtains are installed on the interior side for solar shading. When outside shading is used, e.g., outdoor blinds, awnings, louvers, or eaves, heat absorbed by these features is discharged outdoors, so they are very effective in preventing interior solar heat gain. Outdoor blinds are common in Europe but, despite Japan's long tradition of outside shading with eaves, canopies, and bamboo blinds (Sudare), outdoor blinds have not been commonly used because of the potential for damage by strong (typhoon) winds. In recent years, however, improvements in exterior shading (e.g., strengthened slats, improved driving methods, and positioning control to respond to wind direction or speed) have led to increased use of exterior shading, and outdoor blinds with high wind resistance have begun to be installed (Inoue et al., 2004). Moreover, a choice is now available among several alternatives, including external roll screens, awnings, and louvers. Plantings (e.g., creeping vines or deciduous trees ) are also classified as a type of exterior shading.

\section{Window Systems}

Because fixed double-pane windows with built-in blinds trap solar heat gain between the panes, they are not as effective as airflow windows (ventilation window) at reducing interior solar heat gain. In the latter type of window unit, room air passes between the glass panes, and solar radiation heat absorbed by inside blinds is discharged from the upper part of windows, so the solar heat gain coefficient is very low, 0.1 - 0.2. This small solar heat gain coefficient translates to only a small addition to cooling loads, and a relatively comfortable thermal environment around the window. Thus the perimeter-less air-conditioning system can be realized. This system eliminates the need for fan coil units under the window, simplifies the air-conditioning system, facilitates easy control of cooling and heating, and prevents energy wasting situation such as mixing loss between cooled air and heated air. As a result of all these advantages, these windows can produce significant energy saving effect compared with conventional windows or Low-E glass. Moreover, some examples have been reported in which airflow windows equipped with built-in, automatic, slat-angle-control blinds provided excellent solar shading, daylight utilization, visibility, and 
energy savings (Inoue et al., 1988, Baker et al., 2000 and Inoue, 2000; this reference evaluates the energy consumption associated with various building factors, e.g., window size, orientation, glazing, etc., using numerical simulation). Various other efficient windows, such as the simplified airflow window in which room-side glazing is replaced with blinds or roll screens, have been developed. Double skin façades, in which fresh air is introduced between panes of a multiple or double-pane window by natural ventilation to discharge solar radiation heat outward, are also being increasingly used, allowing ventilation during intermediate seasons (Takemasa et. al., 2004).

\section{Exterior Walls \& Roofs}

Shading performance of non-transparent envelope elements such as exterior walls and roofs can be enhanced by increasing solar-reflective properties as well as by thermal insulation. Solar reflectivity is generally improved by increasing reflectance in visible light region, i.e., using light colors such as white. A material with enhanced reflectance in infrared region, which covers almost half of the total energy of solar radiation, is being put to practical use, and a higher solar shading effect compared with usual materials can be expected from such a material. Improving solar reflectivity reduces total absorption of solar energy in an area and thus is also effective in reducing urban heat-island effects. Moreover, roof -top planting is beginning to be undertaken in Tokyo in hopes of offsetting temperature increases associated with urban heat-island effects through the thermal insulating properties of soil and the evaporative cooling effect of both soil and plants. This approach is also attractive because of the psychological benefit of plants (Hagishima et al., 2004).

Thermal insulation of exterior walls/roofs improves solar shading performance as well as space-heating efficiency, and some solar shading effect can be achieved by sprinkling water on roofs where insulation is insufficient.

Chikamoto et al., (1999) report another strategy for reducing cooling load in a high-rise university building where fresh air intake and ventilation are accomplished through openings under windows, resulting in a large reduction of cooling loads.

The technologies described above were developed to improve occupant comfort as well as reduce energy use and GHG emissions, based on cold-weather insulation/air tightness measures in Europe and the U.S.. These methods and technologies may be helpful in low/middle-latitude regions, such as Asia, where energy consumption is expected to increase as the result of an anticipated rapid increase in population and improvement in living standards.

\subsubsection{Heating}

A heat-recovery heat pump used for non-residential building can cool and heat simultaneously in many cases. In practice, however, simultaneous heating and cooling demand is rare, so the heat-recovery heat pump system is usually combined with a heat-storage tank. These heat pumps are primarily used in 
District Heating and Cooling (DHC) systems that have large heat-storage tanks. For example, for the Harumi Island DHC located in the Tokyo Bay Area, the $\mathrm{CO}_{2}$ emission rate per unit of heat sold is approximately 60 percent of the average level in other Japanese DHC systems. Because the price of a heat-recovery heat pump is the same as the price of a regular centrifugal chiller, the heat pump is economically attractive (Yanagihara, 2006).

\subsubsection{Cooling}

Cooling energy consumption in Japanese commercial buildings is minimized by building-envelope measures to reduce cooling load and multiple-room air conditioning systems that allow control of the temperature for each room served.

\section{Air Conditioner Load Reduction}

As noted earlier, air conditioning cooling load is generally greater than heating load in non-residential buildings in major Japanese cities. In addition, recent attention to the urban heat island phenomenon (annual mean air temperature in major Japanese cities has increased by 2.0-3.0 degrees $\mathrm{C}$ during the past 100 years) has increased emphasis on reducing cooling loads. Thus, in recent years, technologies to save air conditioning energy and mitigate heat islands have been in the spotlight. One strategy is application of highly reflective paint or other materials to wall and roof surfaces; another is rooftop tree planting to reduce air conditioning cooling loads through evaporation and heat insulating properties of soil.

\section{Multi-room Air Conditioners}

Cooling and heating rooms by using air conditioners is as common in small- and medium-size non-residential buildings as in homes. The shipments of the package air-conditioner for business use are shown in Figure 29. These devices are mainly for variable refrigerant volume (VRV) systems, which have one or more outdoor and indoor units connected by piping. Ventilation is performed separately from the air-conditioning system, just as described previously for household air conditioning, and the units can be operated so that their temperatures can be controlled in each room. The COP rating of package air-conditioners for business use is $2.93-4.28$ for cooling, and $3.45-4.71$ for heating (The Energy Conservation Center, Japan, 2006). 


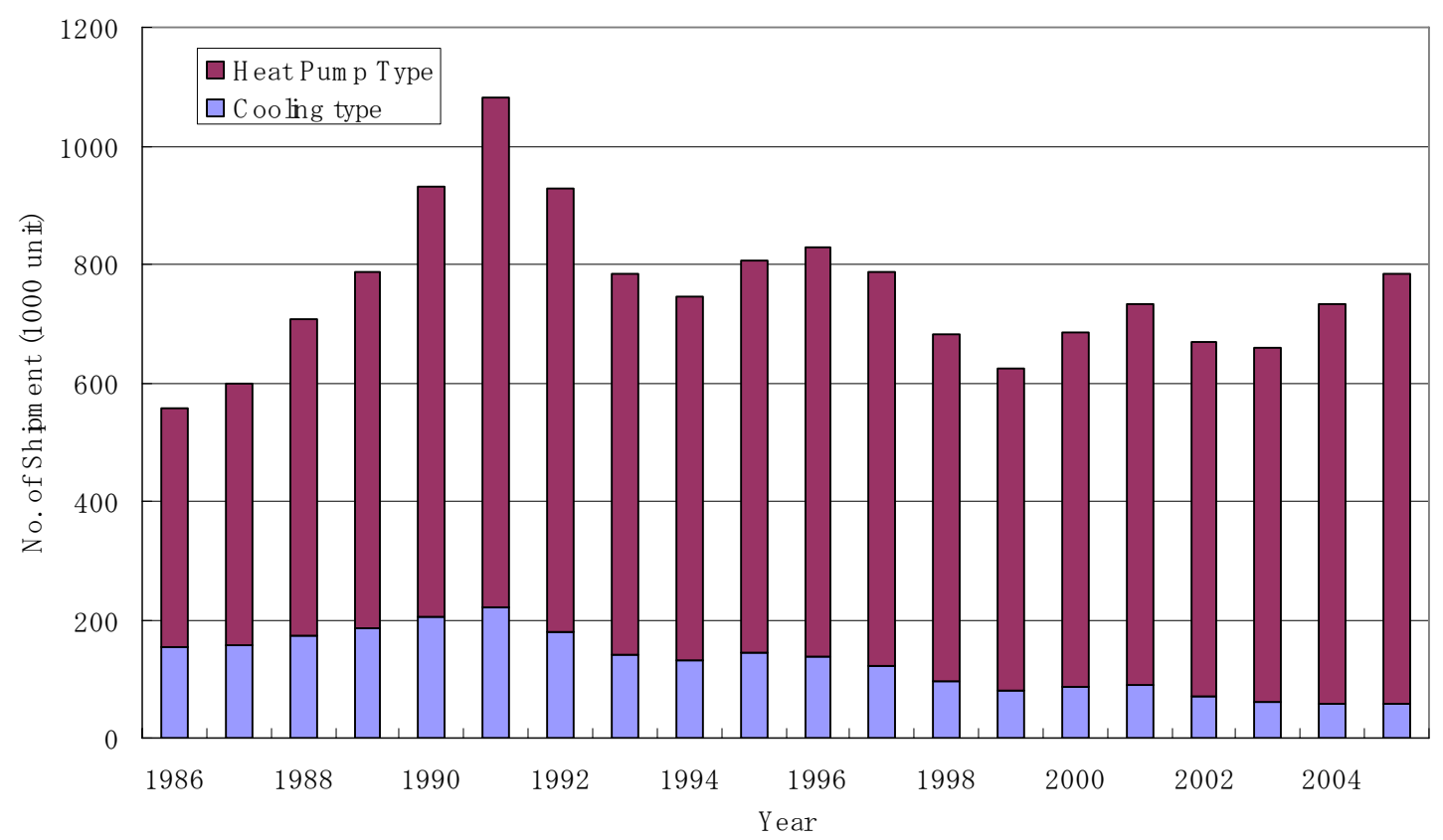

Figure 29. Change in number of commercial air conditioners sold in Japan (The Japan Refrigeration and Air Conditioning Industry Association, 2006)

\section{Thermal Storage Systems}

Thermal storage systems (TSSs) are used to adjust energy supply and demand imbalances. These systems are applicable for solar energy and for power load leveling to avoid daytime demand peaks. TSSs have become increasingly important for the effective use of both energy and electric power. Typical TSSs utilize the temperature difference and sensible heat of water and latent heat of ice. There is also a system that stores heat directly in the building shell. The latent-heat storage systems utilizes chemical substances such asparaffin which melts and congeals at 0 degree $\mathrm{C}$ or more. Some people argue that TSS is cost effective but doesn't contribute to energy savings because of heat loss from the heat storage tank and the lower COP of chillers. However, this is caused by the needs for lower storage temperature than that of water or ice storage. A properly designed TSSs have been shown to be effective at saving energy because its chillers operate efficiently at rated load.

\section{Absorption Chiller Heater}

The absorption chiller heater contributes to summer peak demand savings and improves electricity load ratio, resulting in an efficient power supply and contributing to $\mathrm{CO}_{2}$ emissions reductions. The space, energy, and economic savings associated with absorption chiller heaters has made them popular air conditioning systems for office buildings, shopping malls, schools, and hospitals in Japan. (Shitara et al., 2003) Recently, a high-efficiency absorption chiller heater (COP of 1.60 thanks to triple-effect absorption) was put on the market, in addition to a model with a COP of 1.35 (from double-effect absorption). (Mori et al., 2003) 
Gas-engine Heat Pumps (GHPs)

Two main types of commercial air conditioners are used in Japan: the Electric Heat Pump (EHP), with an electric, motor-driven compressor, and the gas-engine heat pump (GHP), which, as its name indicates, uses a gas engine to drive the compressor. The refrigerating cycle is the same for both devices. Performance, durability, and maintenance improvements are being contemplated for the gas engine on the GHP. Major features of the GHP are: 1) total electricity consumption is about one-tenth of that of the EHP; 2) warm air can be supplied in a short time after start-up because the gas engine has high heat efficiency and it efficiently utilizes exhaust heat from the engine; and 3) heating performance is consistent even in cold temperatures because of the heat collection by the exhaust-gas heat exchanger. Japanese gas companies have been promoting the GHP's high efficiency, in cooperation with the device manufacturers, who put a system with a COP of 1.3 on the market in 2001. In 2005, a more advanced high-efficiency system with a COP of 1.5 was released. (Tachi et al., 2006)

\section{Vapor-compressed Chillers}

The efficiency of vapor-compressed centrifugal chillers has been continually improving. The trends in COPs of centrifugal chillers are shown in Figure 30. The COP of centrifugal chillers has more than doubled during the past 20 years. The cooling COP for the latest model is 6.0, and a COP of 30 has been achieved by incorporating numerous efficiency measures, including mounting the inverter on top of the chiller. In the case of $\mathrm{COP}=30$ achievement, the rated system $\mathrm{COP}$, excluding secondary pumps, is expected to be approximately 6.3 although the previous COP was approximately 3.5, and significant reduction of $\mathrm{CO}_{2}$ emissions can be achieved. A subsidy program offers one-third of the cost difference between these high-efficiency devices and conventional air conditioners (Seki et al., 2004).

\section{Air Conditioner COP Standards}

In 2006, the following COPs are to be satisfied according to METI for each category.

- Centrifugal Chillers • • COP greater than 5.99

- Water Source Chillers • • COP greater than 5.12

- Air Source Heat Pumps • • • COP greater than 3.58

- Multi-system Air Conditioners • • • COP greater than 3.90

*For devices that both heat and cool, the COP is the average of the cooling and warming COP. 


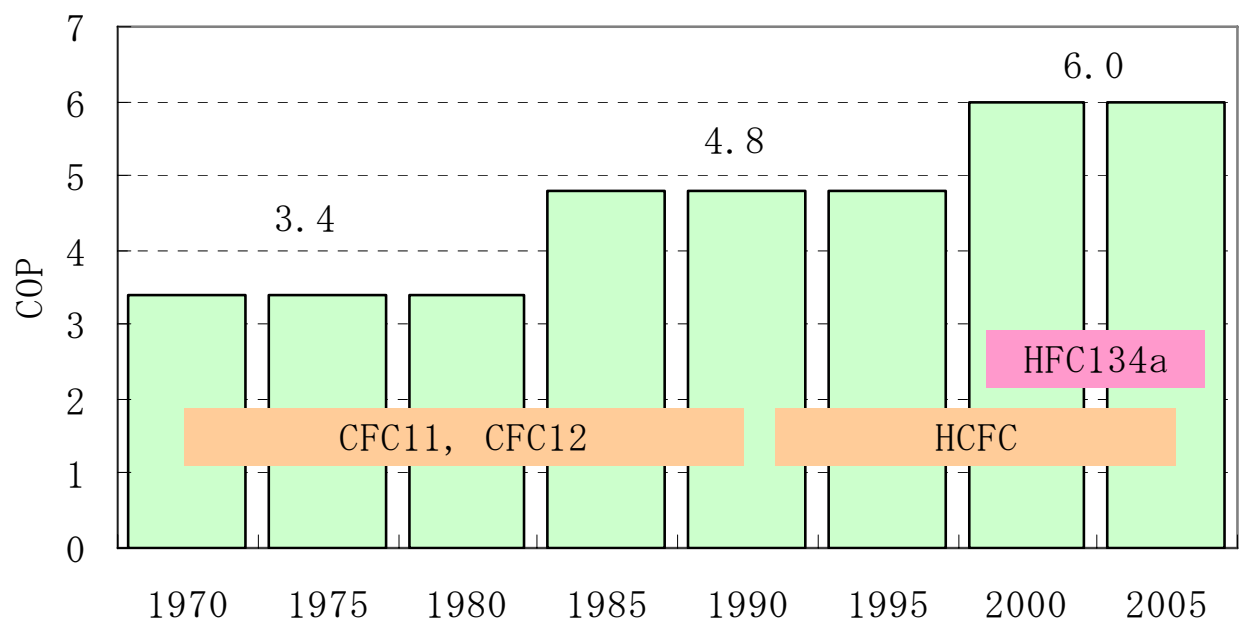

Figure 30. Trends in COPs of centrifugal chillers in Japan

\section{Desiccant Air Conditioning}

Desiccant air conditioning uses a dehumidification agent to process latent heat. This system was used mainly in industrial facilities until recently when it gained popularity for general air conditioning in buildings and supermarket showcase coolers. Silica gel, zeolite, activated carbon, and activated alumina are used as dehumidification agents. The dehumidification agent is selected based on characteristics such as durability or regeneration temperature. The merits of desiccant air conditioning are: 1) the system does not use CFCs and thus does not contribute to ozone layer depletion; 2) Waste heat can be utilized for regeneration of the dehumidification agent. 3) The exhaust heat from decentralized generators can supply dry air (28 degree $\mathrm{C}$, humidity around 30 percent), so a comfortable thermal environment can be realized without a wet or cold feeling; and 4) ventilation air from a desiccant air conditioner is low in humidity, so it is effective in prevention of fungus growth and in sterilization applications.

\subsubsection{Hot Water}

The exhaust gas temperature of conventional boiler is about 200 degree $\mathrm{C}$, and the heat efficiency is about 78 percent. Newly developed condensing boiler is equipped with dedicated secondary heat exchangers on the downstream side of the primary heat exchanger and collect the latent heat from steam contained in the exhaust gas. These devices recover exhaust-gas heat that is up to 80 degree C. Their hot water supply efficiency is 93 percent, and fuel consumption/ $\mathrm{CO}_{2}$ emissions are reduced by 16 percent compared to the performance of conventional boiler (The Energy Conservation Center, Japan, 2002).

\subsubsection{Power Generation/District Heating and Cooling}

A number of energy-efficient power generation and related strategies are commonly employed for commercial buildings in Japan: cogeneration, PV, and district heating/cooling. 


\section{Cogeneration Systems}

A cogeneration system supplies both thermal energy and electric power. Electric power is generated by motors such as gas or diesel engines or gas turbines; the system uses exhaust heat from the electric generator to supply hot water, air cooling and heating. In conventional, large-scale power systems, electricity is generated at a central power station located far from consumers, so heat from the power generation is wasted. The combination of wasted heat and electricity transmission losses result in an energy-use efficiency of around 35 percent for centralized power plants. In contrast, cogeneration entails small, decentralized electric power generation systems operating at the same location where the power is consumed, so both the electricity and heat produced by the system can be used efficiently. With an optimal combination of electricity and heat energy demand, energy-use efficiency of a cogeneration system is 70 to 80 percent. The significant energy savings and reduced $\mathrm{CO}_{2}$ emissions of cogeneration systems compared with conventional power generation can result in a primary energy reduction rate of 23 percent, and a 37-percent reduction of $\mathrm{CO}_{2}$ emissions. (Japan Industrial Publishing, 2005)

\section{Photovoltaic (PV) Power}

PV power generation has mainly penetrated the residential sector in Japan and is not yet in wide use in the commercial sector. The government has started a program to promote new technologies including PV, and a subsidy for half of the cost of a PV system is available through a field-testing project sponsored by The New Energy and Industrial Technology Development Organization (NEDO). In recent years, PV systems with new types of solar batteries, such as a "transparent PV" system that combines the solar cell with glass have been incorporated into building materials in the commercial sector.

\section{District Heating and Cooling}

In Japan, district heating and cooling systems that supply heat for more than two buildings and have a thermal capability of more than 21 GJ are referred to as "heat supply” businesses under the Heat Supply Business Law. The first district heating and cooling system in Japan was introduced in the Senri-Chuo district in Osaka in 1970. Japanese district heating and cooling systems served 151 districts as of 2004, comprising 44,949 houses, 1,515 businesses, 45 million $\mathrm{m}^{2}$ of service area, and a gross floor area of 47 million $\mathrm{m}^{2}$. The residential portion of this total is an 1,316 TJ (mainly for heating and hot water supply), and the non-residential portion is $23,586 \mathrm{TJ}$, of which cooling is $15,108 \mathrm{TJ}$, heating is $8,477 \mathrm{TJ}$ District cooling and heating systems mainly rely on one of three types of energy sources: absorption/boiler (combined absorption chiller and boiler with cogeneration use of exhaust heat); electric-drive chiller/heat pump; or electric drive/absorption, which combines the previous two methods. (Japan Heat Service Utilities Association, 2005)

The district cooling and heating system’s energy-efficiency characteristics include:

1) Large-scale, effective supply of heating and cooling that meets the heat demand of many buildings. Highly efficient operation management and maintenance are possible. 
2) Utilization as a heat source of what would otherwise be waste energy, including exhaust heat from garbage incinerators and factories; use of river water or seawater as heat source in systems that rely on heat pumps (39 districts in 2004); and

3) Utilization of waste heat from cogeneration (47 districts in 2004).

On the other hand, the disadvantage of district heating and cooling such as heat loss during transportation is also exists. Figure 31 shows overall energy-efficiency ratio (EER=Annual heat supply/annual energy consumption converted into primary energy) for 108 district heating and cooling plant and 36 individual buildings as an example of the actual efficiency of a district cooling and heating system (Shimoda et al., 2003, 2006).

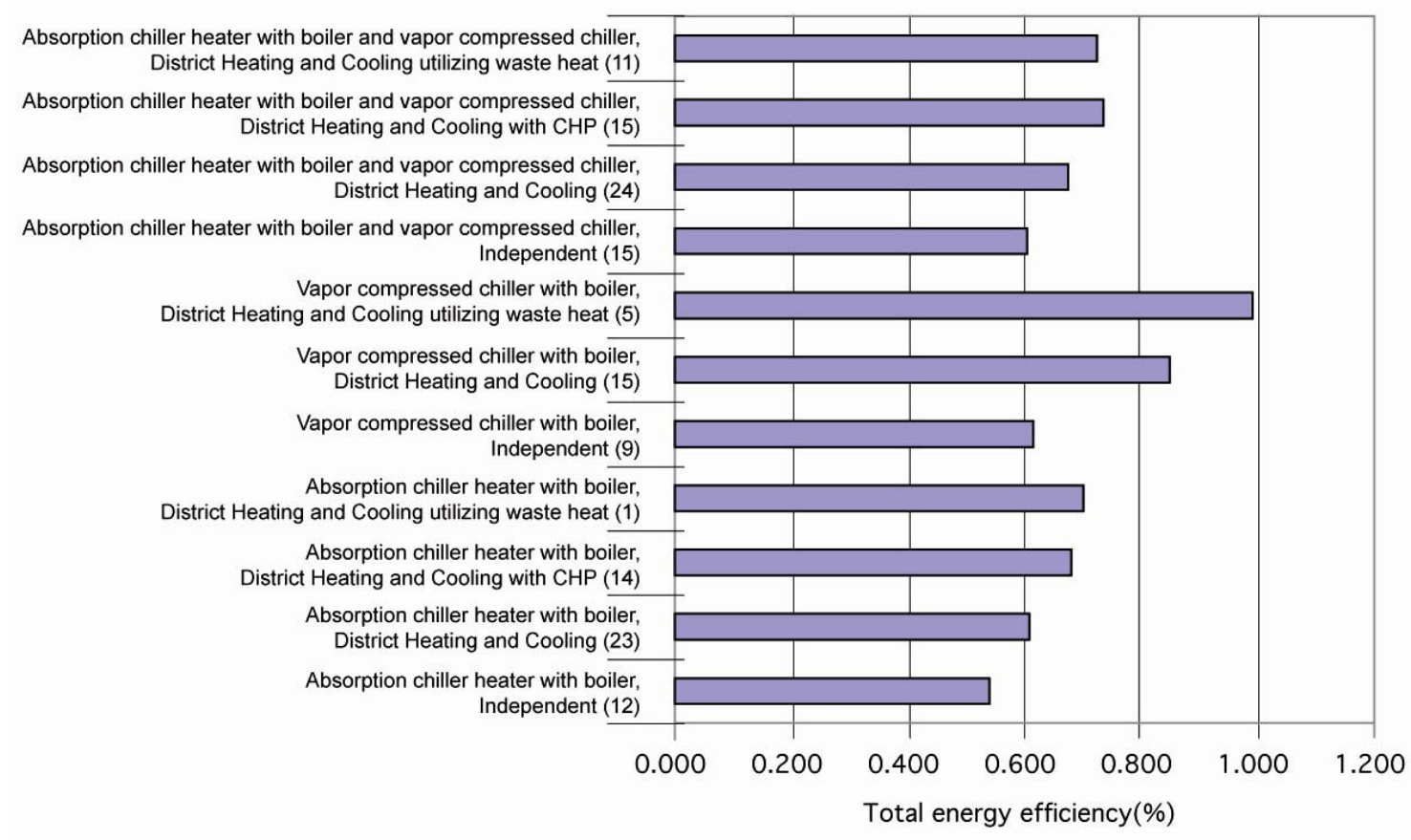

Figure 31. Actual energy efficiency of district cooling and heating serving non-residential customers (Shimoda et. al., 2003, 2006)

\subsubsection{Heating, Ventilation, and Air-Conditioning (HVAC) Systems}

Japan has four distinct seasons, and seasonal changes in heating and cooling loads are very large. The differences between peak and partial loads are large, both for individual heating, ventilation, and air-conditioning (HVAC) systems and for the power system as a whole. As a result, substantial energy can be saved by employing variable air volume (VAV) or variable water volume (VWV) technology, which holds temperature uniform but varies air/water flow rate. In recent years, it has become popular to attach an inverter (variable speed control) to the pump or the fan of VAV and VWV systems, which reduces annual energy consumption. Installing a building energy management system (BEMS) allows for 
real-time display of energy usage and analysis of operations data to enable effective management of lighting and air conditioning, detection of problems, and appropriate maintenance. All of these elements save energy throughout the building. The notion of commissioning buildings, which maximizes energy efficiency, is being promoted in Japan, by the commissioning committee of the Society of Heating, Air-Conditioning and Sanitary Engineers of Japan. The group is studying the development of a commissioning tool. In addition, the Building Service Commissioning Association, a Non Profit Organization (NPO) was established in August 2004 to promote commissioning activities.

\subsubsection{Lighting}

A number of energy-efficient lighting strategies are employed in non-residential Japanese buildings, including high-efficiency fluorescent lamps, light-emitting diode (LED) illumination, and daylighting. Figure 32 shows the reduction of power consumption for fluorescent lamps in Japan.

\section{High-efficiency Fluorescent Lamps}

Since 2003, all non-residential buildings larger than 2,000 $\mathrm{m}^{2}$ must report energy-conservation measures. The standard for energy-efficient lighting is either a performance or specifications standard as described below.

\section{Performance Standard}

$$
\mathrm{CEC} / \mathrm{L}=\frac{\text { Annual energy consumption for lighting }(\mathrm{kWh} / \mathrm{year})}{\text { Annual assumed energy consumption for lighting }(\mathrm{kWh} / \mathrm{year})}
$$

where CEC/L is the coefficient of energy consumption for lighting. The CEC/L prevents overuse of energy by restraining energy consumption of lighting fixtures at a numerator of less than the standard energy consumption at a given denominator for a "normal" or "high-quality" lighting environment. The denominator of standard energy consumption can be increased or decreased through adjustment based on individual situations and space requirements. In other words, the CEC/L is an index of the energy efficiency of lighting fixtures and does not refer to an absolute value of energy consumption.

\section{Specification Standard (point method)}

The specification standard does not require complicated calculations. It determines the appropriateness of energy-conservation measures from the building specifications by summarizing points based on energy conservation measures and elements. The total number of points must be greater than one hundred, (i.e., more than twenty points above the base sum of 80 points). This method is applied to evaluation of energy consumption for space heating, cooling, lighting, appliances etc. only to small buildings (with less than $5,000 \mathrm{~m}^{2}$ of total floor space). 


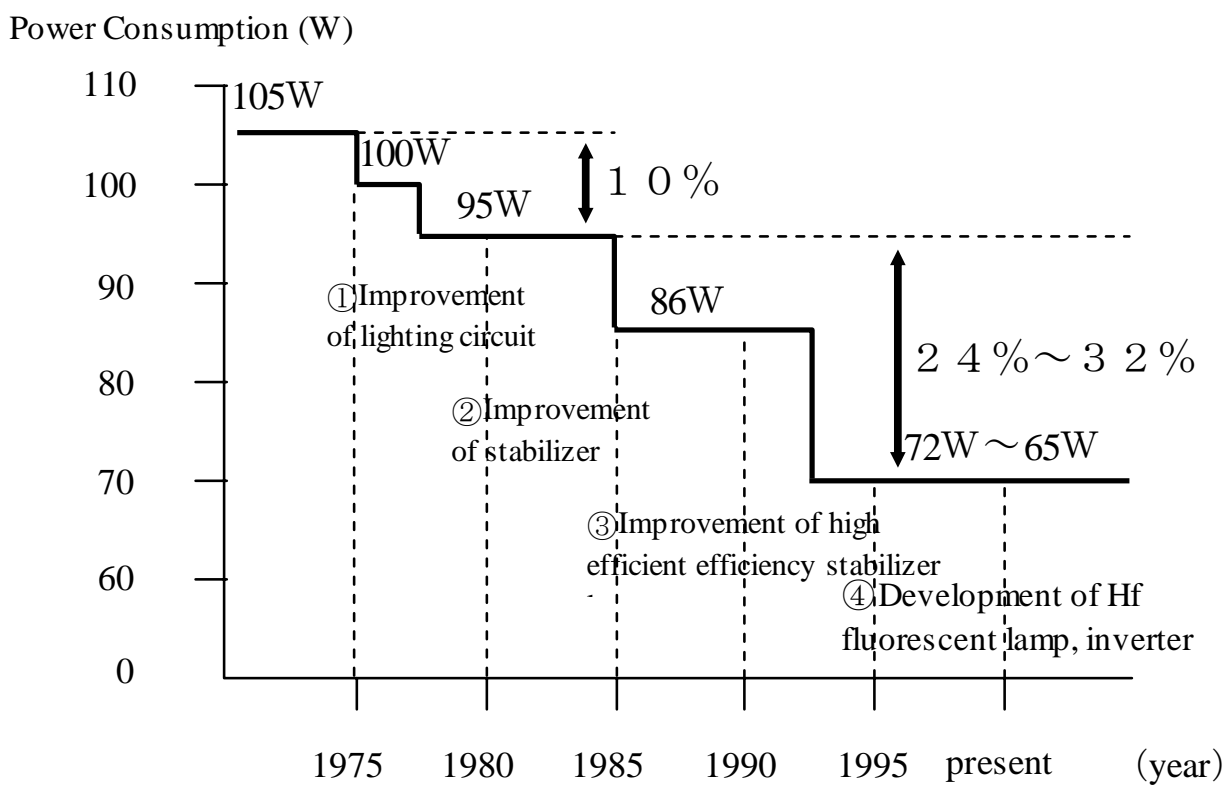

Figure 32. Power consumption for fluorescent fixtures (two 40-W lamps) in Japan

\section{LED Illumination}

Energy-conserving fixtures using light-emitting diodes are already used for traffic lights and indirect illumination. It is expected that LED fixtures will soon be used for indoor lighting with high light output, and the Japanese government anticipates widespread use of white LEDs in consumer lighting fixtures with a target of approximately 10 percent of commercial and residential lighting sector by FY 2010. The development of highly-efficient LED products with high light output is under way. A new generation of LED products has the potential to decrease lighting energy consumption to one-eighth of the consumption of conventional incandescent lamps and half of the consumption of fluorescent lamps

Major characteristics of LED are as follows:

- Small and bright

- Shell type uses transparent resin for the lens, allowing a variety of beam angles from narrow to wide.

- Usable at low temperatures.

- Require direct current (DC) to light diodes, but circuit composition is relatively simple; few parts are needed (compared with fluorescent lamps) when the input voltage is $100 \mathrm{~V}$ alternating current (AC).

- Do not contain mercury, environmentally friendly

\section{Daylighting}

For daylighting in energy-efficient buildings in Japan, automatic illumination control combined with a system that uses sunlight effectively (e.g., a light shelf) is widely used. In recent years, a system equipped with a mirror apparatus that follows the sun and a lens/optical fiber has been introduced and is expected to significantly expand the market share of daylighting. 


\subsubsection{Office Equipment}

During the past 30 years, office automation has increased rapidly, causing a significant increase in power consumption and cooling loads in office buildings. Energy savings have been achieved in computers, disk drives and copiers, based on the Japanese Top Runner Standard. A target energy-efficiency ratio improvement has been established for computers at 83 percent of the 1997 energy use level by 2005 and for copiers at 30 percent of 1997 levels by 2006.

Because there is significant number of hours during which office equipment are not operated, power management strategies (in which a device shifts to standby mode automatically after a certain amount of idle time) play an important role in energy conservation. Figure 33 demonstrates the estimated annual power consumption by office equipment per 1,000 office workers in Japan and the U.S. and the by the level of power management saturation (Kawamoto et al. 2004). Since portable computers, whose energy use is much lower than that of desktop computers are much popular in Japan, the difference in energy consumption between the two countries is clear. 


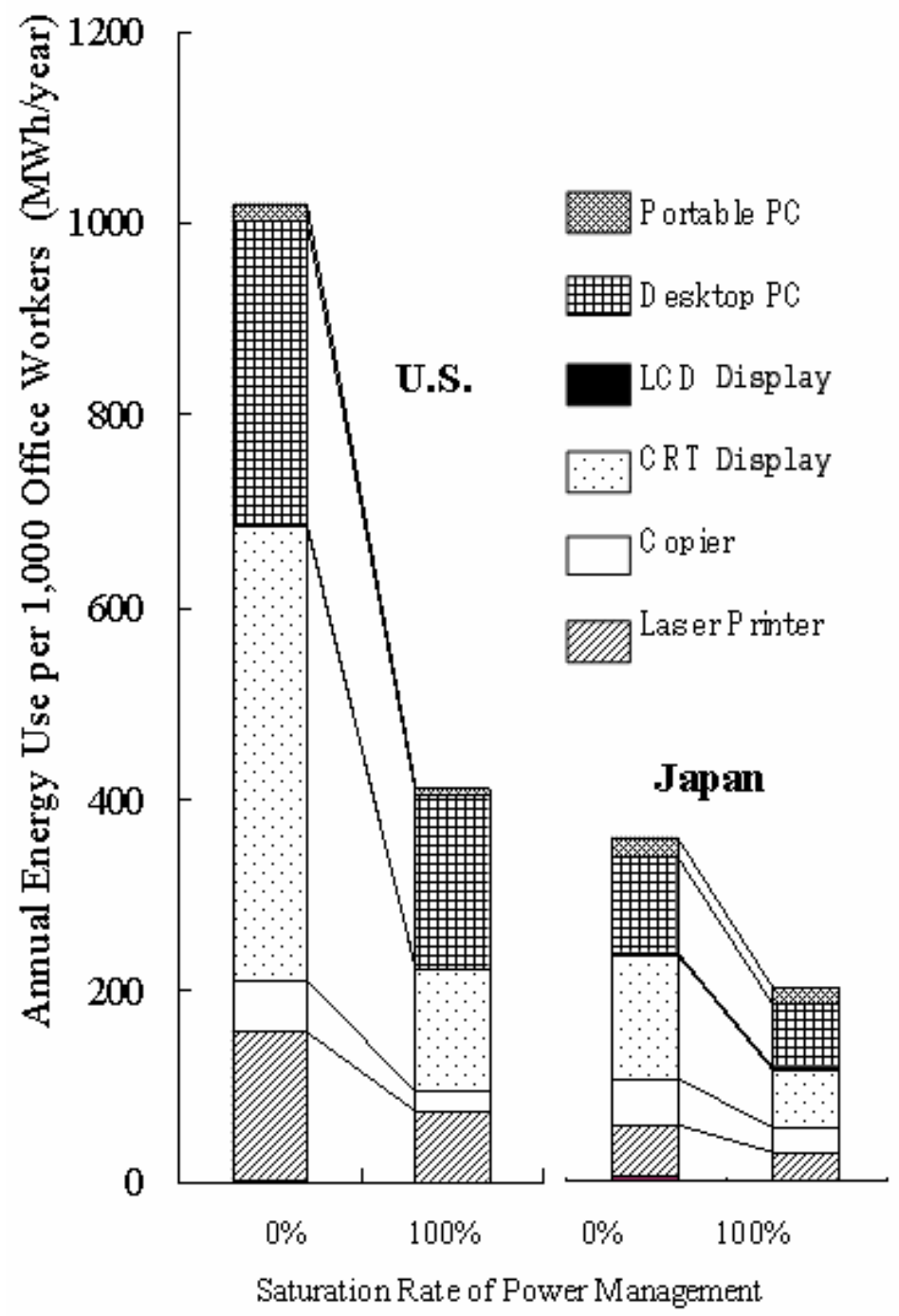

Figure 33. Annual energy use of office equipment per 1,000 office workers in Japan and in U.S. by level of power management saturation (2000).

\section{Policies to Promote Energy Conservation and Prevention of Global Warming in Japanese Buildings}

In accordance with the Kyoto Protocol that came into force in February 2005, Japan has committed to reducing its average GHG emissions by $6 \%$ on the 1990 level over the five years from 2008 to 2012. To meet this target, in April 2005 the Japanese government adopted "Kyoto Protocol Target Achievement Plan” as a Cabinet Decision to promote measures for prevention of global warming. Under the Plan, a reduction in emissions of approximately 34 million $\mathrm{t}-\mathrm{CO}_{2}$ is expected to be achieved by improving the energy conservation efficiency of both residential and non-residential buildings, in addition to a reduction 
in energy-origin emissions of approximately 29 million t- $\mathrm{CO}_{2}$ achieved by improving the efficiency of appliances through the Top Runner Program.

A number of policy instruments are in place in Japan to promote energy conservation and to prevent global warming in accordance with the Kyoto Protocol Target Achievement Plan, including enforcement of the "Law Concerning the Rational Use of Energy" (a.k.a. the "Energy Conservation Law"); assessment of energy efficiency performance, labeling systems, and financial incentives.

\subsection{Enforcement of Japan's Law Concerning Rational Use of Energy}

\subsubsection{Energy Conservation Standards for Residential and Non-residential Buildings}

In Japan, the Energy Conservation Law was enacted in 1979. Based on this law, energy conservation standards for residential and non-residential buildings were issued respectively in 1980.

The standards for residential buildings were revised in 1992 and 1999, for example to enhance the required levels of thermal insulation. The 1999 revision added performance-based standards for annual heating and cooling load along with the conventional prescriptive standards and performance-based standards using thermal loss coefficients, etc. A formula for passive solar systems was also introduced. In 2006, the law was revised to add standards for communal facilities in apartment buildings.

For non-residential buildings, performance-based standards using PAL (Perimeter Annual Load) and CEC (Coefficient of Energy Consumption) indices have been introduced as energy conservation standards. PAL refers to the index for the estimated annual thermal load in the perimeter zone within five meters of exterior walls, per total floor area. CEC is the index for the ratio of estimated annual energy consumption for building equipment such as the air-conditioning system to the virtual annual thermal load. The levels of these indices were made more stringent in the revisions of 1993 and 1999. When the standards were revised in 1993, new CECs were added for elevators, mechanical ventilation, lighting and hot-water supply systems. Prescriptive standards were also added in 2003.

\subsubsection{Mandatory Reporting of Energy Conservation Measures}

Based on the Energy Conservation Law, owners of buildings are obligated to endeavor to introduce measures in compliance with the Energy Conservation Law. The amended Energy Conservation Law was enforced in 2003 requiring owners of non-residential buildings with a total floor area of 2,000 $\mathrm{m} 2$ or more to report the energy conservation measures included in the design to the relevant local authorities when buildings are newly constructed, extended, or rebuilt. As a result, the percentage of non-residential buildings complying with the Energy Conservation Standards has increased from approximately 35 percent in 2001 to approximately 74 percent in 2004. Furthermore, the amended Energy Conservation Law enforced in 2006 stipulates that, prior to major repairs, etc. as well as new construction, extension, or 
rebuilding, building owners shall report energy conservation measures used in the buildings to the relevant local authorities. If these energy conservation measures are insufficient to a significant degree, said authorities may require improvements to be made, and the case may be disclosed to the public if the owner does not follow such instructions without any good reason.

The amended Energy Conservation Law enforced in 2006 also requires the owners of residential buildings with a total floor area of $2,000 \mathrm{~m} 2$ or more to report the energy conservation measures included in the design to the relevant local authorities when buildings are newly constructed, extended, rebuilt, or repaired on a large scale, etc. As in the case of non-residential buildings, when these energy conservation measures are deemed insufficient to a significant degree, the authorities may require improvements to be made, and the case may be disclosed to the public accordingly.

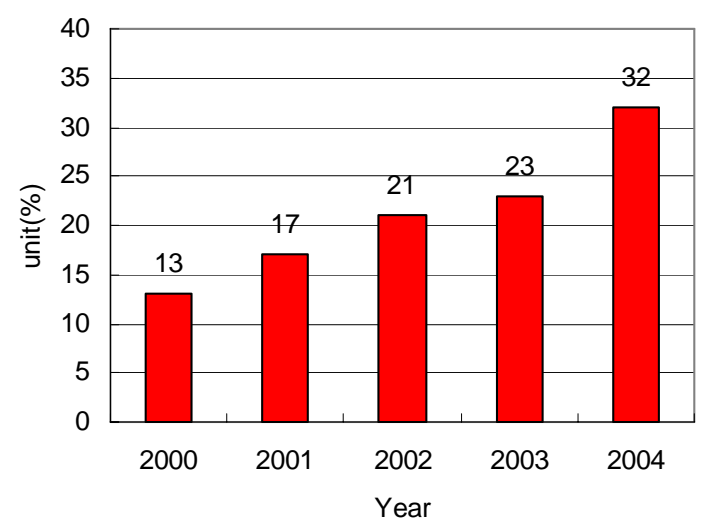

New residential buildings

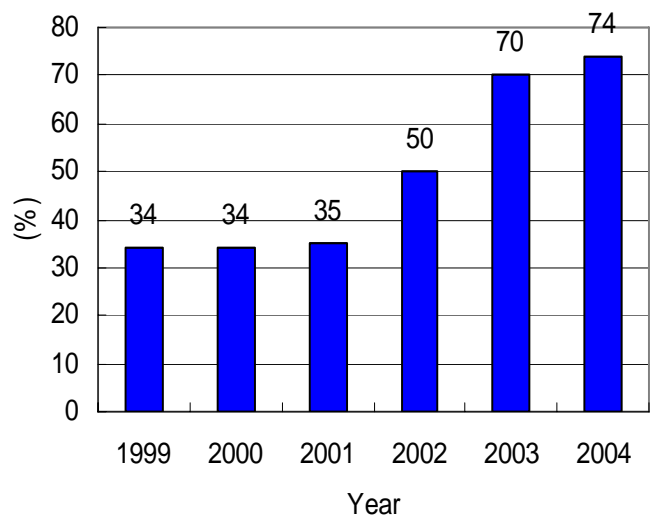

New non-residential buildings

Figure 34. Trends in compliance with 1999 Energy Conservation Standards

\subsection{Energy Efficiency Assessment and Labeling Systems}

The energy efficiency assessment and labeling systems apply to residential and non-residential buildings, and appliances.

\subsubsection{Housing Performance Assessment and Labeling Systems}

The "Housing Performance Indication System" based on the "Housing Quality Assurance Act" commenced full-scale operation from October 2000, the idea being to help consumers choose housing with high energy efficiency. Use of the system is not mandatory. Based on the common assessment and indication standards stipulated by the Minister of Land, Infrastructure and Transport, an independent third-party organization objectively assesses the various housing performances required by consumers 
and ranks the results. Performance of energy efficiencies are included in ten items for assessment, ranked in four levels according to the energy conservation standards for housing, and indicated. In FY 2004, approximately 160,000 new housing units were assessed in the design stage and approximately 110,000 in the construction stage. Those numbers have been increasing year by year.

\subsubsection{Comprehensive Assessment System for Building Environmental Efficiency}

To promote sustainable buildings through market mechanism, a consortium consisting of experts from industry, government and academia was established in 2001, and since then the Comprehensive Assessment System for Building Environmental Efficiency (CASBEE), a environmental labeling method to provide comprehensive assessment and a clear indication of buildings' environmental efficiency, has been developed and disseminated. Since then, "CASBEE for New Construction" (2003), "CASBEE for Existing Building” (2004) and “CASBEE for Renovation” (2005) have been developed. To promote appropriate assessment and operation of CASBEE, a system of certification by a third party (Institute of Building Environment and Energy Conservation (IBEC)) of results of assessment has started since 2004.

The Building Environmental Efficiency (BEE) as an assessment index for this system takes into account building environmental quality and performance (Q) as well as the building environmental loadings (L). The BEE is defined as $\mathrm{Q} / \mathrm{L}$. The building environmental quality and performance includes the indoor environment, quality of services and outdoor environment on site. The building environmental loadings include energy, resources and materials, and the off-site environment. Approximately ninety items are used as input data for the assessment and CASBEE can be utilized in each stage of a building's life cycle - design, construction, operation and renovation. 


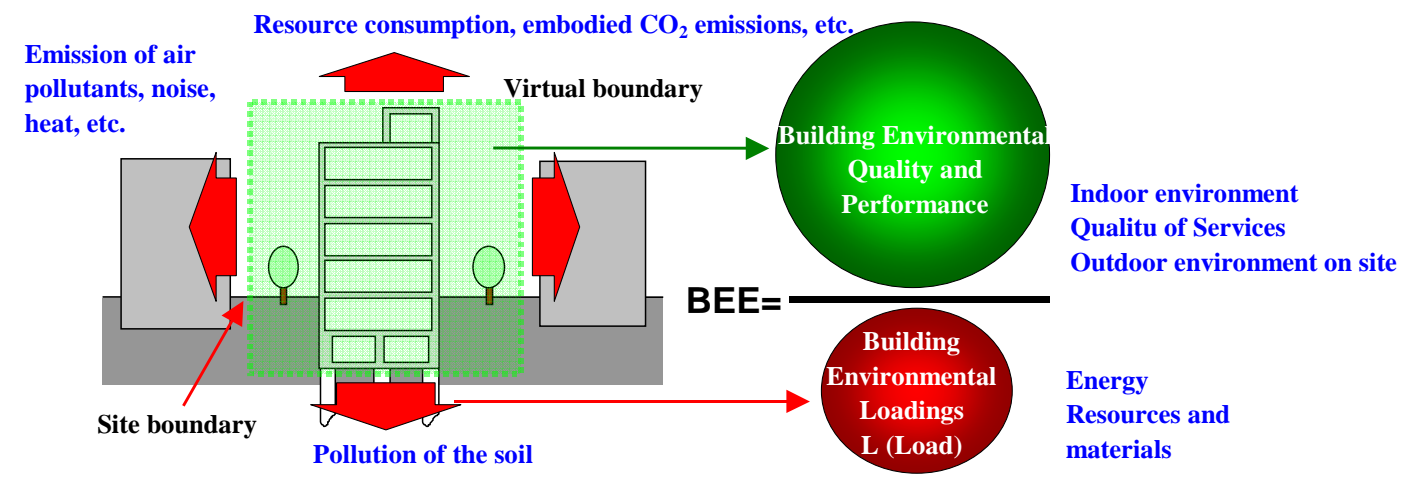

<Sample assessment result $>$
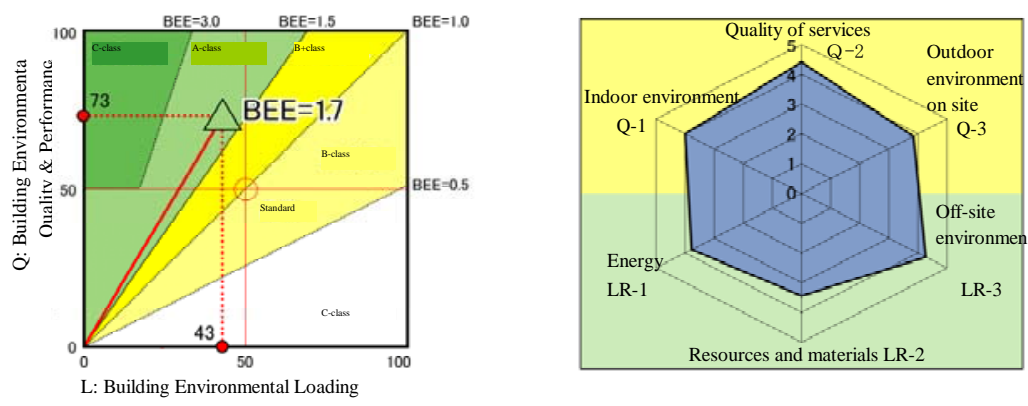

Figure 35. Overview of CASBEE

Recently there has been a growing movement in building administration to require building owners to implement comprehensive assessment of their building's environmental performance, Some local governments have introduced a system that requires building owners to submit and indicate assessment results by CASBEE when a building above a certain size threshold is to be constructed, . As of October 2006, three prefectures and six major cities have introduced, or plan to introduce such system.

"CASBEE-HI" to mitigate heat island phenomenon was developed in 2005, and "CASBEE for Urban Development”, a method of assessment of projects in urban districts, was developed in 2006. In addition, "CASBEE for Home" for detached houses was developed and a trial version has been published in 2006 (Institute of Building Environmental and Energy Conservation (IBEC), 2006).

\subsubsection{Top Runner Program}

When the Japanese government revised its Energy Conservation Law in 1998, the Top Runner Standards system was introduced (The Energy Conservation Center, Japan, 2005). The Top Runner system sets target energy efficiency standards including scope, target values and target years for appliances, based on the idea that manufacturers are to produce products better than those products with the highest energy conservation efficiency of all products in the same group currently on the market. Top Runner standards have been established for 18 items*. The Council is responsible for selecting these items. Energy Efficiency Labeling is a system by which labels indicate how these appliances achieve the target energy 
conservation values stipulated in the Top Runner Standards. These indicator labels are displayed voluntarily.

*The 18 items are: vehicles, air conditioners, fluorescent lights, TV sets, VCRs, photocopying machines, computers, magnetic disk units, freight vehicles, electric refrigerators/freezers, space heaters, gas cooking appliances, gas hot-water suppliers, oil hot-water suppliers, electric toilet seats, vending machines and transformers.

Energy-efficiency values and indicator labels are voluntarily displayed in catalogs and other advertising and publicity material so that consumers can consider energy efficiency when making purchases.

\subsection{Financial Incentives}

Systems to grant financial incentives through loans, etc. have been introduced in Japan to encourage energy conservation in residential and non-residential buildings.

\subsubsection{Low-interest Loans for Residential Buildings}

The Government Housing Loan Corporation is a government financial institution and has offered loans with long-term fixed interest rates to fund the construction and purchase of residential buildings since its establishment in 1950. Favorable interest rates and premium loans from the Corporation have been important incentives to upgrade housing performance.

To improve energy conservation performance, all residential buildings built or purchased with loans from the Corporation are required to comply with the 1980 Energy Conservation Standards. Residential buildings which comply with the 1992 Energy Conservation Standards qualify for premium loans as well as favorable interest rates. On top of that, residential buildings which comply with the 1999 Energy Conservation Standards qualify for further premium loan funding (The Government Housing Loan Corporation, 2006a).

The Government Housing Loan Corporation is scheduled to be abolished in April 2007 and the Japan Housing Finance Agency is established as an independent administrative entity. In line with the change, since 2003 the Corporation has offered a securitization support service* to support and complement loans with long-term fixed interest rates provided by private financial institutions. Since 2005, under the framework for securitized loans, the Corporation has been offering favorable interest rates $(0.3 \%$ reduction for the initial five yeas) for housing complying with the 1999 Energy Conservation Standards, to encourage growth in energy conservation housing.

* To support loans with long-term fixed interest rates provided by private financial institutions, there are two types of service: a "purchase option", in which the Corporation purchases and entrusts loans with 
long-term fixed interest rates from private financial institutions, and issues a Mortgage Backed Security (MBS) against the loan; and a "guarantee option", in which the Corporation sets insurance on loans with long-term fixed interest rates from private financial institutions and guarantees the principal and interest payment of the securities, etc. issued against the loans on due dates (The Government Housing Loan Corporation, 2006).

\subsubsection{Low-interest Loans for Non-residential Buildings}

To promote environmentally friendly non-residential buildings, the Development Bank of Japan, a government financial institution, offers low interest loans to projects with a floor area of $2000 \mathrm{~m}^{2}$ or more with a commitment to energy conservation efficiency higher than the Energy Conservation Standards by 20 percent or more, utilization of water resources and retention of rain water, or other options (Development Bank of Japan).

\subsubsection{Subsidy for Symbiotic Housing Model Project}

To encourage symbiotic housing projects taking into account environmental issues including prevention of global warming, subsidies have been offered as the "Symbiotic Housing Model Project" since 1993. These subsidies are provided for the cost of permeable pavements, roof greening, garbage disposal systems such as compost, etc. in model housing developments which comply with certain requirements including reduction in environmental impact. As of the end of FY 2005, 85 projects were completed or are under implementation.

\subsection{Other Programs}

Other promotional and education programs focused on energy efficiency/GHG emissions reductions include efforts sponsored by NEDO, energy services companies, and the government.

\subsubsection{NEDO Subsidies}

The New Energy and Industrial Technology Development Organization (NEDO) has promoted and supported the research and development for saving energy. In FY2005, NEDO used 288.2 billion yen. From 1999 to 2005, for energy conservation in building sector, NEDO promotes introduction of highly energy-efficient systems in houses or other buildings with partial subsidies. NEDO also collects data to provide performance, cost-benefit analysis, and other related information on these systems. In 2002, NEDO introduced partial subsidies for installation of BEMSs in office buildings (NEDO, 2006). 


\subsubsection{Energy Service Company (ESCO) Activities}

Energy Service Companies (ESCOs) offer comprehensive energy services, including energy-conservation solutions as a private business activity. ESCOs identify strategies to save energy in buildings, design/implement energy-conservation technology, and assist with business capital planning and maintenance and operation management of new facilities. ESCOs were introduced in Japan in 1998, and the Japan Association of Energy Service Companies was established in 1999. So far ESCO energy-efficiency services have been used in 163 buildings: 24 hotels, 48 shops, 20 hospitals, 64 offices, and seven other buildings (The Energy Conservation Center, Japan, 2006).

\subsubsection{Japanese Dress Code}

In 2005, the Japanese Ministry of the Environment (MOE) promoted office-building air-conditioning settings of $28^{\circ} \mathrm{C}$ during summer. As a part of this campaign, MOE has been promoting "Cool Biz," to encourage business people to wear cool and comfortable clothes to work in summer. MOE conducted a web-based survey on the Cool Biz campaign in September, 2005. Approximately 1,200 men and women were randomly chosen from an "internet panel" owned by a research company. The results showed that 95.8 percent of the 562 respondents knew about Cool Biz, and 32.7 percent answered that their offices set air conditioning temperatures higher than in previous years. Based on these results, it was estimated that $\mathrm{CO}_{2}$ emissions had been reduced by approximately 460 thousand tons, or the equivalent of the $\mathrm{CO}_{2}$ emissions from approximately one million households during one month, as a result of the campaign. MOE will continue to promote Cool Biz and higher summer temperatures in offices (MOE, 2006).

\section{Public Awareness}

In recent years, environmental issues, including global warming have attracted increasing attention, and there is increasing focus on what it means to live an environmentally conscious life. Despite this increased awareness, which can be attributed in part to educational efforts carried out by governments and other entities, the reality is that household energy consumption in Japan has not dropped significantly.

Energy use cannot easily be restricted because it depends to a large degree on individual choice, and moral appeals seem to have only a limited effect. In light of this difficult, various attempts are being made to persuade more people in Japan to reduce energy use.

\subsection{Information Sharing}

There is a close relationship between buildings and the lifestyle led inside them. Building-related measures to reduce global warming must take into account occupants' lifestyles. Members of the building and construction communities are in an excellent position to evaluate global-warming-prevention measures for buildings from a human perspective. Partnership between the environmental community and 
the building-trade community can enhance the dissemination of specific information that will allow consumers to take action.

New buildings offer the biggest opportunities for measures to reduce of global warming. Construction of new buildings will eventually decrease, however because of decreasing population and quantitative satisfaction, and measures for existing buildings will become increasingly important, as is clearly demonstrated by the recent boom in housing reforms in Japan. To successfully reduce energy consumption and GHG emissions in the whole residential sector, instead of measures usually taken for new construction housing, the methods for the construction supply side, will not work. Management services that meet the needs of residents and energy end users will be necessary. For this purpose, a new partnership is required, where as among entities such as residential home builders, energy suppliers, and household electrical equipment suppliers, to work together to protect the environment and take into account the perspective of building residents.

\subsection{Local Initiatives}

Although global warming is a national (and international) issue, regional measures are necessary to reduce GHG emissions. The Japanese government has established the Prefecture Center for Climate Change Action in each prefecture, under the Law Concerning Prevention of Global Warming, to transmit information and encourage people to become advisers on the subject of global warming prevention. The government is also promoting the establishment of the Regional Council for Global Warming Prevention to galvanize regional activities.

Because we cannot force energy savings in the home, we must galvanize citizens to take voluntary action. Residents' initiative in their own regions will be the most important force for lifestyle change. Various actions have started to be taken by municipalities and private sector groups. For example, "Candle Night" is an event addressing to turn out the lights for two hours under candlelight on the solstice (Candle night committee, 2006). "Mission Uchimizu" is an event to cool down summer heat by the old Japanese custom of sprinkling water on streets and gardens. Both events are aiming to change the image of energy conservation as a positive action (Mission Uchimizu, 2006).

\subsection{Environmental Education}

As environmental issues become increasingly serious, many stopgap measures have been undertaken, but fundamental causes are often left unaddressed. Environmental education is the most effective way to resolve environmental issues in the long run. Even though many people are aware of environmental issues such as global warming, it is very difficult to turn awareness into action. In many cases, convention and custom are the key obstacles. Programs in schools can help changing customs that prevent environmental action. 
A school in Yamagata Prefecture, for example, started full fledged energy-conservation activities in FY 2000 and has been an "energy-saving model school" since FY 2001. This school reduced its electric power consumption by about 20 percent for the year with its energy-conservation program. Energy-conservation activities and environmental education in schools not only save energy for the schools themselves but also put children in a position to spread information to their families and the local community, which ultimately contributes to global environmental conservation.

\subsection{Municipalities}

Because municipalities are in direct contact with local residents, they can be on the front line of lifestyle reform. Global warming has been raised as an issue by local governments in all regions of Japan; conventionally most localities have pursued the strategy of providing information to enhance residents' awareness of the issue. Economic strategies, such as environmental taxes can be an incentive for lifestyle change. Some towns have introduced economic incentives for energy conservation. For example, the Tachikawa Town gives the local currency to the people who made a contribution to the environment by saving energy at their home. Using the local currency helps to vitalize local business. Energy-conservation activities during six months in 2003 reduced energy consumption by 9.9 percent compared with the same period in the previous year. Takahata Town has a population of about 27,000 with about 7,000 households. The town also runs an energy-saving campaign with prizes presented to residents who reduce electric power consumption for one month. In the 2005 campaign, there were about 1,600 applications; about 1,000 of them actually reported the specific energy data and the average energy reduction was 13.7 percent.

\section{Conclusion}

This report clarifies the current status of energy consumption and $\mathrm{CO}_{2}$ emissions, and shows their future projections. It also describes the various technologies to mitigate global warming and their effects, and the current status of political measures. Since the substantial reduction of $\mathrm{CO}_{2}$ emissions is expected if measures using these technologies available at present are actually implemented, the aggressive promotion of political measures and awareness-raising activities is important. 


\section{References}

Baker, P., T. Inoue, et al, 2000, Advanced Envelopes: Methodology Evaluation and Design Tools, IEA Energy conservation in buildings and community systems, Annex32 (Integral buildings envelope performance assessment), Final report, ISBN 9075741073.

Building-Energy Manager's Association of Japan, 2002, Annual Report. (in Japanese)

Bogaki, K., T. Sawachi, H. Yoshino, K. Suzuki, S. Akabayashi, T. Inoue, H. Ohno, N. Matsubara, T. Hayashi, and D. Morita, 1998a, "Study of heating \& cooling patterns and cooling periods in residential buildings, based on national surveys.” J. Archit. Plan. Environ. Eng., Architectural Institute of Japan, 509: 41-47. (in Japanese)

Bogaki, K., T. Sawachi, H. Yoshino, K. Suzuki, S. Akabayashi, T. Inoue, H. Ohno, N. Matsubara, T. Hayashi, and D. Morita, 1998b, "Study of living room temperatures and regional differences in summer \& winter: Study of energy consumption in residential buildings and is relation to lifestyle, based on national scale surveys, Part 2.” J. Archit. Plan. Environ. Eng, Architectural Institute of Japan,. 505: 23-30. (in Japanese)

Cabinet Office, Government of Japan, 2005, The Kyoto Protocol Target Achievement Plan. (in Japanese)

Candle night committee, 2006, http://www.candle-night.org/english/

Chiba, T., H. Yoshino, K. Hasegawa, and T. Mitamura, 2004, "Energy conservation from a "low-impact” life style in a residential building, Part 2: Calculation for detached house in Sendai city.” Summaries of Technical Papers of Annual Meeting, Architectural Institute of Japan, Environmental Engineering II, pp. 297-298. (in Japanese).

Chikada T., and T. Inoue, 2000, “CO $\mathrm{CO}_{2}$ emissions from daily household activities.” Proceedings of PLEA 2000, pp. 198-203. (in Japanese)

Chikada, T., and T. Inoue, 2003, "Estimation of total global warming effect attributable to detached houses.” New Frontiers in Architecture for a Global Environment, Architectural Institute of Japan, No.1, pp55-61.

Chikamoto, T., S. Kato, and T. Ikaga, 1999, "Hybrid air-conditioning system at Liberty Tower, Meiji University”. HybVent Forum’99, Sydney, Australia.

Development Bank of Japan, 2006,

http://www.dbj.go.jp/japanese/loan/indicator/D01.html (in Japanese) 
Hagishima, A., K. Narita, J. Tanimoto, et.al, 2004, "Field measurement of the micro climate around a building with a large, stepped roof garden.” J. Environ. Eng. Architectural Institute of Japan, 577:47-54. (in Japanese)

Hasegawa, Y., and Inoue, T, 2004, "Household Energy Consumption Reported on A National Questionnaire. Study of the Influence of Household Characteristics on Energy Consumption, Part 1.” J. Environ. Eng. Architectural Institute of Japan, 583: 23-28. (in Japanese)

Ikaga, T., S. Murakami, S. Kato, and Y. Shiraishi, 2000, "Estimation of $\mathrm{CO}_{2}$ emissions associated with building construction and operation through 2050 in Japan: Life-cycle Assessment of Buildings and Cities.” J. Archit. Plan. Environ. Eng. Architectural Institute of Japan, 535: 53-58. (in Japanese)

Ikaga, T., S. Murakami, S. Kato, and Y. Shiraishi, 2002, "Forecast of $\mathrm{CO}_{2}$ emissions from construction and operation of buildings in Japan through 2050.” Journal of Asian Architecture and Building Engineering Vol.1, No.2, pp.149-156.

Ikaga, T., S. Miura, Y. Tonooka, Y. Shimoda, K. Koike, K., and T. Mizuishi, 2005, “Development of Macro-Simulation Method for Household Energy Consumption and CO2 Emissions in Each Administrative Division.” Journal of Technology and Design, Architectural Institute of Japan, Vol. 22, 50. (in Japanese)

Inoue, T., 2000, "Energy saving effect of combination control of solar-shading and daylighting for office buildings”, International Building Physics 2000, pp323-330, Eindhoven, The Netherlands.

Inoue, T, 2003, "Solar shading and daylighting using autonomous responsive dimming glass: practical application”, Energy and Buildings Vol. 35, Issue 5, pp. 463-471.

Inoue, T., T. Ibamoto, T. Kawase, et. al, 1988, "Development of an Optimal Control System for Window Shading Devices in Office Buildings”, ASHRAE Transactions Vol. 94-2 pp. 1034-1049.

Inoue, T. and T. Kawase, 2004, "Effects of Exterior Blinds and Heat-generating Double-glazing in an Office Building”. PLEA2004, Eindhoven, The Netherlands.

Inoue, T., S. Mizutani, and T. Tanaka, 2006, "Household Energy consumption Reported in a National Questionnaire: Analysis of Factors Influencing Annual Energy Consumption, Part 2.” J. Environ. Eng. Architectural Institute of Japan, No.606, pp75-80. (in Japanese)

Institute of Building Environment and Energy Conservation (IBEC), Japan, 2004, Guidelines for Designing Energy-Efficient Buildings. (in Japanese) 
Institute of Building Environment and Energy Conservation (IBEC), 2006.

http://www.ibec.or.jp/CASBEE/english/index.htm (in Japanese)

Japan Heat Service Utilities Association, 2005, The Heat Service Utilities Handbook. (in Japanese)

Japan Industrial Association of Gas and Kerosene Appliances (JGKA), 2006,

http://www.jgka.or.jp/index.html (in Japanese)

Japan Industrial Publishing, 2005, Cogeneration plan and design manual, ISBN-8190-175-5. (in Japanese)

Japan Sustainable Building Consortium, 2005, Advanced Sustainable Buildings in Japan. SB05 Tokyo.

Jyukankyo Research Institute, 2002, Residential Energy Statistics Year Book. (in Japanese)

Kawamoto, K., Y. Shimoda, and M. Mizuno, 2004, "Energy-saving potential of office equipment power management.” Energy and Buildings No.3, pp. 915-923.

Ministry of Environment, Government of Japan, 2006, press release in 10/11/2006, http://www.env.go.jp/press/press.php?serial=7690 (in Japanese)

Miura, S., 2005, "Wood biomass energy for sustainable development and building", Proceedings of International Symposium on Sustainable Development of Asia City Environment.

Mission Uchimizu, 2006, Japan water forum, http://www.uchimizu.jp/eng/index.html

Mizutani, S., T. Inoue and T. Oguma, 2006, "Energy consumption for different uses in housing and energy usage analysis based on national scale questionnaire” J. Environ. Eng. Architectural Institute of Japan, No.606, pp117-124. (in Japanese)

Mori, K. et al, 2003, "Development of triple-effect absorption chiller-heater”, Proceedings of 22nd World Gas Conference, Tokyo.

Murakami, S., T. Mizuishi, and T. Ikaga, 2004, " $\mathrm{LCCO}_{2}$ Assessment of Thermal Insulation of Residential Buildings, including Fluorocarbon Leakage: Study of Thermal Insulation as a Strategy to Reduce Greenhouse Gases emissions Associated with Residential Buildings.” J. Environ. Eng. Architectural Institute of Japan, 579: 89-96. (in Japanese) 
Murakami, S., T. Mizuishi, and T. Ikaga, 2004, "Effect on greenhouse gas emissions of fluorocarbon leakage associated with thermal insulation of houses.” Proceedings of the 6th International Conference on Eco Balance, Tsukuba, Japan.

Nakagami, H., A. Tanaka, C. Murakoshi, and O. Ishihara, O, 2002, "Changes in residential energy consumption patterns and future trends in Japan.” J. Archit. Plan. Environ. Eng. Architectural Institute of Japan, 555: 53-60. (in Japanese)

NEDO (New Energy and Industrial Technology Development Organization), 2006, http://www.nedo.go.jp/english/activities/2_sinenergy/3/p99045e.html

New Energy Foundation, 2006, http://www.nef.or.jp/photovolataicpower/joukyou01.html

Osaka Gas, 2006, http://g-life.osakagas.co.jp/3-cogeneration/0-difference-d.html (in Japanese)

Seki, W. et al., 2004, Highest-Efficiency in the World, Variable Speed Drive Turbo Chiller NART-I Series, Mitsubishi Heavy Industries, Ltd. Technical Review, Vol.41 No.2

Shimoda, Y., S. Sadohara and A. Fukushima, 2003, "Survey of Energy Conservation and $\mathrm{CO}_{2}$ Reduction in District Heating and Cooling." Proceedings of Architectural Institute of Japan Conference D-1, pp.531-536. (in Japanese)

Shimoda, Y. et al, 2006, "Verification of Energy Efficiency of District Heating and Cooling by Simulation of Design and Operation Parameters.” Building and Environment, in press.

Shitara, A. et al, 2003, "Development of a high-efficiency absorption chiller-heater and a compact absorption chiller-heater“, Proceedings of 22nd World Gas Conference, Tokyo.

Sugihara, H., J. Koumoto, F. Sano, and K. Tsuji, 2002, "Potential for Reducing Primary Energy Consumption and $\mathrm{CO}_{2}$ emissions by Optimizing Urban Energy Systems through Reduction of End-use Demand: Toward a 50\% reduction.” Proceedings of the 21st Annual Meeting of Japan Society of Energy and Resources, pp.361-366. (in Japanese)

Tachi, H. et al, 2006, "Development of a high-efficiency gas engine heat pump", Proceedings of 23rd World Gas Conference, Amsterdam, The Netherlands.

Takemasa, Y., M. Hiraoka, M., et. al, 2004, "Performance of a Hybrid Ventilation System Combined with a Double-skin Facade in East-Asian Temperate Climate”, Roomvent 2004, Coimbra, Portugal.

The Energy Conservation Center, Japan, 2002, Energy Conservation Award. (in Japanese) 
The Energy Conservation Center, Japan, 2005, Top Runner Program, Developing the World's Best Energy-Efficient Appliances, http://www.eccj.or.jp/top_runner/index.html

The Energy Conservation Center, Japan, 2006, Energy Efficient Products'catalog, http://www.eccj.or.jp/catalog/2006oair/71-4.html (in Japanese)

The Energy Conservation Center, Japan, 2006, “Cases of the buildings with ESCO: 2005-2006.” (in Japanese)

The Energy Conservation Center, Japan, 2005-2006, ESCO introduction casebook. (in Japanese)

The Government Housing Loan Corporation, 2006,

http://www.jyukou.go.jp/chisiki/chosa/kibo16.html (in Japanese)

The Government Housing Loan Corporation, 2006,

http://www.jyukou.go.jp/kouko/shien_jigyou/index.html (in Japanese)

The Institute of Energy Economics, Japan, Energy Data and Modeling Center, 1998-1999, Investigation of Energy Consumption in Residential Buildings.

The Institute of Energy Economics, Japan, Energy Data and Modeling Center, 2006, EDMC Handbook of Energy \& Economic Statistics in Japan.

The Japan Refrigeration and Air Conditioning Industry Association (JRAIA), 2006, http://www.jraia.or.jp/frameset_statistic.html (in Japanese)

Tokyo Gas, 2006, http://home.tokyo-gas.co.jp/living/kitchen/shokusenki/ (in Japanese)

TOTO, 2004, http://www.toto.co.jp/press/2004/03/24_2.htm (in Japanese)

Watanabe, H., 1998, “Intelligent windows that use a hydrogel layer for energy efficiency.” Solar Energy Materials and Solar Cells 54: 203-211.

Yatabe, T., 2006, "Heat Pumps the Trump Card in Fight against Global Warming”, The Japan Journal, Oct 06, P22-24.

Yanagihara et.al., 2006, “Harumi Island DHC”, The Society of Heating, Air-Conditioning and Sanitary Engineers of Japan, Vol.78-10, pp885-891. (in Japanese)

Yoshida, Kenko, 1331, Tsurezuregusa, Essays in Idleness. (in Japanese) 
Yoshino. H., Xie, J., Hasegawa, K., Mitamura, T., Genjo, K., Yuasa, K., Chiba, T., and Sugawara, H., 2005, "Energy Saving Effect of Low-Impact Lifestyle for Residential Buildings in Tohoku District.”, Journal of Technology and Design, Architectural Institute of Japan, No.22, 325-328. (In Japanese)

Yuasa, K., J.H. Yoo, H., Yoshino, and K. Hasegawa, 2005, "Effect of a low-impact life style on energy conservation in a residential building." Proceedings of the 21st Conference on Energy, Economy, and Environment, pp. 31-33. (in Japanese) 


\section{Appendices}

Japanese newly built buildings adopt various energy saving technologies. The environmental performance of these buildings was assessed by CASBEE based on the measurement of energy consumption and indoor environment. In this section, four examples listed below of advanced sustainable buildings in Japan will be shown. These buildings were awarded by the Institute for Building Environment and Energy Conservation (IBEC) and included in the leaflet of Advanced Sustainable Buildings in Japan, SB05Tokyo (Japan Industrial Publishing, 2005).

1) NEC Tamagawa renaissance City

2) Aoyamagakuin University Saitama Campus

3) Shiodome Tower

4) “Earthport” Tokyo Gas Kohoku New Town Building 


\section{NEC Tamagawa Renaissance City}
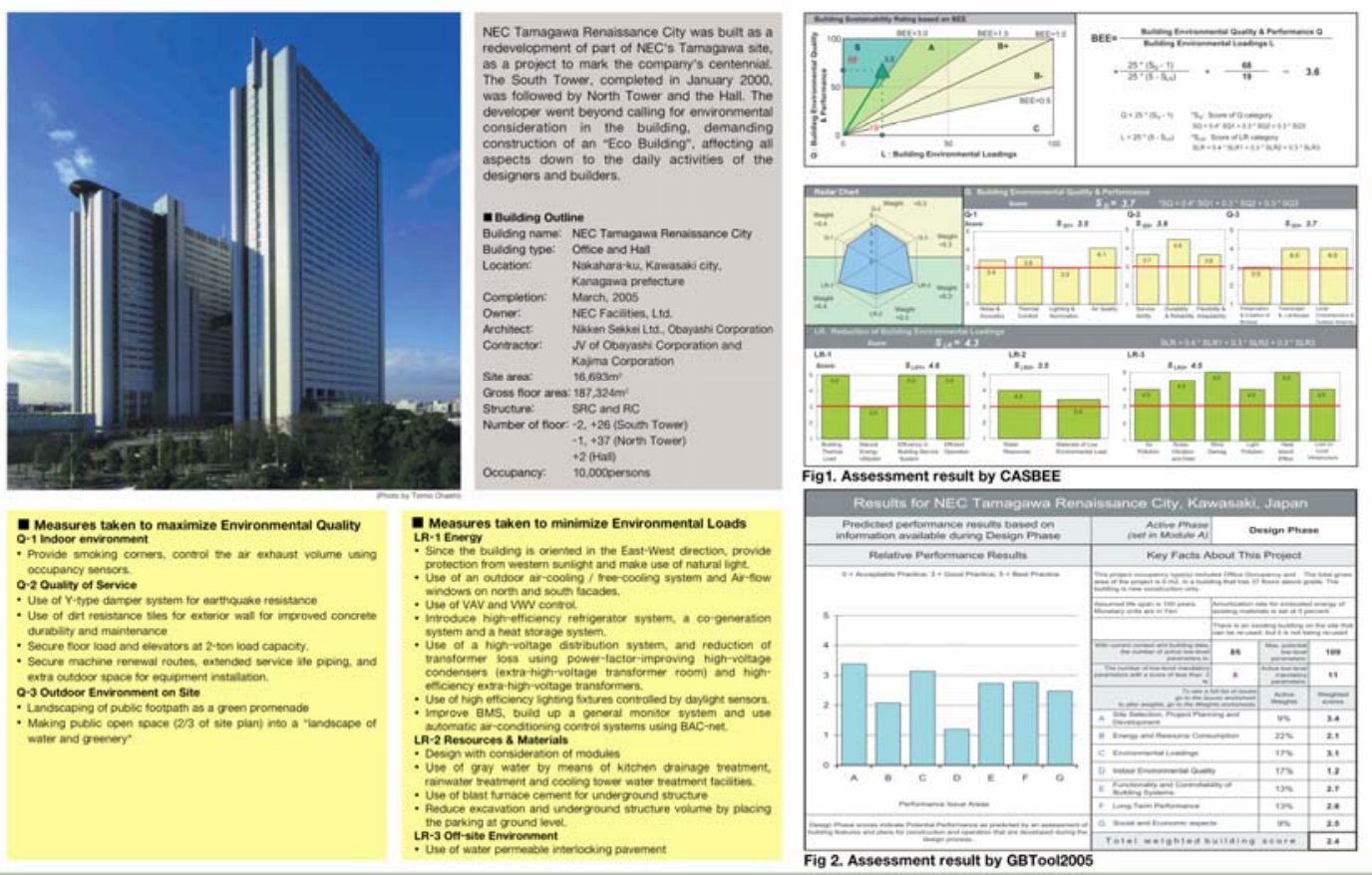

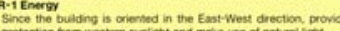

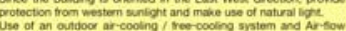

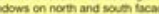

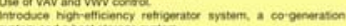

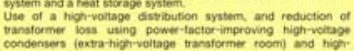

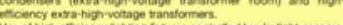

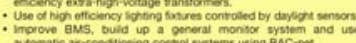

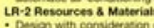

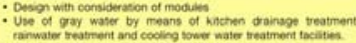

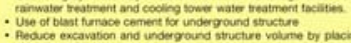

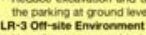

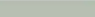

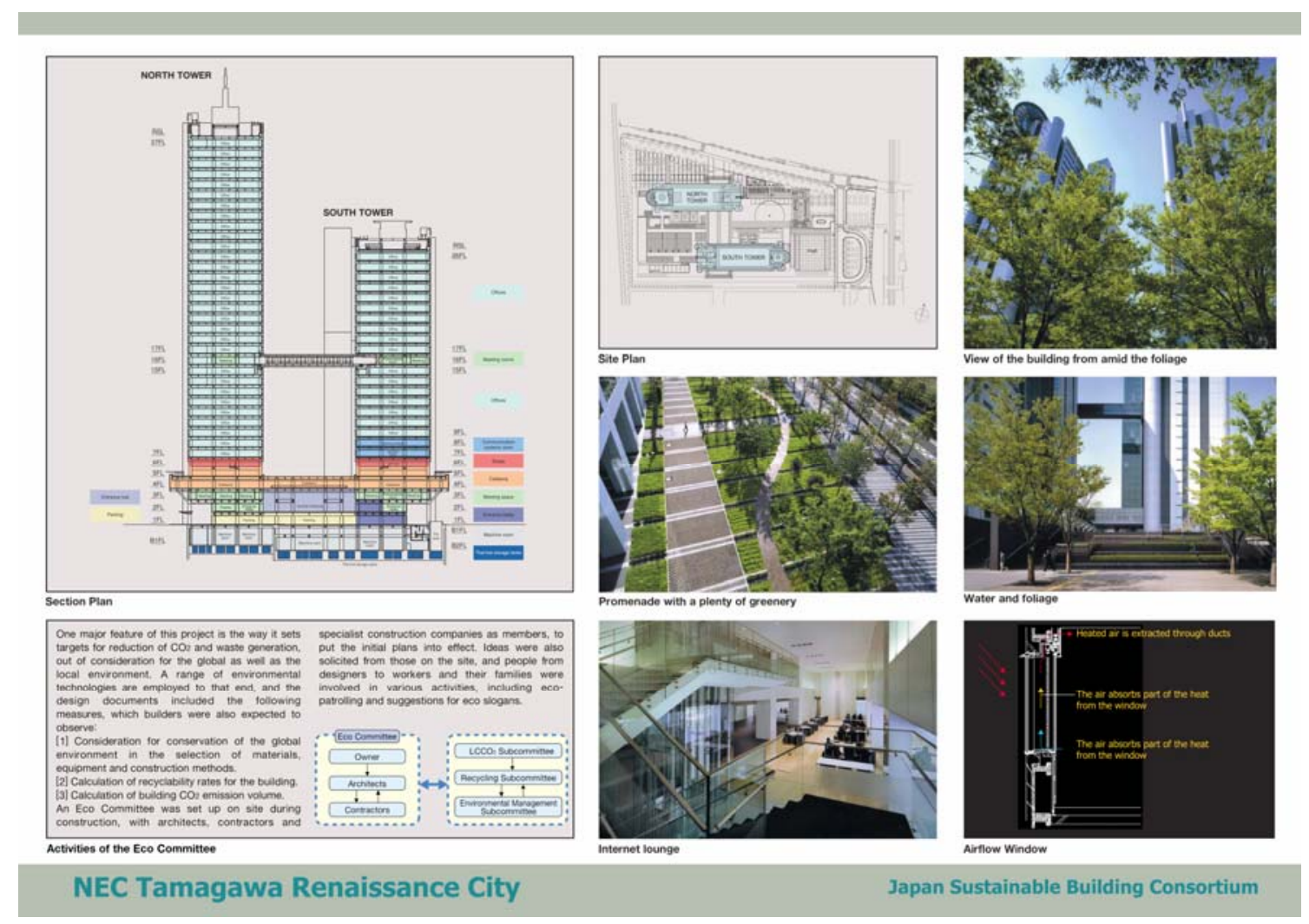




\section{Aoyamagakuin University Sagamihara Campus}
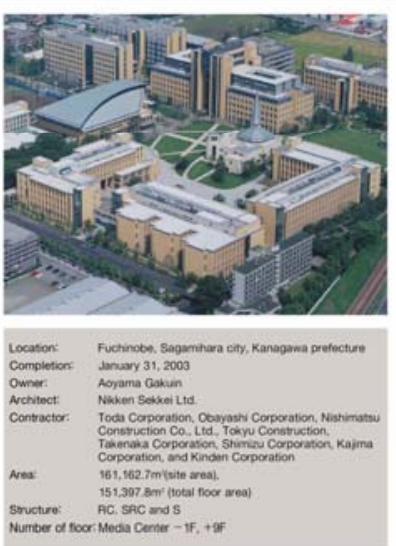

- Measures taten to mavinire Environmente Ountor

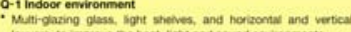

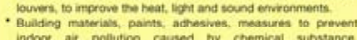
insoor ait polution caused by chemical substimca 0.20 cuality of Services

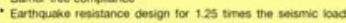

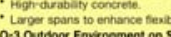

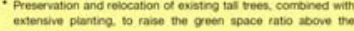

The existing Atsugi Campus and Sotagaya Campus were merged to form a new campus at Sagamihara, bringing together approximately 10,000 students and teaching statt. from entering the buildings, and to thoroughly exploit natural energy and resources present on the site, and diverse energy-saving systems were deployed, ranging from individual devices to campus-wide schemes.

The tall trees existing on the site were put to effective use under thermal enviroment design, to provide cool spot and alleviate the heat island phenomenon.

Measures taken to minimine Invitonnonten Londs

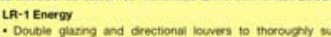
athading and insulatsion

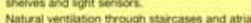
and

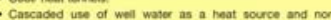

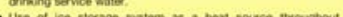

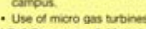

LA-2 Rescources \& Material

stees and une of bisst Mrnose

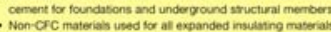

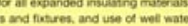
LA? 3 Ott-ate Environment

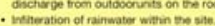

- Aredetion in kechen waste trough conpositina.

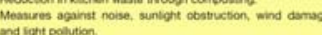

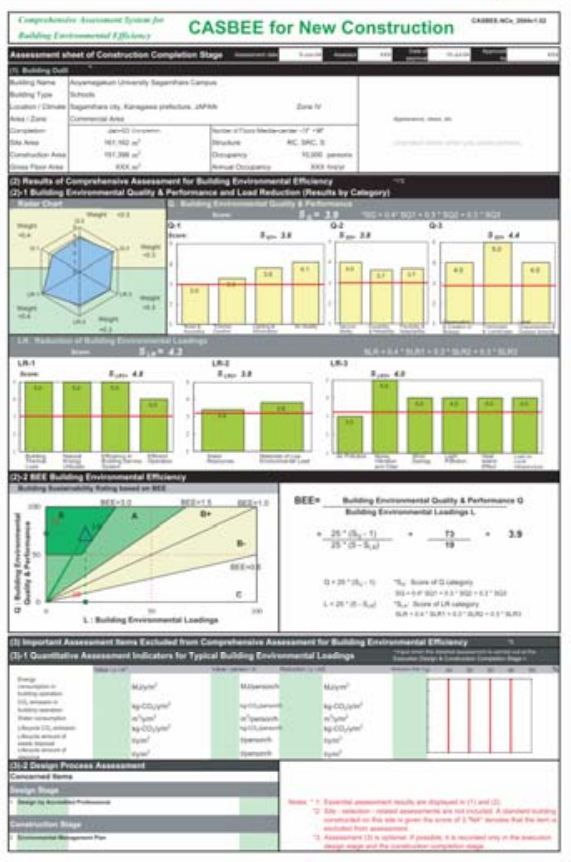

Fig. Assessment resuit by CASBEE
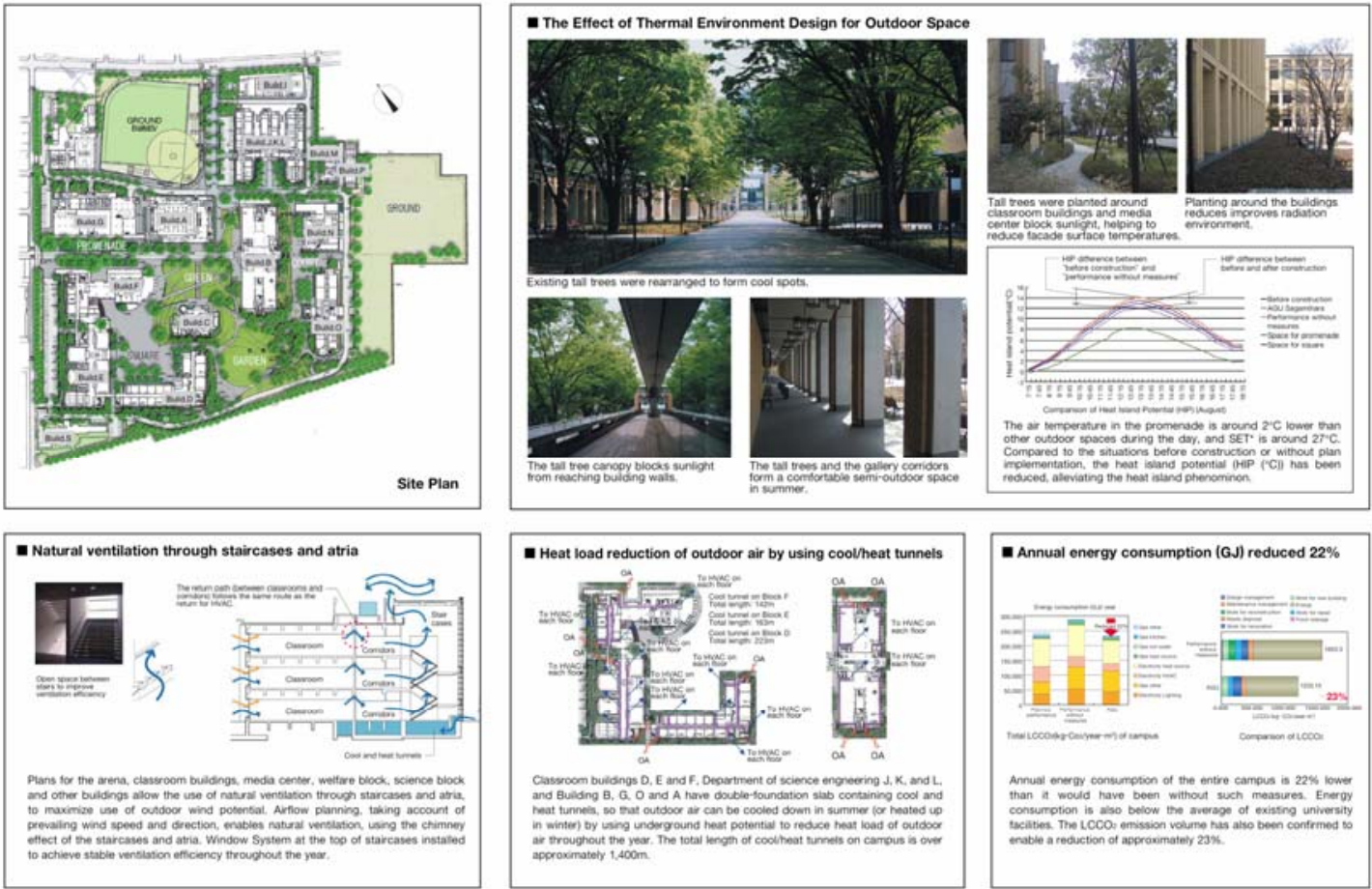

Aoyamagakuin University Sagamihara Campus

Japan Sustainable Building Consortium 


\section{SHIODOME TOWER}

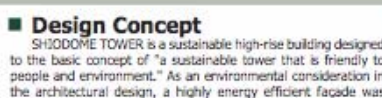

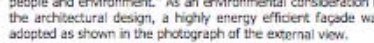

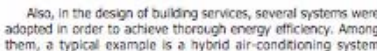

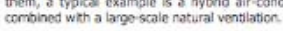

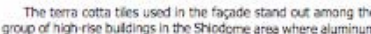

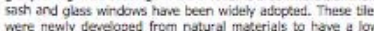

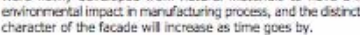
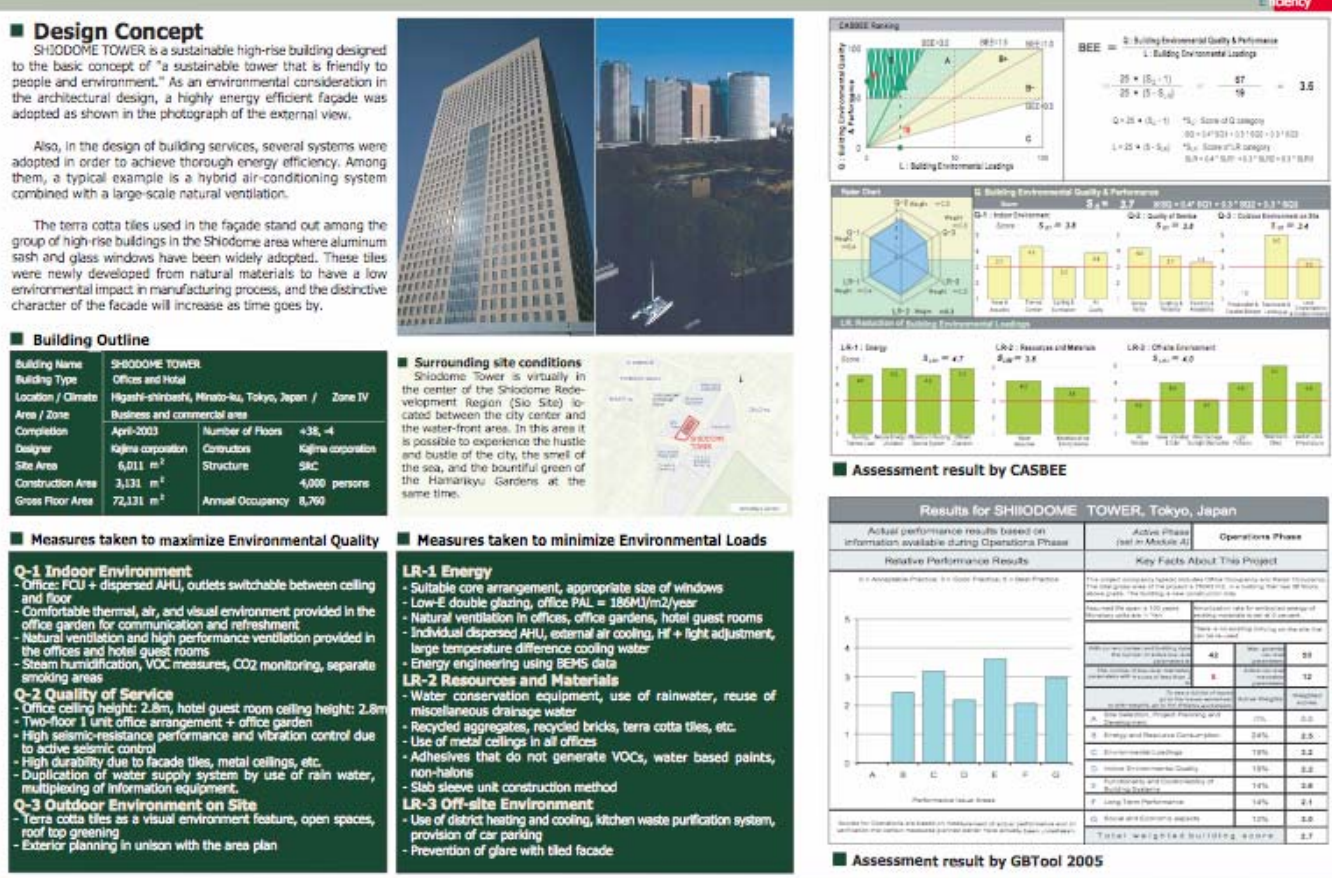

- Assessment result by GBTool 2005
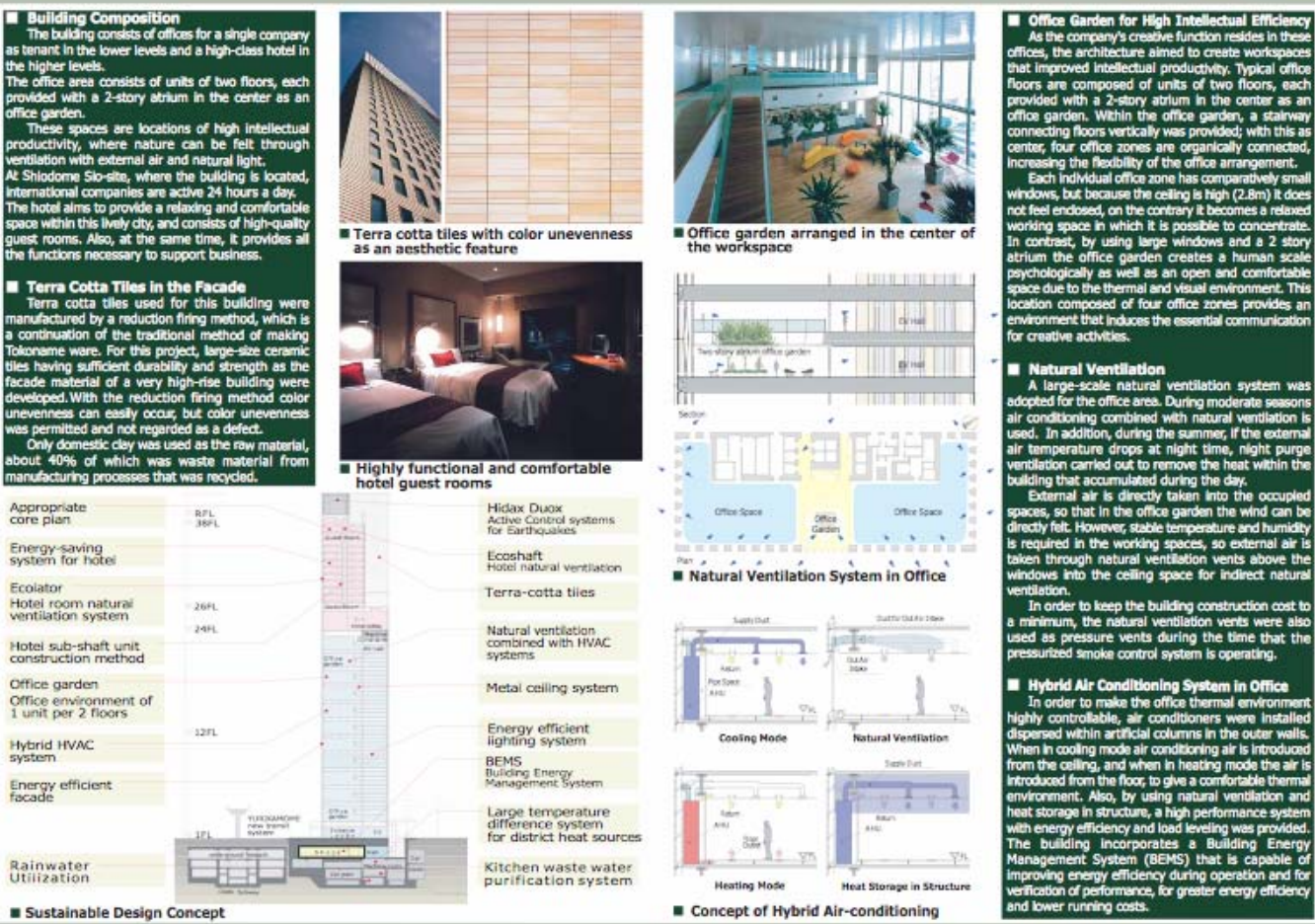

SHIODOME TOWER

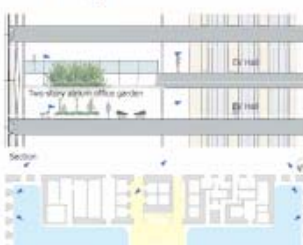

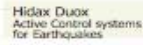

Ecoshat

Terra-cotta ties

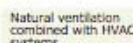

Metal celling system

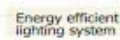

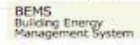

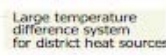

kitchen waste water
purfification $5 y$ stem
- Natural ventilation System in oirice
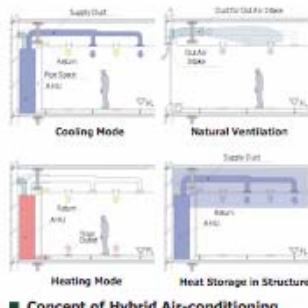

- Concept of Hybrid Air-conditioning

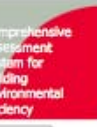




\section{"Earthport"}

Tokyo Gas Kohoku New Town Building

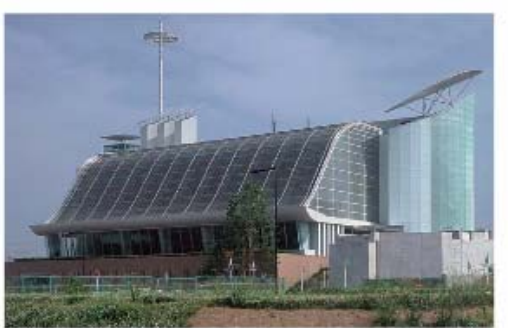

Architectual Concept

Tokyo Gas Kohoku New Town building. which is called "Earthport", was completed in March 1956, with a concept of "a life-cycle

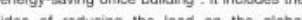

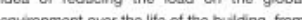
the time of ts constiotion the the time of demolition. while satisfying both energy saing efforts and interior amenities.

office space are generally sepamsest in this case, the building core (stairs, elevators and halls) is connected to the showroom and it functions as an athum which bads to each fooc Ths vertical wide atrum is calied "Ecologica as well as working as the key factor for natural energy use systems such as natura lighting and natural ventilation, by chimney effect.

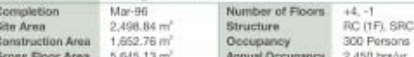

Measures taken to maximize Environmental Quality

Q-1 Indoor Environment

- Massing effect by a wall of water

- Use of daylight by natural light wa

- Thermal and sound insulaton by two-layer energy-saving glas

Q-2 Quality of Service

Q. Wigh celing orice $(2.8-3.4 m)$

- No collum olfioe socommodates any type of the oftice layout - All of the roof top equipment is installed on an elevated desk O-3 Outdoor Environment on Site Q-3 Outdoor Environment on Site
Measures taken to minimize Environmental Loads

LR-1 Energy

High grade heat insulation and sun shading glass Natural lighting

VAV, VWV and VWT system

- Monitoring by BEMS

LR-2 Resources and Materials

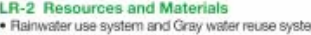

- Use of Eco-Friendly materials

LA-3 Off-site Environment

Composting of organic gartiage
Energy Consumption

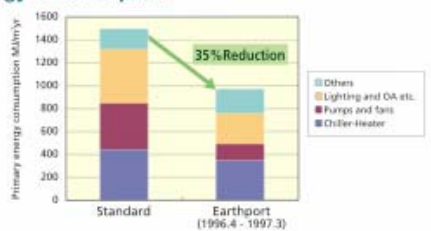

Assessment result by CASBEE - EB Bulding Sertainubility Rating based on att:

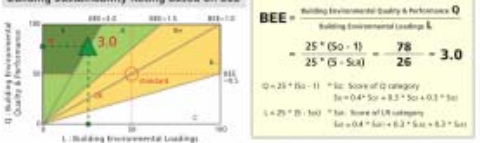

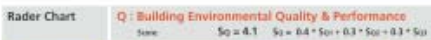

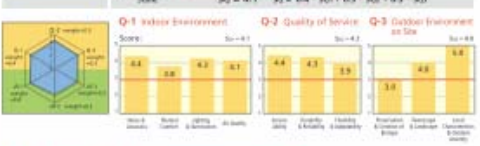

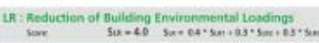

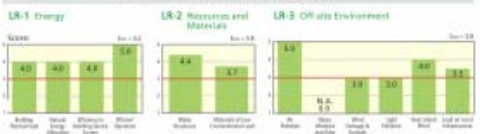

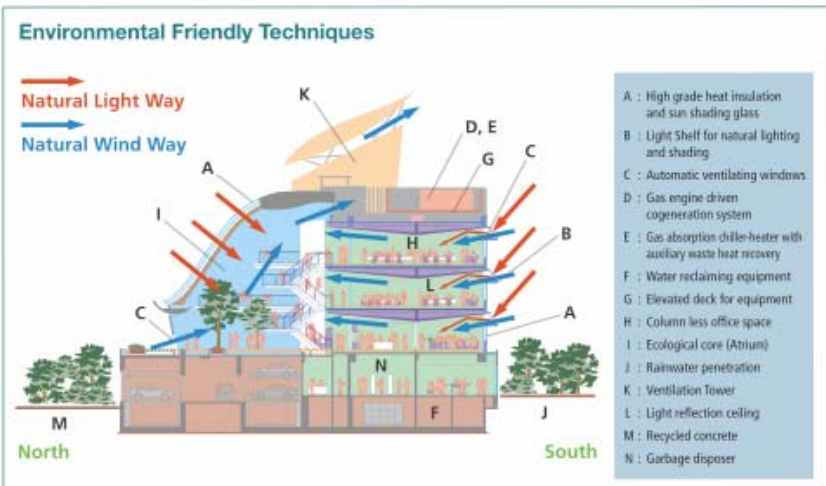

Efficient Use of Energy - $32 \mathrm{~W}$ W gas engine diven cogeneration system supplate
part of electricity load of the building. Waste heat from gas engine is used for a tr - VWV syster
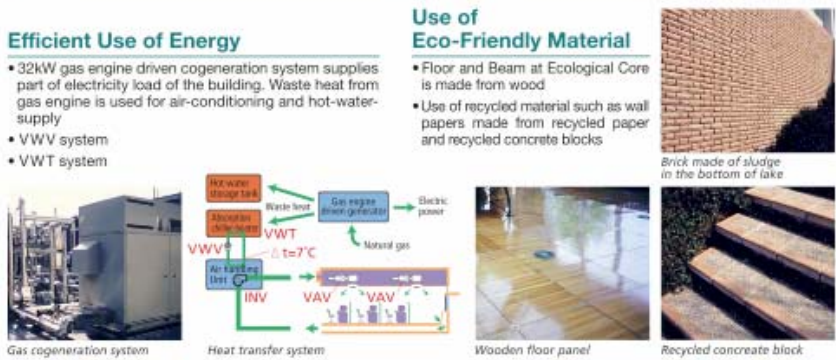

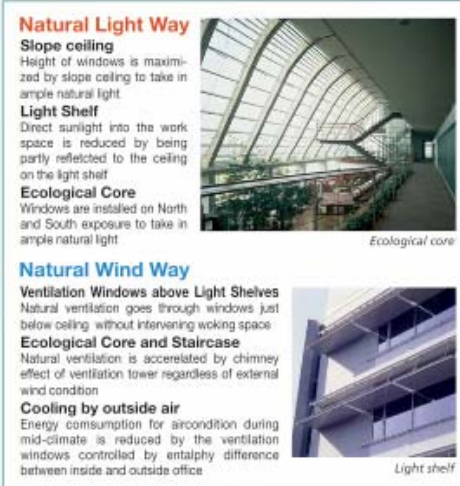

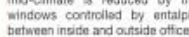

Long Service Life

- Spacious layout and high ceiling tor various use of the space

External shaft space

(is installed on an elevated deck for

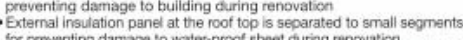
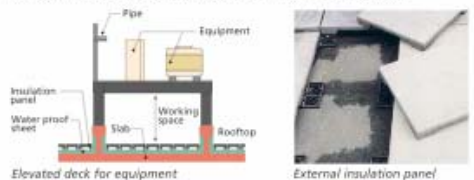

"Earthport"-Tokyo Gas Kohoku New Town Building Japan Sustainable Building Consortium 
